\title{
Avaliação endocrinológica do ciclo ovariano de macaco bugio (Alouatta caraya - HUMBOLDT, 1812) por meio de extração e dosagem de metabólitos de esteróides fecais
}

Dissertação apresentada ao Programa de Pós-graduação em Reprodução Animal da Faculdade de Medicina Veterinária e Zootecnia da Universidade de São Paulo para obtenção do título de Mestre em Medicina Veterinária

Departamento:

Reprodução Animal

Área de concentração:

Reprodução Animal

Orientador:

Prof. Dr. Cláudio Alvarenga de Oliveira 
Autorizo a reprodução parcial ou total desta obra, para fins acadêmicos, desde que citada a fonte.

\section{DADOS INTERNACIONAIS DE CATALOGAÇÃO-NA-PUBLICAÇÃO}

(Biblioteca da Faculdade de Medicina Veterinária e Zootecnia da Universidade de São Paulo)

T.1496 Kugelmeier, Tatiana

FMVZ Avaliação endocrinológica do ciclo ovariano de macaco bugio (Alouatta caraya - HUMBOLDT, 1812) por meio de extração e dosagem de metabólitos de esteróides fecais / Tatiana Kugelmeier. - São Paulo : T. Kugelmeier, 2005.

120 f. : il.

Dissertação (mestrado) - Universidade de São Paulo. Faculdade de Medicina Veterinária e Zootecnia. Departamento de Reprodução Animal, 2005.

Programa de Pós-graduação: Reprodução Animal.

Área de concentração: Reprodução Animal.

Orientador: Prof. Dr. Cláudio Alvarenga de Oliveira.

1. Endocrinologia. 2. Esteróides.

3. Metabólitos.

4. Reprodução animal. 5. Primatas. I. Título. 
Faculdade de Medicina Veterinária e Zootecnia

Cidade Universitária "Armando de Salles Oliveira"

Comissão Bioética

\section{CERTIFICADO}

Certificamos que o Projeto intitulado "Ciclo ovariano de fêmeas de macaco bugio (Alouatta caraya) - Humboldt, 1812): Avaliação endocrinológica por meio de extração e dosagem de hormônios esteróides fecais.", Protocolo n²94/2003, utilizando 05 bugios, sob a responsabilidade do Prof. Dr. Claudio Alvarenga de Oliveira, está de acordo com os princípios éticos de experimentação animal da Comissão de Bioética da Faculdade de Medicina Veterinária e Zootecnia da Universidade de São Paulo e foi aprovado "ad referendun".

(We certify that the Research "Ovarian cycle in the howler monkey (Alouatta caraya - HUMBOLDT, 1812): endocrinological assessment by fecal esteroid analysis" protocol number 294/2003, utilizing 05 monkeys, under the responsibility of Prof. Dr. Claudio Alvarenga de Oliviera, agree with Ethical Principles in Animal Research adopted by Bioethic Commission of the Faculty of Veterinary Medicine and Zootechny of University of São Paulo and was approved "ad referendun".

São Paulo, 15 de setembro de 2003

Prof $^{a}{ }^{a}{ }^{a}$ Júlia Maria Materuluce

Presidente da Comissão de Bioética

FMV̌Z/USP 
MINISTÉRIO DO MEIO AMBIENTE E DA AMAZÔNIA LEGAL

INSTITUTO BRASILEIRO DO MEIO AMBIENTE E DOS RECURSOS NATURAIS RENOVÁVEIS

DIRETORIA DE ECOSSISTEMAS

LICENÇA PARA CAPTURA / COLETA / TRANSPORTE / EXPOSIÇÃO

\begin{tabular}{|c|c|c|c|c|}
\hline $\begin{array}{l}\text { NUMERO LICENÇA } \\
0113 / 2003\end{array}$ & No REGISTRO NO IBAMA & \multicolumn{2}{|c|}{$\begin{array}{l}\text { PERIODO DE VALIDADE } \\
22 / 12 / 2003 \text { a } 20 / 06 / 2004\end{array}$} & $\begin{array}{c}\text { DOCUMENTO No } \\
02018.017929 / 03-67\end{array}$ \\
\hline \multicolumn{3}{|l|}{ OBJETO: } & \multicolumn{2}{|c|}{ FAVORECIDO: } \\
\hline \multicolumn{3}{|c|}{ CAPTURA E/OU COLETAITRANSPORTE DE ANIMAIS SILVESTRESMATERIAL ZOOLÖGICO } & \multicolumn{2}{|c|}{ ZOOLÓGICO } \\
\hline \multicolumn{3}{|c|}{ COLETA E TRANSPORTE DE MATERIAL BOTÃNICO } & \multicolumn{2}{|c|}{ INSTITUIÇĀO CIENTIFICA } \\
\hline \multicolumn{3}{|c|}{ TRANSPORTE DE PRODUTOS E SUBPRODUTOS DA FAUNA (AMOSTRAS FECAIS) } & \multicolumn{2}{|c|}{ PESQUISADOR } \\
\hline \multicolumn{3}{|c|}{ ] EXPOSIÇÃO EIOU CONCURSO DE ANIMAIS SILVESTRES } & \multicolumn{2}{|c|}{ EXPOSITOR/CONCURSD } \\
\hline \multicolumn{3}{|l|}{ OUTROS } & \multicolumn{2}{|c|}{ [] CRIADOURO } \\
\hline
\end{tabular}

FAVORECIDO: FACULDADE DE MEDICINA VETERINARIA E ZOOTECNIA DA USP

ENDEREÇO:AV. PROF. ORLANDO MARQUES DE PAIVA, 87 - CIDADE UNIVERSITÁRIA -CEP: 05508-000 - SÃO PAULO - SP

RESPONSÁVEL PELA COLETAV TRANSPORTE : TATIANA KUGELMEIER

TRANSPORTADOR: O RESPONSÁVEL

TIPO DE TRANSPORTE: TERRESTRE I AÉREO

PROCEDENCIA / LOCAL DE CAPTURA E COLETA: CENP-PA (AMOSTRAS DE FEZES DE ANIMAIS MANTIDOS EM CATIVEIRO)

DESTINO: Lab. De Dosagens Hormonais - Dpto. De Reprodução Animal - FMVZ - USP - São Paulo - SP

\begin{tabular}{|c|c|c|}
\hline \hline $\begin{array}{c}\text { LISTA DAS ESPECIES } \\
\text { QUANTIDADE }\end{array}$ & NOME CIENTIFICO & NOME COMUM \\
\hline \hline \multirow{2}{*}{ Amostras de fezes } & Alouatta caraya & guariba \\
\hline
\end{tabular}

ATENGAO:

1) O RESPONSAVEl PELA PESQUISA DEVERA APRESENTAR RELATORIO FINAL DA PESQUISA, ALEM DE ENCAMNHAR COPIA DAS PUBLICAÇŐES RESULTANTES DOS TRABALHOS OBJETOS DA PRESENTE LICENÇA

2) ESTA LICENÇA NÃO AUTORIZZ O USO DO MATERIAL BIOLOGICO PARA ACESSAR INFORMAÇÃO DE ORIGEM GENETICA, CONTIDA NO TODO OU PARTE DE ESPECIME VEGETAL, FÜGICO, MICROBIANO OU ANIMAL; EM SUBSTANCIAS PROVENENTES DO METABOLISMO DESSE SER VIVO E DE EXTRATOS OBTIDOS DESSE ORGANISMO VIVO OU MORTO, ENCONTRADOS EM CONDIÇOES IN SITU, NO TERRITORIO NACIONAL, NA PLATAFORMA CONTINENTAL, OU NA ZONA ECONOMICA EXCLUSIVA, VISANDO ATIMIADE EXPLORATORIA PARA IDENTIFICAR COMPONENTES DO PATRIMONIO GENETICO E INFORMAÇÃO SOBRE O CONHECIMENTO TRADICIONAL ASSOCIADO, COM POTENCIAL DE USO COMERCIAL.

3) ESTA LICENÇA NÃO EXIME O PESQUISADOR DE CUMPRIR O DISPOSTO NA MP 2.186-16/01 QUE VERSA SOBRE ACESSO AO PATRIMÓNIO GENÉTICO. NO CASO DE ACESSO A AMOSTRA DE COMPONENTE DO PATRIMÔNIO GENÉTICO, ESTE SOMENTE SE DARÁ MEDIANTE AUTORIZAÇÃO EXPRESSA DO CONSELHO DE GESTÃO DO PATRIMÔNIO GENĖTICO (CGEN) NOS TERMOS DA MP 2.186-16/01 E DECRETO $3.945 / 01$

\section{DATA DA EMISSĀO:}

ASSINATURA E CARIMBO/AUTORIDADE EXPEDIDORA

BELÉM(PA), 22112/2003

- VÁLIDA EXCLUSIVAMENTE NO TERRITÓRIO BRASILEIRO.

- ESTALICENÇA NÃO AUTORIZA:

1. CAPTURACOLETATRANSPORTE DE ESPÉCIES AMEAÇADAS DE EXTINÇÃO, SALVO QUANDO CONSTANTE DE PROJETO ESPECIFICO APROVADO;

2. CAPTURAICOLETATRANSPORTE DE MATERIAL BIOLÓGICO NAS ÁREAS DE INFUENCIA DE EMPREENDIMENTOS SUJEITOS AO LICENCIAMENTO AMBIENTAL, CONFORME RESOLUÇAO DO CONAMA N0237 DE19/12/97, SALVO QUANDO ESPECIFICADO.

3. VALIDA SOMENTE SEM RASURAS.

4. EXPORTAÇĀO DE ANIMAIS VIVOS OU MATERIAL ZOOLÓGICO.

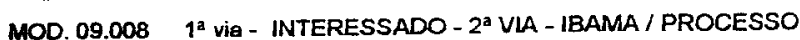




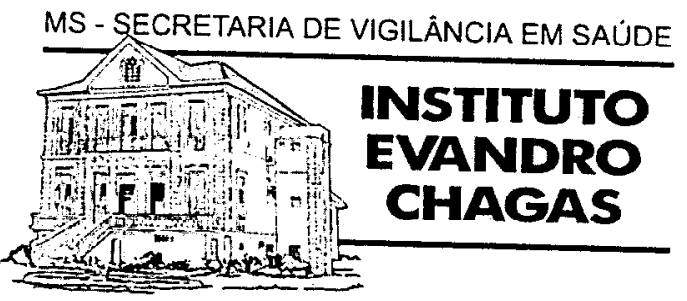

Protocolo CEPAN - N" 0010/2003

Parecer $\mathrm{N}^{\mathrm{o}} 0004 / 2004$

Belém/PA, 20 de setembro de 2004.

Projeto: "Ciclo ovariano de fêmeas de macaco bugio (Alouatta caraya-Humboldt, 1812): Avaliação endocrinológica por meio de extração e dosagem de esteróides fecais"

Pesquisador Responsável: TATIANA KUGELMEIER

Conforme decisão do Comitê de Ética em Pesquisa com Animais do Instituto Evandro Chagas, em sua reunião realizada no dia 13/09/2004, cientificamos que o projeto acima foi considerado aprovado.

Outro sim, informamos que, por renovação dos membros do Comitê ocorrido no dia $01 / 03 / 2004$, Portaria de $\mathrm{n}^{\circ} 03 / 04$, os protocolos foram analisados somente após o termino de alguns projetos, portanto, solicitamos ao pesquisador responsável que encaminhe um consolidado atualizado do protocolo, bem como, os resultados finais quando da conclusão.

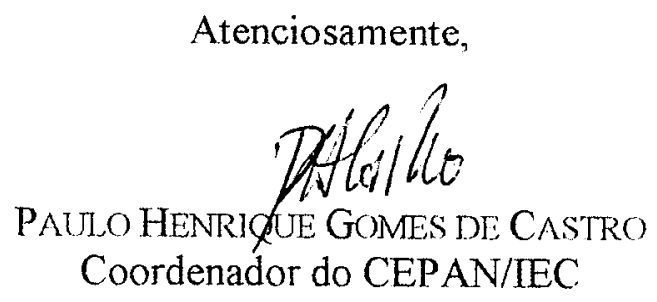

AV. ALMIRANTE BARROSO, 492 - BAIRRO: MARCO - CEP: 66090-000 - BELÉM-PA - C.N.P.J.: 26.989.350/0489-09 - FONE: (091) 246-6422 - FAX: (091) 266-4669 RODOVIA BR 316 - KM 07, S/NN - BAIRRO - LEVILÂNDIA - CEP: 67.030-000 - ANANINDEUA-PA - FONE: (091) 214-2000 


\section{FOLHA DE AVALIAÇÃO}

Nome da autora: KUGELMEIER, Tatiana

Título: Avaliação endocrinológica do ciclo ovariano de macaco bugio (Alouatta caraya - HUMBOLDT, 1812) por meio de extração e dosagem de metabólitos de esteróides fecais

Dissertação apresentada ao Programa de Pós-graduação em Reprodução Animal da Faculdade de Medicina Veterinária e Zootecnia da Universidade de São Paulo para obtenção do título de Mestre em Medicina Veterinária

Data:

Banca Examinadora

Prof. Dr.

Instituição:

Assinatura:

Julgamento:

Prof. Dr.

Instituição:

Assinatura:

Julgamento:

Prof. Dr. Instituição:

Assinatura: Julgamento: 
Aos meus pais por me mostrarem as opções sem jamais determinarem a escolha. Por estarem sempre ao meu lado e me apoiarem de todas as formas que lhes são cabiveis. Por proporcionarem todas as condições para que eu possa lutar e atingir meus objetivos....

Aos bugios pelo simples fato de existirem e continuarem encantando com seu rugido. Aos animais que participaram deste trabalho por contribuirem para o melhor entendimento da sua espécie. 


\section{AGRADECIMENTOS}

Ao Prof. Dr. Cláudio Alvarenga de Oliveira pela orientação, amizade e confiança em mim depositada. Pelo espirito empreendedor e disposição em aceitar novos desafios.

Ao Prof. Dr. Marcelo Alcindo de Barros Vaz Guimarães pela preciosa ajuda desde o início do mestrado, pelas longas conversas, incentivo $e$ orientação.

Ao Dr. Reinaldo de Amorim Carvalho, pelo apoio, orientação e por proporcionar todas as condições necessárias ao desenvolvimento do estudo.

Ao amigo Prof. José Muniz Augusto Pereira Carneiro Muniz pela dedicação e confiança depositada desde o estágio de conclusão de curso e depois no aceite para o mestrado. Pela garra, determinação e valiosos conselhos.

À Fundação de Amparo à Pesquisa do Estado de São Paulo (FAPESP) pela concessão da bolsa de mestrado (processo 02/10920-5) e pelo suporte financeiro ao estudo.

Ao Centro Nacional de Primatas (CENP) pelo apoio logistico e financeiro.

À D. Laura Soares, pelo carinho de mãe durante minha estadia no CENP $e$ ajuda na aquisição da literatura para o projeto.

Aos médicos veterinários Paulo Henrique Castro, Klena Sarges Marruaz da Silva, Humberto Ferreira, pelo apoio técnico e amizade.

Aos tratadores do CENP pela dedicação e ajuda indispensáveis à execução do estudo, pela paciência e descontração. 
A todos os funcionários do CENP que direta ou indiretamente contribuiram para o estudo, pelo carinho e amizade durante o tempo que fiquei na instituição.

Aos amigos Rodrigo Del Valle, Frederico Monteiro e Sheyla Domingues por compartilharem sua experiência e me ajudarem no desenvolvimento do projeto. Pela amizade e companhia (até o último instante).

Aos Profs. Drs. Washington, Diva Guimarães, Camila I. Vanucchi, Patricia Izar, Eduardo Ottoni e Dr. Domingo Canales Espinosa pelas dicas, apoio técnico e enriquecimento do trabalho.

A Profa. Dra. Maria das Dores Palha, ao Prof. Dr. Milton Thiago de Melo e aos amigos, Cristina Whiteman, Kátia de Paula e Jairo por me incluírem nas atividades relacionadas à conservação de animais selvagens no Pará e compartilharam sua experiência no assunto.

A todos os professores e demais funcionários do Departamento de Reprodução Animal pela amizade, auxílio e incentivo indispensáveis.

Aos colegas e amigos pós-graduandos Adriana, Alexandre, André, Christiane, Cláudia, Débora, Eduardo, Everton, Flaviana, Haníbal, Heloisa, Karina, Lindsay, Manoel, Monique, Nélcio, Paola, Paulo, Priscila, Regina, Rogério, Samuel, Thiesa e Torres, pelas discussões técnicas enriquecedoras e pelos momentos de descontração.

Aos colegas Marie-Odille, Christoph Knogge e Patricia Berbare pela disponibilidade em revisar a dissertação ou ajudar na análise dos resultados e ao Prof. Dr. Fumio Honna Ito pela revisão do resumo em inglês.

Aos estagiários Adriana, Ana Luiza, Juliano, Mariana, Laila, Prisila e Rosana pela ajuda nas diferentes etapas do estudo e companhia... 
À técnica e amiga do Laboratório de Dosagens Hormonais Érika C. G. Felippe pela dedicação e competência.

Aos colegas, funcionários e professores da Faculdade de Medicina Veterinária e Zootecnia de Botucatu, em especial aos Profs. Drs. Carlos Alberto Hussni, Maria Denise Lopes, Mariângela Luzano Cruz e Márcio $\boldsymbol{R}$. G. Kuchembuck, por contribuirem para minha formação profissional e pessoal.

Ao serviço de biblioteca da FMVZ-USP pela ajuda na busca e aquisição da literatura e à Elza Mara R. B. Faquim pela revisão e formatação final da dissertação.

As minhas companheiras de república: Lilian, Lorena, Tatiana Ueno e Laura pela convivência prazerosa, experimentos de madrugada, companhia e amizade.

Aos meus queridos amigos de infância, de agora e sempre: Tania, Daniela, Liliane, Livia, Júnia, Joana, Vanessa, Tatiana Prestes, Christian, Ian, Christiane, Sandy, Ana Paula, Júlia, Renata, Cristina, Yugi, Gilson, Mário, Luciano, por tantos anos de companheirismo, compreensão, acolhimento e diversão.

Agradecimento especial à minha familia que sempre me dá forças seguir em frente, pelos ensinamentos de dignidade, amor e honestidade. À tia Lourdes, Dani, Márcio e Lucy, pelo carinho e enorme paciência em me compreender nos momentos mais dificeis.

Ao meu querido Marcelo pelo amor e companheirismo. Pela paciência em agüentar tantos meses de distância e mais tantos de correria...

À minha segunda familia Melissa, Bete, Paulo, Dona Terezinha, Seu Paulo, tios e primos, pela acolhida, carinho e amizade.

Enfim, a Deus e ao Universo por eu ter chegado até aqui. 
“... para Aristóteles, na reprodução, a muโher era passiva e receptora, enquanto o homem era ativo e produtivo... a mulher era apenas o solo que acolhia e fazia germinar a semente que vinha do "semeador", ou seja, o homem... É surpreendente e lamentável que um homem como Aristóteles, tão inteligente para tantos assuntos, pudesse se enganar desse jeito no que se refere à relação entre os sexos." 


\section{RESUMO}

KUGELMEIER, T. Avaliação endocrinológica do ciclo ovariano de macaco bugio (Alouatta caraya - HUMBOLDT, 1812) por meio de extração e dosagem de metabólitos de esteróides fecais. [Endocrinological evaluation of ovarian cycle in howler monkeys (Alouatta caraya - HUMBOLDT, 1812) by extraction and measurement of fecal steroids]. 2005. 120 f. Dissertação (Mestrado em Medicina Veterinária) - Faculdade de Medicina Veterinária e Zootecnia, Universidade de São Paulo, São Paulo, 2005.

A endocrinologia ovariana de cinco fêmeas de bugio da espécie Alouatta caraya foi estudada por meio de extração e dosagem de metabólitos fecais de estrógenos e progestinas durante um período de cinco meses. Adicionalmente observou-se a presença de eritrócitos por meio de citologia vaginal em três das fêmeas estudadas. Duas fêmeas, uma em condição nutricional desfavorável e outra pré-púbere, apresentaram concentrações basais de estrógenos com mediana menor que 3,7 $\mathrm{ng} / \mathrm{g}$ e de progestinas menor que $29,7 \mathrm{ng} / \mathrm{g}$ de fezes úmidas. Nas outras três fêmeas a mediana dos valores de pico de estrógenos fecais foi $711,55 \mathrm{ng} / \mathrm{g}$ e dos valores basais $130,51 \mathrm{ng} / \mathrm{g}$ de fezes úmidas. Para as progestinas fecais a mediana dos valores de pico foi $2653,54 \mathrm{ng} / \mathrm{g}$ e dos valores basais foi $149,88 \mathrm{ng} / \mathrm{g}$ de fezes úmidas. Nestes três animais as concentrações de ambos os metabólitos apresentaram uma variação cíclica e o intervalo entre picos de estrógenos fecais foi 19,6 $\pm 1,9$ dias (média $\pm E P M$ ). Estes metabólitos permaneceram elevados durante $9,1 \pm 0,9$ dias. Elevações sustentadas de metabólitos fecais de progestinas acompanhadas de pico e elevações de metabólitos fecais de estrógenos foram observadas em apenas quatro períodos. Nestes casos ambos os metabólitos elevaram-se aproximadamente ao mesmo tempo e estimou-se que a ovulação tivesse ocorrido antes do início destas elevações. Os períodos de sangramento coincidiram com a queda nas concentrações de estrógenos e progestinas fecais.

Palavras-chave: Endocrinologia. Esteróides. Metabólitos. Reprodução Animal. Primatas. 


\begin{abstract}
KUGELMEIER, T. Endocrinological evaluation of ovarian cycle in howler monkeys (Alouatta caraya - HUMBOLDT, 1812) by extraction and measurement of fecal steroids. [Avaliação endocrinológica do ciclo ovariano de macaco bugio (Alouata caraya - HUMBOLDT, 1812) por meio de extração e dosagem de metabólitos de esteróides fecais]. 2005. 120 f. Dissertação (Mestrado em Medicina Veterinária) - Faculdade de Medicina Veterinária e Zootecnia, Universidade de São Paulo, São Paulo, 2005.
\end{abstract}

The ovarian endocrinology was assessed in five female howler monkeys (Alouatta caraya) by means of estrogen and progestogen metabolites extracted from fecal samples. Measurements were conducted for a period of five months, and erythrocytes were observed by vaginal cytology, in three females. In one subadult and in one undernourished female, estrogen concentrations remained at median basal levels $<3.7 \mathrm{ng} / \mathrm{g}$, and the progestogen concentrations were $<29.7 \mathrm{ng} / \mathrm{g}$ of wet feces for almost the entire period of the experiment. For the other three females, median fecal estrogen peak concentration was $711.55 \mathrm{ng} / \mathrm{g}$ and basal concentration was $130.51 \mathrm{ng} / \mathrm{g}$ of wet feces. Median fecal progestogen concentration was $2653.54 \mathrm{ng} / \mathrm{g}$ and for basal concentration was $149.88 \mathrm{ng} / \mathrm{g}$ of wet feces. The three females were found with a cyclical pattern for both metabolites concentrations, with fecal estrogen peak intervals of $19.6 \pm 1.9$ (mean \pm SEM) days and the estrogen metabolites remained elevated for $9.1 \pm 0.9$ days. Fecal progestogen showed sustained elevations concurrently with fecal estrogen increase only in four periods and it was presumed that ovulation had occurred before the onset of those elevations. Bleeding periods occurred with the falling of both steroid metabolites.

Key words: Endocrinology. Steroids. Metabolites. Animal reproduction. Primates. 


\section{LISTA DE FIGURAS}

Figura 1 - Fêmea de bugio (Alouatta caraya) com o filhote macho. Notar a pelagem de cor dourada para ambos. CENP, Ananindeua - PA.... 44

Figura 2 - Macho de bugio (Alouatta caraya). Notar a pelagem de coloração preta. CENP, Ananindeua - PA

Figura 3 - Gaiola onde foram alojados os bugios (Alouatta caraya), até novembro de 2003, antes da mudança de galpões. CENP, Ananindeua - PA

Figura 4 - Gaiola onde foram alojadas os bugios (Alouatta caraya), durante a maior parte do estudo, após a mudança de galpões. CENP, Ananindeua - PA

Figura 5 - Colheita de amostras fecais de fêmeas de bugio ( $A$. caraya). CENP, Ananindeua, PA

Figura 6 - Armazenamento das amostras fecais de fêmeas de bugio ( $A$. caraya) em sacos plásticos tipo "zip"

Figura 7 - Contenção de fêmea de bugio (Alouatta caraya) com o auxílio de puçá. CENP, Ananindeua - PA.

Figura 8 - $\quad$ Retirada de fêmea de bugio (Alouatta caraya) do puçá. CENP, Ananindeua - PA

Figura 9 - $\quad$ Limpeza da vulva de fêmea de bugio (Alouatta caraya)

Figura 10 - Introdução de escova ginecológica na fêmea de bugio ( $A$. caraya)

Figura 11 - Deslizamento da escova sobre a lâmina de vidro

Figura 12 - Representação gráfica da curva de regressão linear entre a curva formada pelas concentrações de um "pool" de amostras fecais em diluições sucessivas e a curva padrão do conjunto diagnóstico da DPC ${ }^{\circledR}$ MedLab para dosagem de estradiol. São Paulo, 2005

Figura 13 - Representação gráfica da curva de regressão linear entre a curva formada pelas concentrações de um "pool" de extratos fecais em diluições sucessivas e a curva padrão do conjunto diagnóstico da DPC ${ }^{\circledR}$ MedLab para dosagem de progesterona. São Paulo, 2005 
Figura 14 - Representação gráfica do perfil das concentrações de metabólitos fecais de progestinas e estrógenos da fêmea 4 , durante quatro meses e meio de colheita. A seta indica o dia da mudança de galpão. São Paulo, 2005

Figura 15 - Representação gráfica do perfil das concentrações de metabólitos fecais de progestinas e estrógenos da fêmea 5 , durante cinco meses de colheita. A seta indica o dia da mudança de galpão. São Paulo, 2005

Figura 16 - Representação gráfica do perfil das concentrações de metabólitos fecais de estrógenos e progestinas da fêmea 1 durante cinco meses de colheita. As estrelas ressaltam os picos dos metabólitos de estrógenos acompanhados de valores elevados. As tarjas vermelhas indicam períodos de sangramento. São Paulo, 2005

Figura 17 - Perfil dos metabólitos de estrógenos nas fezes da fêmea 1 no período de aparecimento dos picos. São Paulo, 2005

Figura 18 - Representação gráfica do perfil das concentrações de metabólitos fecais de estrógenos e progestinas da fêmea 2, durante cinco meses de colheita. As estrelas ressaltam os picos acompanhados de valores elevados dos metabólitos de estrógenos. As tarjas vermelhas indicam períodos de sangramento. São Paulo, 2005

Figura 19 - Perfil dos metabólitos de estrógenos da fêmea 2 no período de aparecimento de picos. São Paulo, 2005

Figura 20 - Representação gráfica do perfil das concentrações de metabólitos fecais de estrógenos e progestinas da fêmea 3 , durante seis meses de colheita. As estrelas ressaltam os picos acompanhados por valores elevados dos metabólitos de estrógenos. As tarjas vermelhas indicam períodos de sangramento. São Paulo, 2005

Figura 21 - Perfil dos metabólitos de estrógenos da fêmea 3 no período de aparecimento de picos. São Paulo, 2005

Figura 22 - Representação gráfica (curva suavizada) da variação das concentrações de metabólitos fecais de estrógenos e progestinas durante um intervalo entre sangramentos obtido a partir dos dados de duas fêmeas (1 e 2) de bugio (Alouatta caraya). O dia 1 corresponde ao primeiro dia de observação de sangramento. São Paulo, 2005

Figura 23 - Representação gráfica (curva suavizada) do perfil de metabólitos fecais de estrógenos das fêmeas 1 e 2 mostrando o fenômeno da 
sincronização dos períodos de elevação destes metabólitos. As estrelas representam os valores de pico. São Paulo, 2005.

Figura 24 - Espécies do gênero Alouatta mesoamericanas (A) e sulamericanas (B), de acordo com Groves (2001). Fonte: CortésOrtiz et al. (2003)

Figura 25 - Representação gráfica do método adotado para determinação dos valores elevados (rosa) e basais (roxo) de estrógenos fecais (ng/g fezes úmidas), utilizando a média+1,5DP e p<0,05 (Animal 1). São Paulo, 2005

Figura 26 - Representação gráfica do método adotado para determinação dos valores elevados (azul escuro) e basais (azul claro) de progestinas fecais (ng/g fezes úmidas), utilizando a média+2DP e p<0,05 (Animal 1). São Paulo, 2005

Figura 27 - Aspecto da lâmina colpocitológica no momento do aparecimento de células sangüíneas (fêmea 2). Coloração Panótico, aumento 200x. São Paulo, 2005

Figura 28 - Aspecto da lâmina colpocitológica no momento do aparecimento de células sangüíneas (fêmea 2). Coloração Papanicolaou, aumento 200x. São Paulo, 2005

Figura 29 - Aspecto da lâmina colpocitológica corada pelo corante de Shorr (fêmea 2), aumento 100x. São Paulo, 2005

Figura 30 - Aspecto da lâmina colpocitológica corada pelo corante de Leishman (fêmea 2), aumento 100x. São Paulo, 2005 


\section{LISTA DE TABELAS}

Tabela 1 - Controle de qualidade dos ensaios de metabólitos de estrógenos em amostras fecais de fêmeas de bugio (Alouatta caraya). São Paulo, 2005

Tabela 2 - Controle de qualidade dos ensaios de metabólitos de estrógenos em amostras fecais de fêmeas de bugio (Alouatta caraya). São Paulo, 2005

Tabela 3 - Médias, erros padrões, valores mínimos, máximos e medianas das concentrações de metabólitos fecais de estrógenos (ng/g) em fêmeas de bugio (Alouatta caraya). São Paulo, 2005

Tabela 4 - Médias, erros padrões, valores mínimos, máximos e medianas das concentrações de progestinas fecais $(\mathrm{ng} / \mathrm{g})$ em fêmeas de bugio (Alouatta caraya). São Paulo, 2005.

Tabela 5 - Valores basais, de elevação e pico para os metabólitos fecais de estrógenos e progestinas ( $\mathrm{ng} / \mathrm{g}$ ) em fêmeas de bugio (Alouatta caraya). São Paulo, 2005

Tabela 6 - Valores mínimos e máximos, medianas, médias e erros padrões (EP) das concentrações basais e de pico de metabólitos fecais de estrógenos e progestinas $(\mathrm{ng} / \mathrm{g})$ em fêmeas de bugio (Alouatta caraya). São Paulo, 2005

Tabela 7 - Medianas dos intervalos entre picos em dias, valores mínimos e máximos destes intervalos e número de dias que os valores de estrógenos fecais permaneceram elevados para fêmeas de bugio (Alouatta caraya). São Paulo, 2005.

Tabela 8 - Médias e erros padrões das médias (média $\pm E P M)$ dos intervalos entre picos de estrógenos fecais, do número de dias em que os valores destes metabólitos permaneceram elevados, dos períodos de concentrações basais e elevadas de progestinas fecais, intervalos entre períodos de sangramento e da duração destes períodos nas fêmeas de bugio (Alouatta caraya). São Paulo, 2005

Tabela 9 - Percentual de reações cruzadas dos conjuntos diagnósticos comerciais da DPC ${ }^{\circledR}$ MedLab para dosagem de estradiol por radioimunoensaio, em fase sólida. Fornecido pelo fabricante

Tabela 10- Percentual de reações cruzadas dos conjuntos diagnósticos comerciais da DPC $^{\circledR}$ MedLab para dosagem de progesterona por radioimunoensaio, em fase sólida. Fornecido pelo fabricante 


\section{LISTA DE QUADROS}

Quadro 1 - Identificação, procedência, idade e histórico reprodutivo das fêmeas de bugio (Alouatta caraya) participantes do estudo. São Paulo, 2005

Quadro 2 - Peso corporal e resultados dos exames hemograma, leucograma, bioquímica sérica e coproparasitológico realizados nas fêmeas de bugio (Alouatta caraya). São Paulo, 2005

Quadro 3 - Resultados dos exames ultra-sonográficos e colpocitológicos realizados nas fêmeas de bugio (Alouatta caraya). São Paulo, 2005 115

Quadro 4 - Etapas da técnica de Papanicolaou para a coloração de lâminas citológicas 


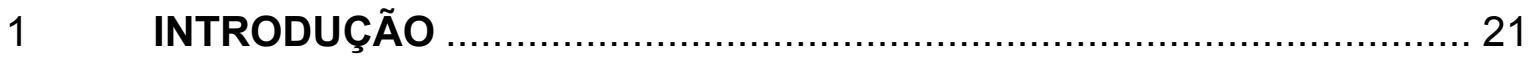

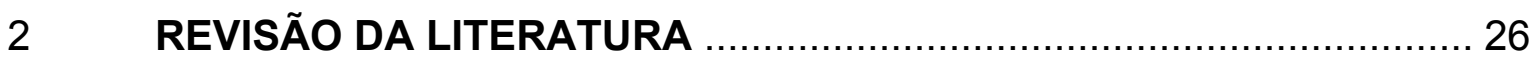

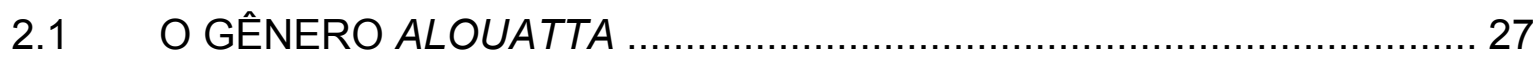

2.1.1 Aspectos reprodutivos do gênero ………….............................. 29

2.2 ESTUDO DA FISIOLOGIA REPRODUTIVA ATRAVÉS DA DOSAGEM HORMONAL NÃO-INVASIVA ......................................... 34

2.3 DIFERENÇAS ENTRE O CICLO ESTRAL E MENSTRUAL .................. 37

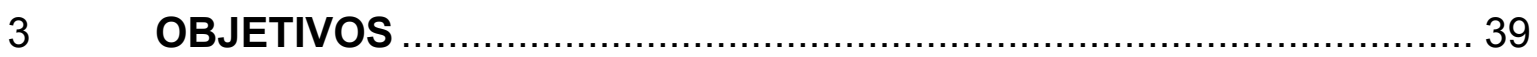

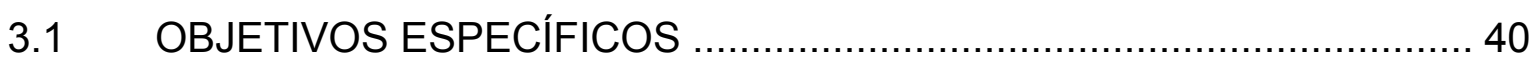

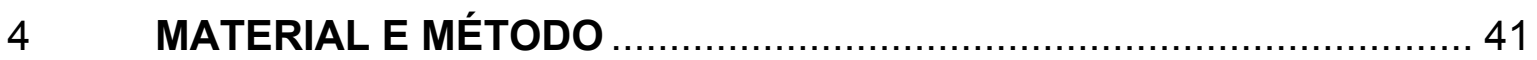

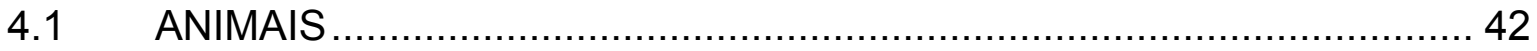

4.2 COLHEITA E ARMAZENAMENTO DAS AMOSTRAS FECAIS .............. 46

4.3 COLHEITA E ANÁLISE DE CITOLOGIA VAGINAL ............................. 47

4.4 PROCESSAMENTO DAS AMOSTRAS FECAIS PARA EXTRAÇÃO

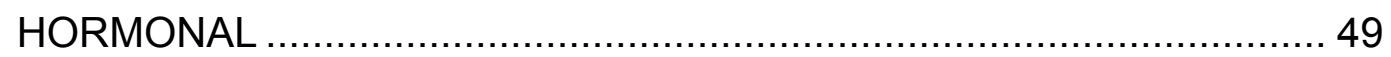

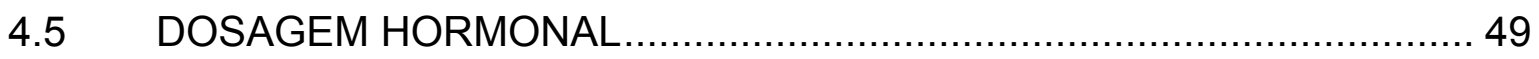

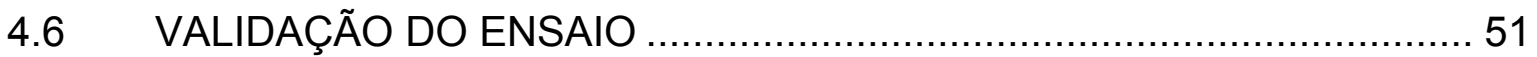

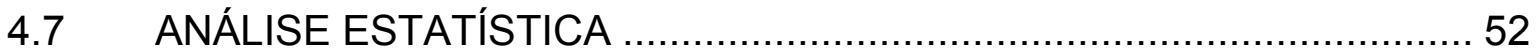

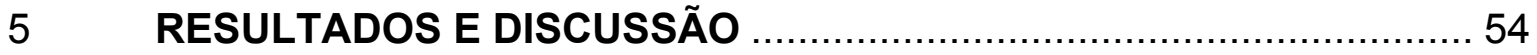

5.1 CONTROLE DE QUALIDADE DOS ENSAIOS …................................. 55

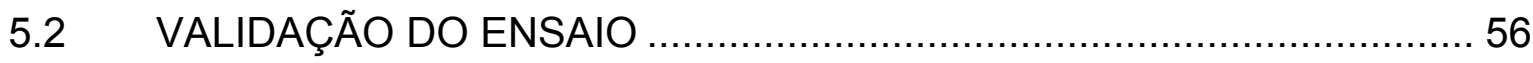

5.3 PERFIS HORMONAIS DE METABÓLITOS DE ESTRÓGENOS E

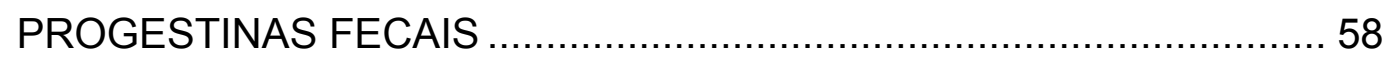

5.3.1 Perfil hormonal das fêmeas $\mathbf{4}$ e $\mathbf{5}$ e a validação fisiológica ................60

5.3.2 Função ovariana das fêmeas 1, 2 e 3 …...................................... 65

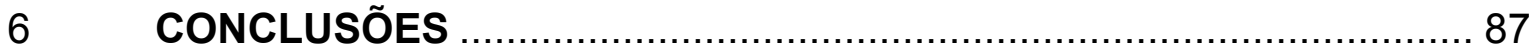

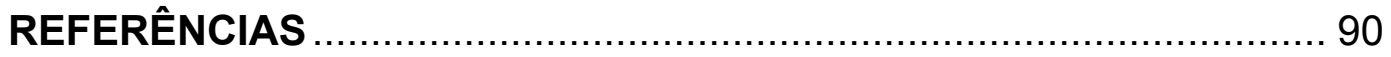

ANEXOS e APÊNDICES ............................................................ 110 


\title{
1 INTRODUÇÃO
}

A situação ambiental hoje é extremamente delicada. A sociedade humana vem degradando o meio ambiente em escala global, por meio de mudanças climáticas, extinção de espécies e degradação de ecossistemas.

\begin{abstract}
Apesar do efeito mobilizador exercido pela Rio 92, as ações que vêm sendo empreendidas em nome da gestão ambiental ou do desenvolvimento sustentável têm se mostrado até certo ponto ambíguas, fragmentadas e pouco capazes de fazer justiça à complexidade dos desafios criados pela busca de redução das desigualdades no interior de cada país e entre países, de consolidação progressiva de novos arranjos institucionais para um controle democrático-participativo dos riscos da evolução técnica, e de internalização de uma relação de simbiose autêntica e duradoura dos seres humanos com a natureza.
\end{abstract}

Vieira (2002)

A reversão desta situação somente será possível a partir de uma profunda mudança nos modos de agir e de pensar da sociedade. No âmbito econômico, as mudanças já vêm ocorrendo, relacionando-se a biodiversidade a valores econômicos. Em termos de biodiversidade, o Brasil é um país extremamente rico e o desafio reside em não violentarmos o equilíbrio dessa vida diversa e múltipla, nem permitirmos que outros o façam.

Para a preservação desta riqueza, estudos científicos visando o melhor conhecimento da fisiologia reprodutiva de espécies selvagens são de fundamental importância. Estes estudos podem facilitar o manejo e criação de espécies em cativeiro, assim como auxiliar na obtenção de melhores resultados na aplicação de técnicas de reprodução assistida (MORATO, 2001). Indiretamente o conhecimento da fisiologia reprodutiva pode permitir a realização de projetos de reintrodução de 
espécies ameaçadas, reposição de animais em instituições de pesquisas biomédicas e a conservação da biodiversidade faunística, in situ e ex situ.

Trabalhos baseados apenas na análise dos parâmetros comportamentais são importantes no conhecimento da reprodução das espécies, porém não possibilitam determinar seu ciclo reprodutivo com precisão. Portanto é importante associar o conhecimento do comportamento sexual à fisiologia hormonal (RIBEIRO, 1994).

Os métodos não-invasivos de dosagem hormonal fecal ou urinária representam um grande avanço nesta área do conhecimento (HEARN, 1986). Tais métodos poupam os animais do estresse causado pela contenção física e/ou química (GUIMARÃES, 2001a), possibilitam a colheita diária de amostras durante longos períodos e podem ser aplicados em estudos com animais tanto em cativeiro quanto em vida livre.

A análise de hormônios esteróides nas fezes ou urina constitui-se em importante ferramenta para a compreensão da complexa inter-relação entre a fisiologia de um animal e o ambiente no qual ele está inserido (WASSER; MONFORT; WILDT, 1991). Assim, o método possui ampla aplicabilidade desde a avaliação do bem-estar animal (BOINSKI et al., 1999; VON HOHENDORFF, 2003; WHITTEN et al., 1998), da função reprodutiva de espécies selvagens (FOLEY; PAPAGEORGE; WASSER, 2001; GRAHAM; BROWN, 1996; LÖTTKER et al., 2004; MARSHALL; HOHMANN, 2005; PATTON et al., 1999; RAMINELLI et al., 2001), diagnóstico de prenhez (BAMBERG et al., 1991) até estudos filogenéticos (PRYCE et al., 1995) e etológicos (CAROSI, HEISTERMANN, VISALBERGHI, 1999; SMITH; McGREER-WHITWORTH; FRENCH, 1998).

O Laboratório de Dosagens Hormonais, da Faculdade de Medicina Veterinária e Zootecnia, Universidade de São Paulo (LDH/FMVZ/USP) validou a técnica de 
estudo da endocrinologia reprodutiva por meio de extração e dosagem de hormônios esteróides nas fezes de animais domésticos e selvagens. Entre as espécies estudadas encontram-se Amazona aestiva, (papagaio-verdadeiro) (DIAS, 2003); Capra hircus (cabra) (CAPEZZUTO, 2005); Dasyprocta aguti (cutia) (LUIZ; OLIVEIRA, 2003); Herpailurus yagouarundi, (gato-mourisco) (BERBARE, 2004); Mesocricetus auratus (hamster) (CHELINI, 2002); Panthera onca (onça-pintada) (FURTADO, 2003) e Trichechus inunguis (peixe-boi da Amazônia) (NASCIMENTO, 2004).

Os primatas não humanos representam uma importante ordem a ser estudada, devido à fragilidade em que se encontram muitas de suas espécies e por sua semelhança anatômica, fisiológica e etológica com a espécie humana (AURICCHIO, 1995). Quase metade das 250 espécies de primatas é considerada de interesse para a conservação e uma a cada cinco é classificada como ameaçada ou criticamente ameaçada (MITTERMEIER, 1996).

O Centro Nacional de Primatas, órgão pertencente à Secretaria de Vigilância em Saúde, filiada ao Ministério da Saúde (CENP/SVS/MS) e sediado na cidade de Ananindeua, estado do Pará, é responsável pela criação de primatas não-humanos sob condições controladas para pesquisas biomédicas. Entre as linhas de pesquisa do CENP, inserem-se os estudos sobre a reprodução das espécies mantidas na instituição, como o Alouatta caraya (bugio) (VALLE, 2002); Aotus azarae infulatus (macaco-da-noite) (FERREIRA, 1998; MONTEIRO, 2003); Cebus apella (macacoprego) (DOMINGUES et al., 2003).

O potencial biomédico do gênero Alouatta é evidenciado pelas zoonoses descritas no gênero, das quais destacam-se a tripanossomose (DEREURE et al., 2001; FUNAYAMA; BARRETO, 1970; ZICCARDI et al., 2000); a malária (ARRUDA 
et al., 1989; CROGSWELL, 2000; DEANE; NETO, 1973); a meningoencefalite eosinofílica por Angiostrongylus cantonensis (CARLISLE et al., 1998; GARDINER et al., 1990); a febre de Mayaro (BRACK, 1987; TALARMIN, 1998) e a febre amarela (RODHAIN, 1991; SEYMOUR et al., 1983; TORRES, 2002). Os bugios são particularmente susceptíveis à febre amarela (BRACK, 1987; HERVÉ et al., 1985), desenvolvendo a doença na forma grave, semelhante ao que ocorre no homem (TOMORI, 1999; VASCONCELOS, 2003). Almeida et al. (2001) isolaram anticorpos anti-rábicos em A. guariba. Foram descritos ainda parasitismo por Amblyomma cajennense, carrapato que também pode infestar o homem (LABRUNA et al., 2002) e amebíase severa (MÁRQUEZ-MONTER et al., 1991).

Entre os estudos biomédicos utilizando primatas do gênero Alouatta, destacam-se os de Schou et al. (1993), Valsecchi et al. (1980) e Wirthlin (1991), nos quais os autores afirmam que os bugios são bons modelos biológicos para estudos de doenças periodontal e afecções da tireóide.

Além do interesse biomédico, particularidades anatômicas e comportamentais tornaram o gênero Alouatta um dos mais bem documentados entre os primatas neotropicais (CROCKETT; EISENBREG, 1987; GUEDES et al., 2000). No entanto poucos estudos focaram aspectos reprodutivos das espécies do gênero.

A. caraya não consta nas Listas Oficiais de Espécies da Fauna Brasileira Ameaçada de Extinção do IBAMA (Instituto Nacional do Meio Ambiente e dos Recursos Naturais não-renováveis) (2003), nem na Lista Vermelha da IUCN (International Union for Conservation of Nature) (2001). No entanto, a espécie consta no Livro Vermelho da Fauna Ameaçada do Estado do Paraná (2004) e outras espécies do gênero são classificadas como criticamente ameaçadas ( $A$. belzebul ululata e A. guariba gariba) (HILTON-TAYLOR; RYLANDS, 2002). 
Segundo Moreland et al. (2001), e espécie $A$. caraya pode ser utilizada como modelo no desenvolvimento de tecnologias para reprodução assistida nas espécies criticamente ameaçadas.

Os bugios ainda são importantes dispersores de sementes devido aos seus hábitos alimentares, desta forma exercendo efeito fundamental na distribuição de espécies de plantas e regeneração de florestas tropicais (BRAVO; ZUNINO, 2000; ESTRADA; COATES-ESTRADA, 1986). São resistentes a um certo nível de desmatamento (KOWALEWSKI; ZUNINO, 1999) e podem favorecer ecossistemas agroecológicos ao depositar quantidades significativas de nutrientes no solo da plantação através da defecação (ESTRADA, 2005).

A crescente destruição e fragmentação de habitats, constante pressão de caça para alimentação, criação como "pets" ou outros propósitos, principais causas de declínio de populações de primatas em todo o mundo (MITTERMEIER, 1986; TERBORGH, 1986), tornam urgente os investimentos em estudos sobre sua reprodução. 


\section{REVISÃO DA LITERATURA}

A ordem Primates é dividida em duas subordens, dos Prosimii (prossímios) e Anthropoidea (símios e antropóides). A subordem Prosimii por sua vez é dividida nas infraordens dos Lemuriformes (lemuriformes), Lorosiformes (lorisiformes) e Tarsiiformes (társios). A subordem Anthropoidea é dividida nas infraordens dos Catarrhini (primatas do velho mundo) e dos Platyrrhini (primatas do novo mundo ou neotropicais) (ROWE, 1996).

Os Platyrrhini dividem-se nas famílias Callitrichidae (micos e sagüis), Aotidae (macacos-da-noite), Cebidae (macacos-prego e micos-de-cheiro), Pitheciidae (parauacus, uacaris e sauás) e Atelidae (muriquis, macacos-aranha, macacosbarrigudo e bugios), segundo a classificação proposta por Rylands (2000).

\subsection{O GÊNERO ALOUATTA}

A classificação taxonômica do gênero Alouatta tem sido objeto de vários estudos e novas classificações foram propostas recentemente (BRANDON-JONES; RYLANDS, 1999; CORTÉS-ORTIZ, 2003; MEIRELES, 1999; SCHENEIDER, 2000). De acordo com Rylands $(2000,2001)$ o gênero Alouatta pertence à subfamília Alouattinae e possui mais de 20 espécies e subespécies. O mapa da distribuição das espécies do gênero encontra-se no anexo $A$. 
Bugio ou guariba são os nomes populares mais comuns para as espécies do gênero e características de coloração de pelagem são utilizadas para diferenciá-las. Os bugios estão entre os maiores primatas das Américas e podem ser encontrados desde o sul do México, América Central e Sul, até o norte da Argentina (KYNZEY, 1997).

A característica morfológica mais marcante do gênero é a presença do osso hióide bastante desenvolvido, o qual age como ressonador para o ronco ou rugido, vocalização de longo alcance caracterizada por sons roucos e graves e que originou o nome, em inglês, "howler monkey" (CROCKETT; EISENBERG, 1987). Tal característica permite o desenvolvimento de um sofisticado sistema de comunicação, fundamental para o tipo de organização social e comportamento dos bugios (OLIVEIRA, 1997, 2002).

A cauda preênsil é outra característica importante pois permite sua fácil locomoção pelos estratos arbóreos entre 10 e 20 metros de altura (AURICCHIO, 1995). São animais folívoros-frugívoros (MILTON, 1980) e, embora alimentem-se preferencialmente de frutos, são folívoros obrigatórios (QUEIROZ, 1995). Na sua dieta podem incluir-se também flores, sementes e brotos (RODRIGUEZ; MARINHOFILHO, 1996).

De modo geral, os bugios são pouco ativos, passando a maior parte do tempo em descanso (SANTINI, 1985). Milton $(1988,1993)$ relaciona este comportamento à dieta alimentar pouco energética. São animais diurnos com padrão bimodal de atividades, apresentando picos de movimentação no meio da manhã e no meio da tarde. Podendo ocorrer variações inter- e intra-específicas nestes padrões (SANTINI, 1985). 
Os bugios vivem em grupos familiares com 4 a 10 indivíduos, em média, formados pelo macho dominante, por fêmeas reprodutivas e suas crias, animais subadultos e machos subordinados com pouco ou nenhum acesso às fêmeas (TREVES, 2001).

\subsubsection{Aspectos reprodutivos do gênero}

Os bugios são animais poligínicos, ou seja, há várias fêmeas para um macho (STEELE, 1989) e poligâmicos, a mesma fêmea pode acasalar-se com vários machos (NEVILLE et al., 1988) dentro ou fora de seu grupo social (AGORAMOORTHY; HSU, 2000). Para Kowaleski, Peker e Zunino (2005) a promiscuidade da fêmea refletiria uma estratégia para aumentar a taxa de concepção e confundir a paternidade de machos potencialmente agressivos.

Em geral as espécies do gênero não apresentam evidência de sazonalidade reprodutiva (BITETTI; JANSON, 2000; STRIER; MENDES; SANTOS, 2001). No entanto, Queiroz (1995) observou um padrão sazonal para A. seniculus na Amazônia com cópulas apenas nos meses de outubro a dezembro, época menos úmida na região.

O desmame dos filhotes ocorre aos seis meses de idade (BITETTI; JANSON, 2000). Machos e fêmeas emigram de seus grupos natais próximo ou depois de atingirem a maturidade sexual (PUSEY; PACKER, 1987), o que pode estar relacionado à forte competição reprodutiva observada entre membros do grupo do mesmo sexo (JONES, 1980). 
No gênero Alouatta o dimorfismo sexual é bem evidente, o tamanho corporal e volume do osso hióide são maiores nos machos do que nas fêmeas (BICCAMARQUES; CALEGARO-MARQUES, 1998). Os machos pesam entre 5,0 e 9,0kg enquanto as fêmeas pesam entre 3,0 e 6,0kg, em média (FORD; DAVIS, 1992). Em duas espécies ( $A$. caraya e $A$. guariba clamitans) há dicromatismo sexual.

Segundo Auricchio (1995) a espécie $A$. caraya habita desde o nordeste da Bolívia, Paraguai e norte da Argentina até o Brasil central e oeste dos estados de Minas Gerais, São Paulo. Outros relatos estendem a distribuição da espécie para o nordeste, estado do Piauí (FLESHER, 2001) até o sul, no Rio Grande do Sul (CALEGARO-MARQUES; BICCA-MARQUES, 1996).

Nesta espécie o dicromatismo sexual é bem evidente, os machos são negros e as fêmeas de cor dourada, assim como os filhotes machos e fêmeas. Entre quatro e cinco anos de idade o jovem macho muda da cor dourada para preta (THORINGTON JR.; RUIZ; EISENBERG, 1984). Pelas características da pelagem $A$. caraya é popularmente conhecido como bugio preto ou preto e dourado.

Segundo Crockett e Eisenberg (1987) a maturidade sexual em $A$. caraya é atingida com 24 a 37 meses de idade para os machos e 35 a 42 meses de idade para as fêmeas. Na maturidade sexual das fêmeas ocorre escurecimento da pelagem, mudanças na estrutura vulvar e interrupção das brincadeiras infantis (SHOEMAKER, 1982).

Colillas e Coppo (1978) estudaram a reprodução do bugio preto através de citologia vaginal e análise microscópica dos ovários. A duração do ciclo ovariano foi

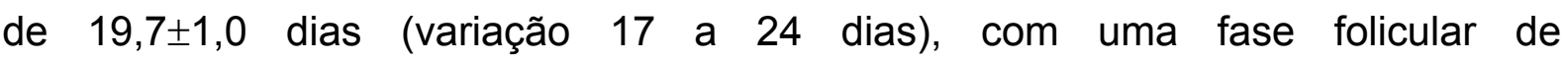
aproximadamente nove dias e fase lútea de sete dias. Foi observado um aumento no número de células escamosas entre 48 a $75 \%$ e a quantidade destas células 
permaneceu elevada durante 48 a 72 horas. Eritrócitos foram observados em alguns casos, de quatro a 10 dias após o pico de células escamosas. Nos dias anteriores ou imediatamente após o pico, as células intermediárias e parabasais foram predominantes. No final do ciclo notaram-se células pequenas similares a células basais ou endometriais.

Os autores não observaram mudanças nos órgãos sexuais que pudessem ser correlacionadas as alterações citológicas. Os ovários apresentaram muitos folículos atrésicos, raros corpos lúteos e tecido intersticial abundante. Os autores acreditam que fêmeas de $A$. caraya são poliéstricas e que os ciclos podem ser estudados através de citologia vaginal com a ovulação ocorrendo imediatamente após o pico de células escamosas.

Crockett e Eisenberg (1987) também não observaram alterações nas estruturas genitais externas durante o estro na espécie que, segundo Kowaleski e Zunino (2004) dura três dias. Os mesmos autores reportam um período de gestação de 180 dias e intervalo entre partos (IEP) de 18 meses, em vida livre. Em cativeiro, o intervalo cai para 12 a 15 meses (SHOEMAKER, 1982) ou apenas nove meses (CARMINATTI; SETZ, 2004).

Valle (2002) estudou as características físicas e morfológicas do sêmen de $A$. caraya colhido por eletroejaculação. O volume do ejaculado foi $0,09 \pm 0,05 \mathrm{ml}$ e a concentração média foi $649,5 \pm 926,7 \times 10^{6}$ espermatozóides por mililitro. O autor comparou animais acasalados e não acasalados e encontrou diferenças significativas na concentração espermática (maior para os não acasalados) e nos defeitos maiores (maior para os animais acasalados). Em vista destes resultados o autor sugere que concentração espermática mais baixa e maior percentual de anormalidades não necessariamente implicam em infertilidade. 
Para A. palliata, a duração do ciclo estral, baseado em observações comportamentais, é de 16,3 dias e as fêmeas permanecem receptivas durante 2 a 4 dias (GLANDER, 1980). Neste período, as fêmeas demonstram mudanças na coloração da pele dos órgãos genitais, aumento súbito da intumescência e realizam várias cópulas antes da concepção (CROCKETT; EISENBERG, 1987).

A maturidade sexual em $A$. palliata ocorre aos 36 e 42 meses de idade para fêmeas e machos, respectivamente. A gestação dura 186 dias, em média e o IEP é de 22,5 meses (GLANDER, 1980).

Fêmeas de $A$. seniculus possuem um ciclo estral de 17 dias e um estro de 2,5 a 3 dias, quando também mostram alterações na genitália sexual (CROCKETT; EISENBERG, 1987; CROCKETT; SEKULIC, 1982). Os dados sobre a duração da gestação na espécie são bastante discrepantes, podendo durar 139 dias (BRAZA; ALVAREZ; AZCÁRATE, 1981) ou 191 dias (CROCKETT; SEKULIC, 1982).

Em A. guariba clamitans os nascimentos ocorrem ao longo de todo o ano e o IEP é de 21,2 $\pm 2,5$ meses. O intervalo entre desmame e concepção é de seis meses (STRIER; MENDES; SANTOS, 2001).

Veras (2004) estudou a anatomia do aparelho reprodutor de fêmeas de $A$. guariba clamitans e A. caraya. A autora observou que os ovários eram estruturas bilaterais compactas, ovóides em $A$. guariba clamitans e mais globosas em $A$. caraya. Os ovários ligavam-se ao útero através do ligamento próprio do ovário, o qual mantinha as gônadas próximas ao órgão. O comprimento dos ovários variou de 8 a $21 \mathrm{~mm}$ (diâmetro longitudinal), a largura (diâmetro dorso-ventral) variou de 3,4 a 7,3mm e sua altura de 4 a 7,9mm (diâmetro latero-lateral).

O útero apresentou-se simples e alongado, com contorno piriforme. Em $A$. guariba foi caracterizado por fundo globóide e por uma cérvix marcadamente longa, 
que se projetava no canal vaginal e formava uma fenda circular (fórnix vaginal). Em A. caraya, o fundo uterino mostrou-se menos globóide e seu diâmetro anteroposterior foi menor que o diâmetro latero-lateral, dando aparência achatada ao fundo. O órgão não se apresentou anterovertido nem retrovertido e, devido ao grande comprimento do ceco, posicionou-se ligeiramente deslocado para o lado.

O miométrio era espesso, com feixes de fibras musculares circulares e longitudinais e altamente vascularizado. A camada mais interna da parede uterina ou endométrio apresentou variações na espessura conforme os estágios de desenvolvimento folicular. O comprimento uterino variou entre 17,8 e $32,5 \mathrm{~mm}$ e a cérvix mediu entre 8 e 15,9mm.

O comprimento médio da vagina variou de 19 a $43 \mathrm{~mm}$ e o número de camadas epiteliais foi maior nas fêmeas adultas. A vulva apresentou características peculiares. Quando o animal assumia uma postura quadrúpede o órgão apresentava disposição pendular. A curta rima estava contida entre os lábios maiores e seu comprimento médio foi de $19,1 \mathrm{~mm}$. Foram observadas diferenças na cor dos grandes lábios entre as espécies e entre fêmeas da mesma espécie, provenientes de regiões distintas. Os pequenos lábios mostraram-se como pregas delgadas, róseas e totalmente encobertas pelos grandes lábios. O clítores mostrou-se como estrutura cilíndrica de cor rósea, disposta fora da comissura vulvar e recoberta por um prepúcio. Não foi encontrado um os clitóridis. 


\subsection{ESTUDO DA FISIOLOGIA REPRODUTIVA ATRAVÉS DA DOSAGEM HORMONAL NÃO-INVASIVA}

Todos os primatas exibem um ciclo ovariano que compreende uma fase de crescimento folicular, a ovulação e uma fase de atividade do corpo lúteo (HODGES, 1987). A expressão destes eventos cíclicos, porém, varia consideravelmente entre as espécies. Existem diferenças na duração do ciclo e suas fases, sob influência ou não da sazonalidade e na ocorrência ou não da menstruação (HODGES, 1987).

A dosagem não-invasiva de metabólitos de hormônios esteróides permitiu o estudo da endocrinologia reprodutiva e o conhecimento destas diferenças em várias espécies de primatas. Entre os prossímios algumas das espécies estudadas foram Eulemur fulvus rufus (OSTNER; HEISTERMAN, 2003), E. mongoz (CURTIS et al., 2000), E. macaco flavifrons, E. rubriventer, Hapalemur griseus occidentalis (GERBER; MOISSON; HEISTERMANN, 2004). Entre os primatas do velho mundo encontram-se o Gorilla gorilla (BELLEM et al., 1995; MYIAMOTO et al., 2001), Macaca fasciculares (MATSUMURO et al., 1999; SHIDELER et al., 1993), M. silenus (HEISTERMANN et al., 2001), M. fuscata (FUJITA et al., 2001, 2004), Pan paniscus (HEISTERMANN et al., 1996); Papio cynocephalus (LYNCH et al., 2003; WASSER; MONFORT; WILDT, 1991; WASSER et al., 1994) e Presbytis entellus (ZIEGLER et al., 2000).

Entre as espécies de primatas neotropicais foram estudadas o Ateles geoffroy (CAMPBELL et al., 2001), Brachyteles spp (STRIER; ZIEGLER, 1994, 1997; STRIER; ZIEGLER; WITTWER, 1999; ZIEGLER et al., 1997); Callicebus moloch (VALEGGIA et al., 1999), Callimico goeldi (PRYCE; SCHWARZENBERGER; 
DÖBELI, 1994), Callithrix spp e Saguinus spp (HEISTERMANN; TARI; HODGES, 1993; LÖTTKER et al., 2004; SOUZA; ZIEGLER, 1998; ZIEGLER et al., 1989; ZIEGLER et al., 1996); Cebus spp (CAROSI; HEISTERMAN; VISALBERGUI, 1999; GUIMARÃES, 1999; LYNCH; ZIEGLER; STRIER, 2002), Leontopithecus spp (CHAOUI; HASLER-GALLUSSER, 1999; RIBEIRO, 1994); Pithecia pithecia (SAVAGE et al., 1995; SCHIDELER et al., 1994); Saimiri sciureus (MOORMAN et al., 2002).

No gênero Alouatta, alguns estudos foram realizados mas poucos foram publicados na íntegra. Assim, muitas informações foram obtidas com os próprios pesquisadores.

Em A. caraya, Moreland et al. (2001), estudaram a fisiologia reprodutiva de machos através da colheita e análise do sêmen e dosagem de testosterona fecal. Os autores verificaram que as características do sêmen foram similares entre os machos de diferentes idades e os níveis de testosterona nas fezes foram constantes ao longo do ano.

Herrick et al. (2000), realizaram um trabalho com dosagem de progesterona urinária de $A$. senicilus em vida livre, por radioimunoensaio. Os autores estimaram

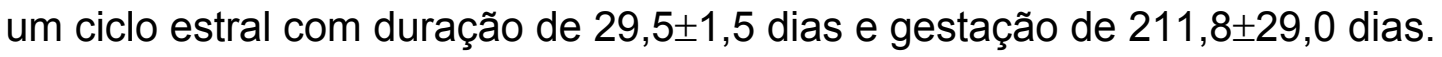

Espinosa (2000) investigaram a função ovariana de $A$. palliata mexicana através da dosagem de pregnanediol e estrona urinários por radioimunoensaio e encontraram ciclos com duração entre 6 e 33 dias.

Clarke, Zucker e Harrison (1991) correlacionaram a dosagem de estrógenos fecais com as alterações na genitália externa e comportamento sociossexual de fêmeas de $A$. palliata em vida livre na Costa Rica. Os autores encontraram diferenças significativas nas concentrações de estrógenos fecais entre as fêmeas 
que estavam ciclando e as fêmeas lactantes ou gestantes. Todas as cópulas ocorreram em associação a altos níveis de estrógenos fecais, no entanto nenhuma correlação foi encontrada entre alterações na genitália sexual externa e os níveis hormonais.

Zucker, Clarke e Harrison (1995) e Zucker et al. (1994) tentaram validar a dosagem de metabólitos fecais de estrógenos e progestinas para a espécie $A$. palliata através da comparação com a dosagem de estradiol e progesterona no sangue.

Em outro estudo, Zucker et al. (1996) não encontraram correlação significativa entre a idade de machos de $A$. palliata e as concentrações de testosterona em amostras fecais. Os autores especulam que os níveis de testosterona estariam então relacionados à freqüência de cópula.

Clarke et al. (1997) utilizaram a dosagem de esteróides sexuais fecais para estudar o padrão de migração de machos e de fêmeas em diferentes grupos de $A$ palliata em Hacienda La Pacifica, Costa Rica. Os autores encontraram menores níveis de estrógenos fecais em fêmeas que emigraram aos dois anos de idade, enquanto as que emigraram aos três anos tiveram níveis mais elevados do que aquelas que permaneceram em seus grupos natais. Os juvenis que permaneceram em seus grupos natais apresentaram níveis de estrógenos fecais semelhantes aos encontrados em adultos.

Clarke e Teaford (2002) dosaram cortisol fecal em machos da mesma espécie e observaram uma correlação inversa entre os níveis de cortisol e a posição social do animal. Os dados gerais da população de $A$. palliata estudada em longo prazo na Costa Rica encontram-se em Clarke et al. (2002). 


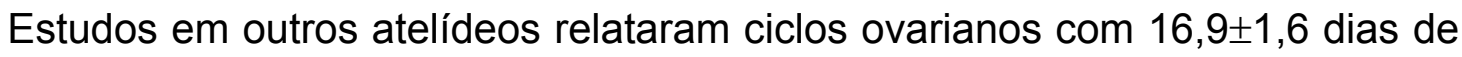
duração em $P$. pithecia (parauacu) (SAVAGE et al., 1995). A gestação durou $146,1 \pm 5,2$ dias e o IEP foi 343 a 479 dias.

Para A. Geoffroy (macaco-aranha), Campbell et al. (2001) registraram um ciclo de aproximadamente 20 dias com uma fase folicular curta, de 2 a 3 dias para fêmeas em cativeiro. Nas fêmeas em vida livre a duração do ciclo foi de 22,7 dias e a fase folicular durou de 4 a 8 dias.

Para B. hypoxantus em vida livre, a duração do ciclo estral foi de $21,0 \pm 5.4$ dias e da gestação $216,4 \pm 1,5$ dias, por meio da extração e dosagem de esteróides fecais (STRIER; ZIELGER, 1997).

\subsection{DIFERENÇAS ENTRE O CICLO ESTRAL E MENSTRUAL}

O ciclo menstrual, definido como o intervalo de tempo decorrido entre dois episódios sucessivos de menstruação, depende de condições ovarianas que diferem completamente das condições associadas com o estro (ROBINSON; GOY, 1986).

O estro geralmente ocorre no momento máximo de crescimento folicular e produção de estrógenos e a duração do ciclo estral é definida pelo intervalo de tempo decorrido entre dois estros consecutivos (CUNNINGHAN, 1993).

O estro também pode ser definido como um estado comportamental no qual a fêmea apresenta maior motivação sexual o que se reflete na atração sexual da fêmea e aproximação do macho. Neste sentido ele é característico da maioria, se não de todos os mamíferos (NADLER, 2000). 
A menstruação ocorre em associação com a senescência do corpo lúteo, momento em que quase não há secreção de hormônios ovarianos. O primeiro dia do ciclo menstrual é usualmente o dia em que um sangramento é observado diretamente escorrendo pela vagina ou por meio de citologia vaginal. Este sangramento é decorrente da descamação do epitélio uterino no final do ciclo ovariano com a queda dos níveis hormonais e na ausência de fertilização. A duração da menstruação varia conforme a espécie. Logo após esta descarga sangüínea inicia-se uma nova onda de crescimento folicular e a secreção de estrógenos. Os estrógenos estimulam o espessamento do endométrio preparando-o novamente para uma possível gravidez. A ovulação ocorre entre os períodos menstruais, não necessariamente no meio. As durações das fases folicular e lútea variam, mas há maior constância na duração da fase lútea (ROBINSON; GOY, 1986).

Nas espécies em que a menstruação ocorre, a vascularização endometrial é caracterizada por arteríolas espirais com anastomose e formação de lagos venosos (CUNNINGHAN, 1993). Em primatas do velho mundo é precedida de vasoconstrição das arteríolas, resultando em necrose dos tecidos e lesões epiteliais nos vasos. Quando estes vasos relaxam ocorre o sangramento (GUIMARÃES, 2001b).

Nas espécies de primatas neotropicais em que foi verificado sangramento menstrual (COLILLAS; COPPO, 1978; GOODMAN; WISLOCKI; 1934; HAMLETT, 1939; HERNÁNDEZ-LÓPEZ et al., 1998; LANG, 1967), estes ocorrem de forma discreta devido à ausência de arteríolas espirais no endométrio (GUIMARÃES, $2001 b)$. 


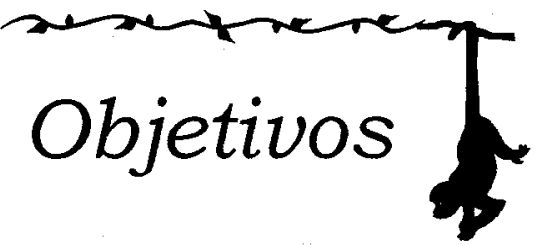




\section{OBJETIVOS}

O objetivo geral do presente estudo foi avaliar a função reprodutiva de cinco fêmeas de bugio (Alouatta caraya), particularmente nos aspectos relacionados à fisiologia ovariana, por meio do emprego de técnicas para extração e dosagem por radioimunoensaio de metabólitos fecais de estrógenos e progestinas.

\subsection{OBJETIVOS ESPECÍFICOS}

- Validar a técnica de extração e dosagem de metabólitos fecais de estrógenos e progestinas para a espécie;

- estimar a faixa de variação das concentrações destes metabólitos;

- estimar as concentrações de pico, elevadas e basais para os metabólitos estudados;

- calcular o intervalo em dias entre os picos de estrógenos fecais e as durações das elevações nas concentrações de metabólitos fecais de estrógenos e progestinas que acompanham os picos;

- estimar a ocorrência de ovulação;

- observar a ocorrência de eritrócitos através da análise de lâminas colpocitológicas e o momento que eles aparecem no perfil hormonal;

- avaliar a aplicabilidade e a confiabilidade da técnica não-invasiva aqui empregada no estudo da fisiologia reprodutiva de bugios. 


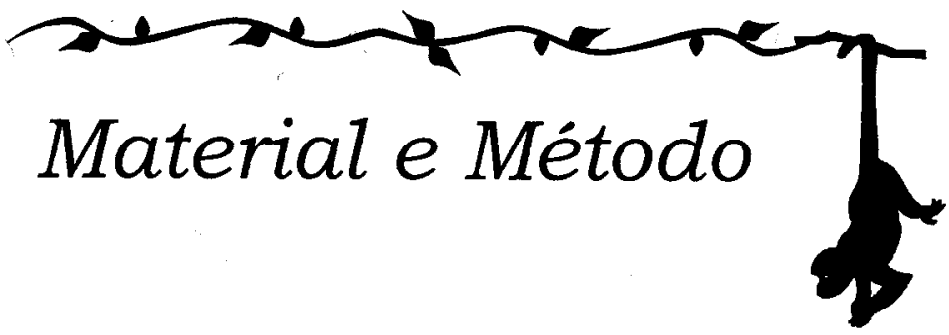




\section{MATERIAL E MÉTODO}

A seguir serão descritos o material e a metodologia empregada no estudo.

\subsection{ANIMAIS}

Para a realização do presente estudo foram utilizadas cinco fêmeas de macaco bugio da espécie Alouatta caraya, mantidas no Centro Nacional de Primatas (CENP) - Secretaria de Vigilância em Saúde (SVS) - Ministério da Saúde (MS), Ananindeua - PA. Das cinco fêmeas, uma era subadulta e quatro eram adultas, sendo que destas três estavam lactantes (Figura 1). As fêmeas foram alojadas individualmente, no mesmo galpão, de forma que podiam ver e ouvir os machos (Figura 2) e umas as outras, porém sem contato físico. As fêmeas lactantes permaneceram alojadas com seus filhotes.

Entre agosto e outubro de 2003 os animais permaneceram em gaiolas de 2,66 metros de comprimento x 2,50 metros de largura x 2,29 metros de altura (Figura 3). Neste período as fêmeas foram apartadas dos machos e submetidas à avaliação clínica e reprodutiva em dois momentos. As fêmeas lactantes permaneceram alojadas com seus filhotes e as demais individualmente.

A avaliação clínica consistiu em exames físico e laboratoriais, como hemograma, bioquímica sérica e coproparasitológico. Adicionalmente colheu-se sangue para pesquisa de arbovírus. A avaliação reprodutiva consistiu em exame 


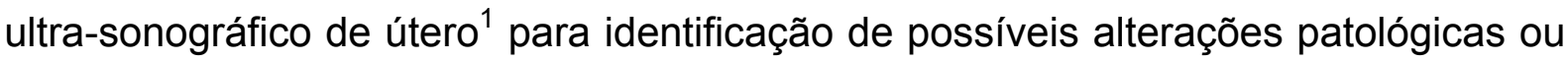
prenhez e exame colpocitológico. Os resultados das avaliações clínica e reprodutiva encontram-se no apêndice $A$.

Em novembro de 2003 os animais foram transferidos de galpão e passaram para gaiolas com $3,85 m$ de comprimento $\times 1,20 m$ de largura $\times 2,40 m$ de altura (Figura 4).

O manejo empregado durante o estudo foi o mesmo adotado rotineiramente no CENP. Diariamente as fêmeas receberam dieta balanceada composta por frutas variadas, legumes, ovos, leite, ração canina (com $28 \%$ de proteína) e suplementos vitamínicos e minerais misturados à água de beber. Ainda foram oferecidas folhas de embaúba (Cecropia sp) e mamoeiro (Carica papaya). Os animais foram submetidos a um regime de luz natural, pois os galpões são edificados de forma a permitir a penetração de luz solar durante todo o dia.

O quadro 1 resume os dados sobre procedência, idade e histórico reprodutivo das fêmeas estudadas.

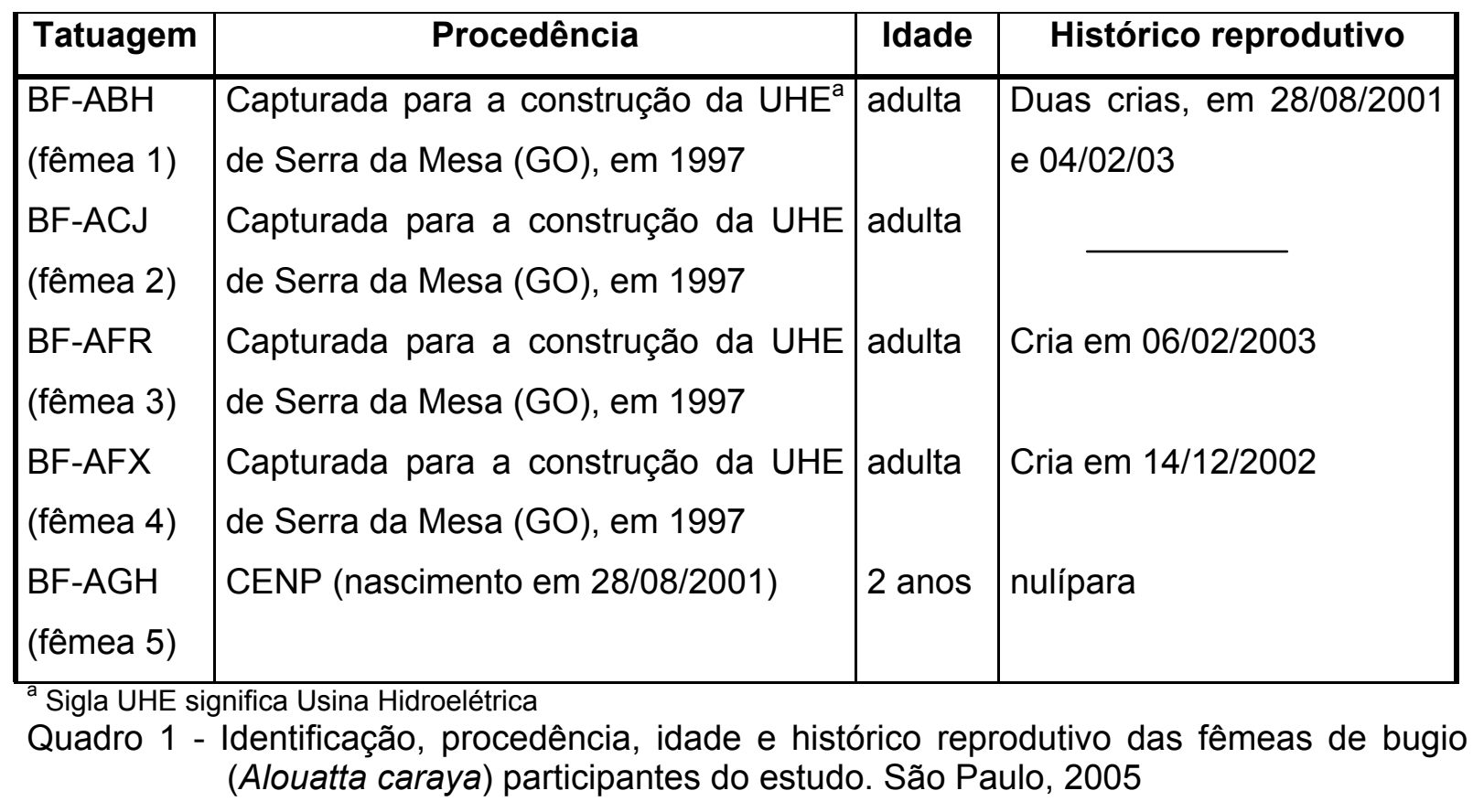

\footnotetext{
${ }^{1}$ Aparato ultra-sônico $\mathrm{GE}^{\circledR}$ Logiq $\alpha-100 \mathrm{MP}$, em modo $\mathrm{B}$, com transdutor linear de $7,5 \mathrm{MHz}$.
} 


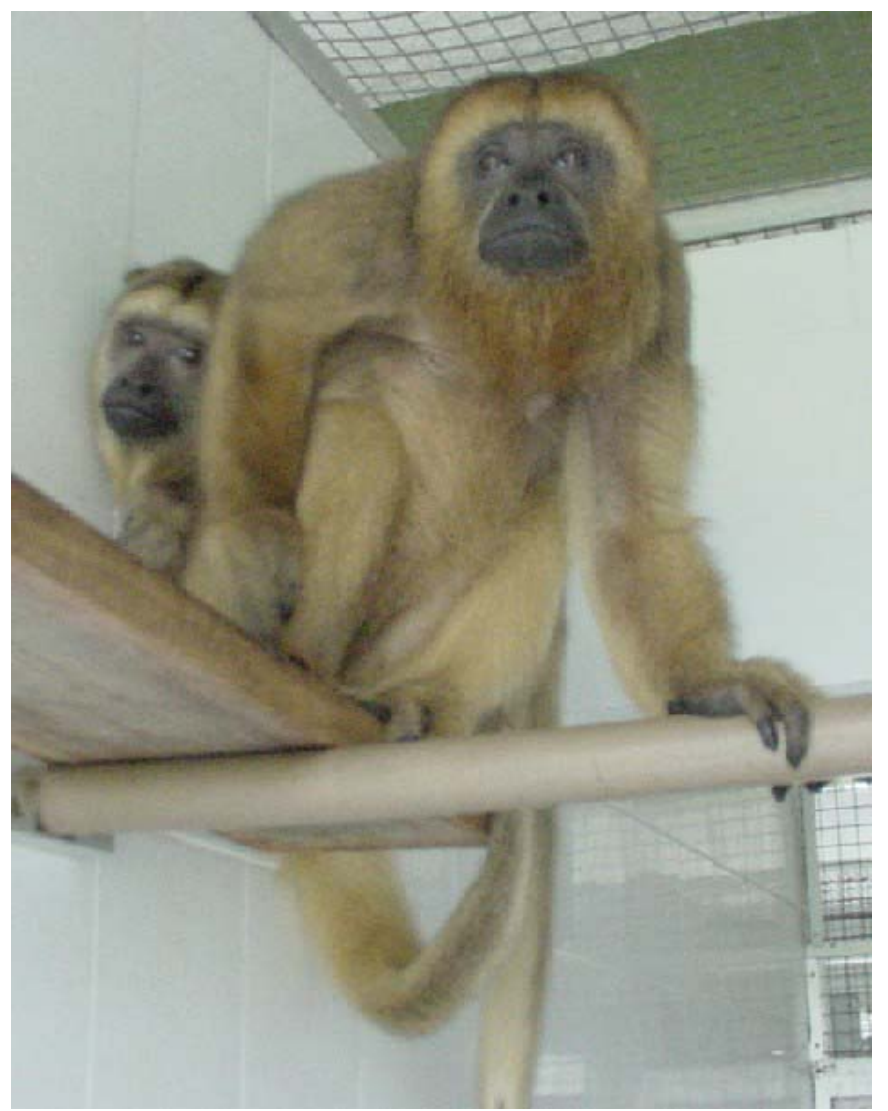

Figura 1 - Fêmea de bugio (Alouatta caraya) com o filhote macho. Notar a pelagem de cor dourada para ambos. CENP, Ananindeua - PA

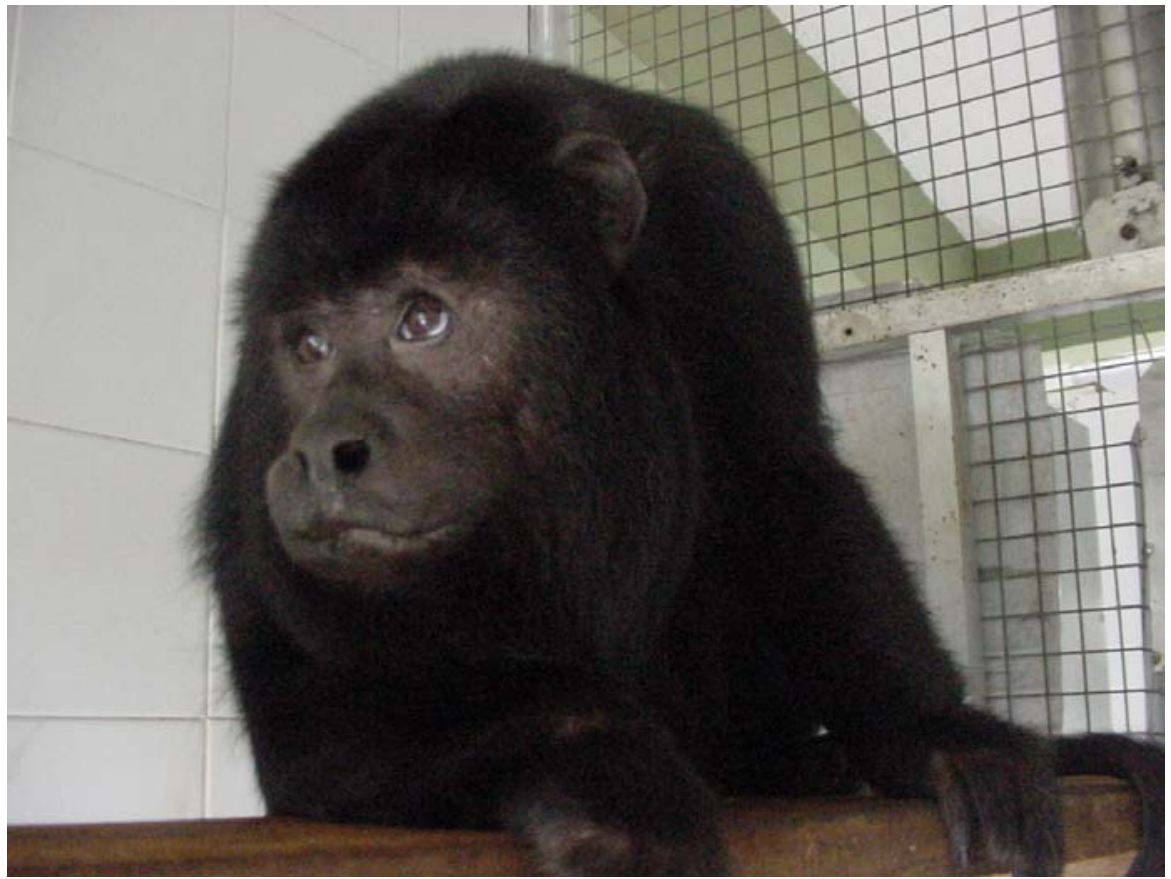

Figura 2 - Macho de bugio (Alouatta caraya). Notar a pelagem de coloração preta. CENP, Ananindeua - PA 


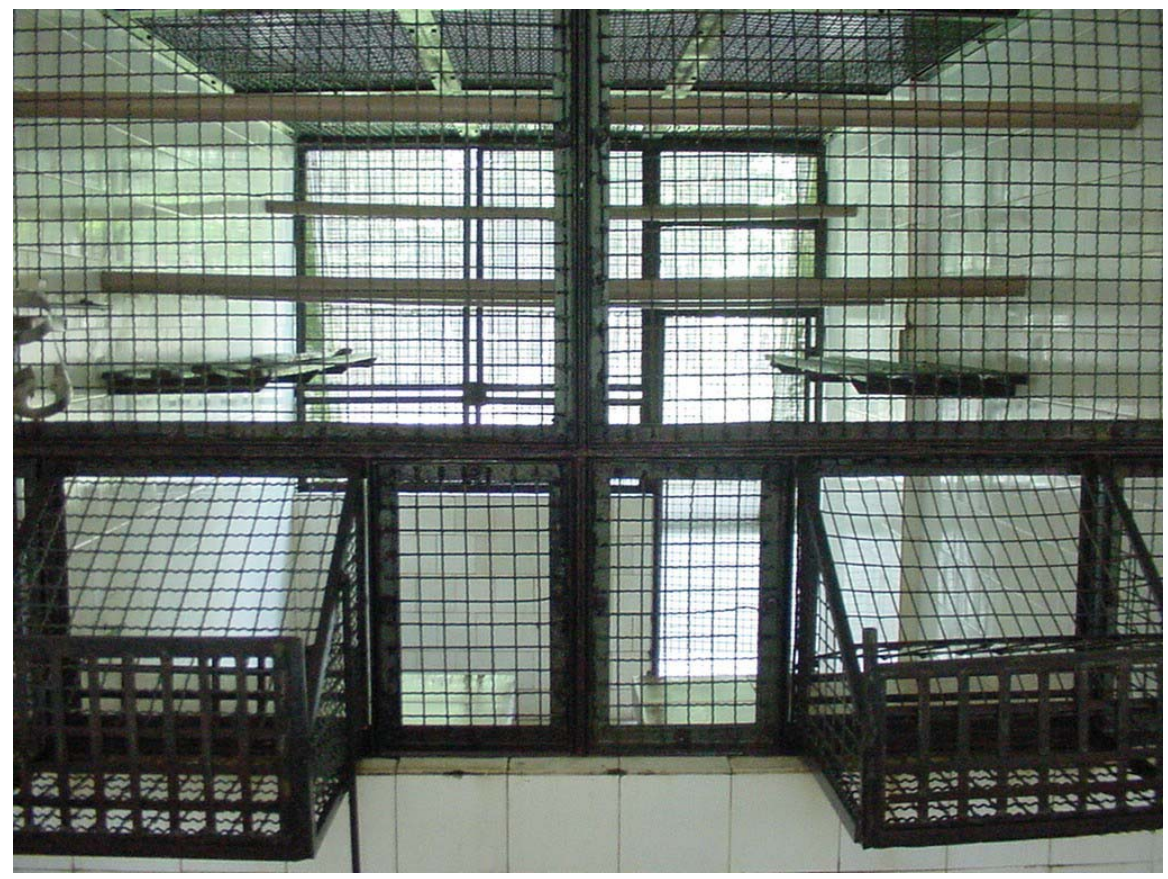

Figura 3 - Gaiola onde foram alojados os bugios (Alouatta caraya), até novembro de 2003, antes da mudança de galpões. CENP, Ananindeua - PA

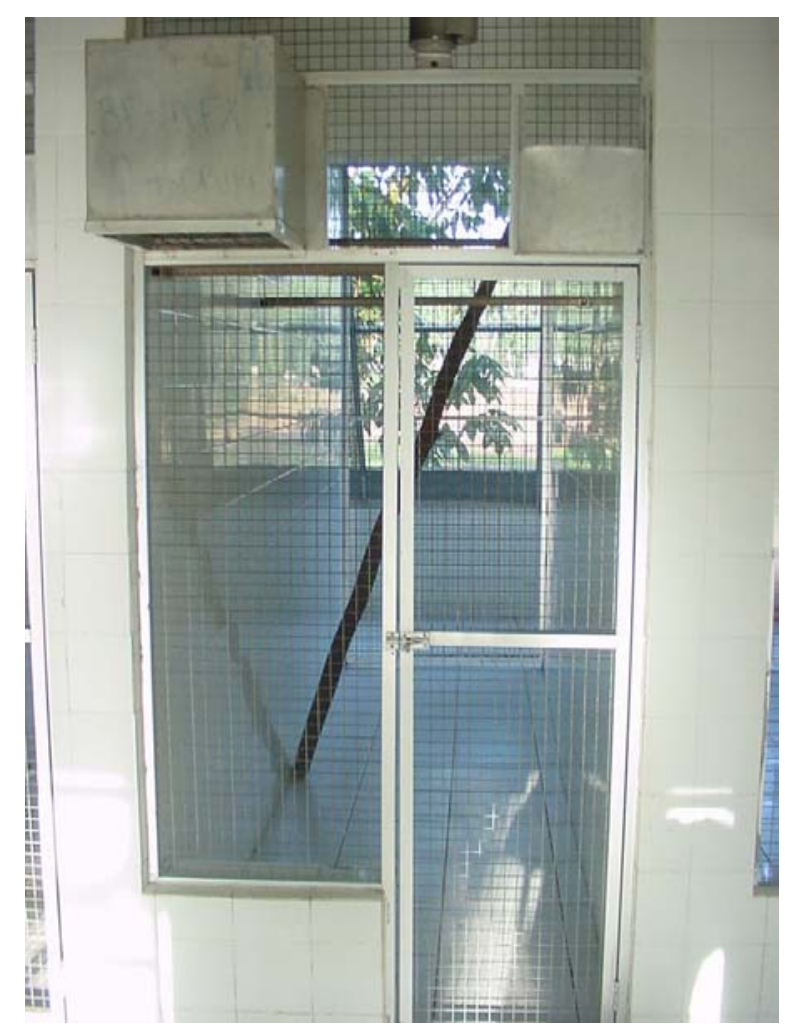

Figura 4 - Gaiola onde foram alojadas os bugios (Alouatta caraya), durante a maior parte do estudo, após a mudança de galpões. CENP, Ananindeua PA 


\subsection{COLHEITA E ARMAZENAMENTO DAS AMOSTRAS FECAIS}

A colheita de amostras fecais foi realizada em dias alternados, pela manhã (6:00 as 10:00h). O período de colheita iniciou-se em agosto de 2003 e terminou em abril de 2004 porém foram extraídas e dosadas as amostras colhidas durante cinco meses consecutivos para cada fêmea. Apenas uma das fêmeas lactantes (fêmea 3) teve suas amostras dosadas em um período de seis meses por ter perdido seu filhote.

Cada amostra foi homogeneizada no momento da colheita com uma espátula de madeira e armazenada em saco plástico tipo "zip" devidamente identificado. Em seguida foram armazenadas em freezer $\mathrm{a}-20^{\circ} \mathrm{C}$ até serem processadas.

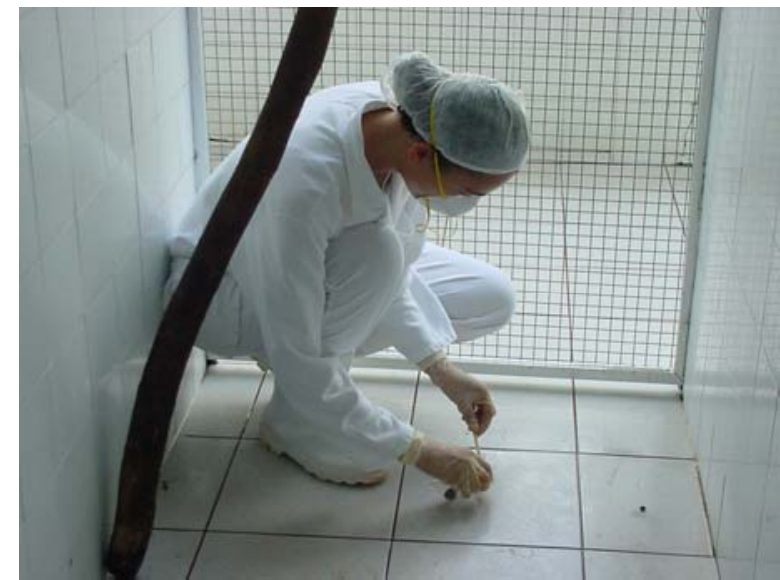

Figura 5 - Colheita de amostras fecais de fêmeas de bugio ( $A$. caraya). CENP, Ananindeua, PA

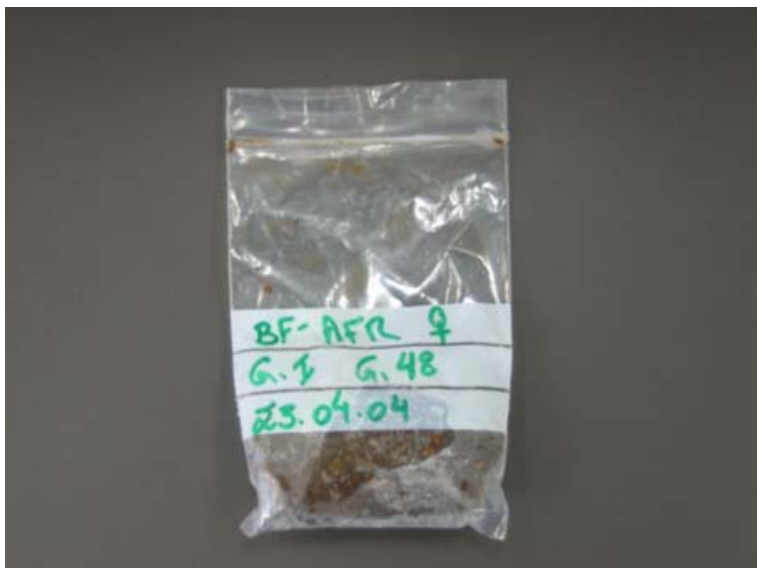

Figura 6 - Armazenamento das amostras fecais de fêmeas de bugio $(A$. caraya) em sacos plásticos tipo "zip" 


\subsection{COLHEITA E ANÁLISE DE CITOLOGIA VAGINAL}

O procedimento de colheita de material vaginal foi realizado principalmente para observação de períodos de sangramento e o momento em que eles ocorreram em relação às concentrações de metabólitos fecais de estrógenos e progestinas.

A colheita de material colpocitológico foi realizada nas fêmeas 1,2 e 3 entre meados de janeiro até 02 de abril de 2004. Assim, houve um intervalo de pelo menos dois meses de colheita de material fecal sem manipulação dos animais.

Para a realização das colheitas as fêmeas foram contidas fisicamente com auxílio de puçá (Figuras 7 e 8).

Após a contenção e retirada do animal de dentro do puçá seguiu-se limpeza da vulva com solução fisiológica a $0,9 \%$, introdução da escova ginecológica, rotação no sentido anti-horário aproximadamente 10 vezes e realização do esfregaço por rolamento da escova em lâmina de vidro para microscópio (Figuras 9, 10 e 11). Ao final de cada procedimento o animal recebeu recompensa em forma de alimento (frutas com leite condensado ou gelatina).

As lâminas foram coradas pelos métodos Panótico rápido, Papanicolaou, Shorr e Leishman para comparação da melhor técnica de coloração. A descrição das técnicas encontra-se no apêndice B. Após a coloração as lâminas foram lidas em microscópio óptico, com a contagem de 200 células, classificadas em: basais, parabasais, intermediárias pequenas e grandes, superficiais nucleadas e anucleadas (ou cornificadas), leucócitos e eritrócitos. 


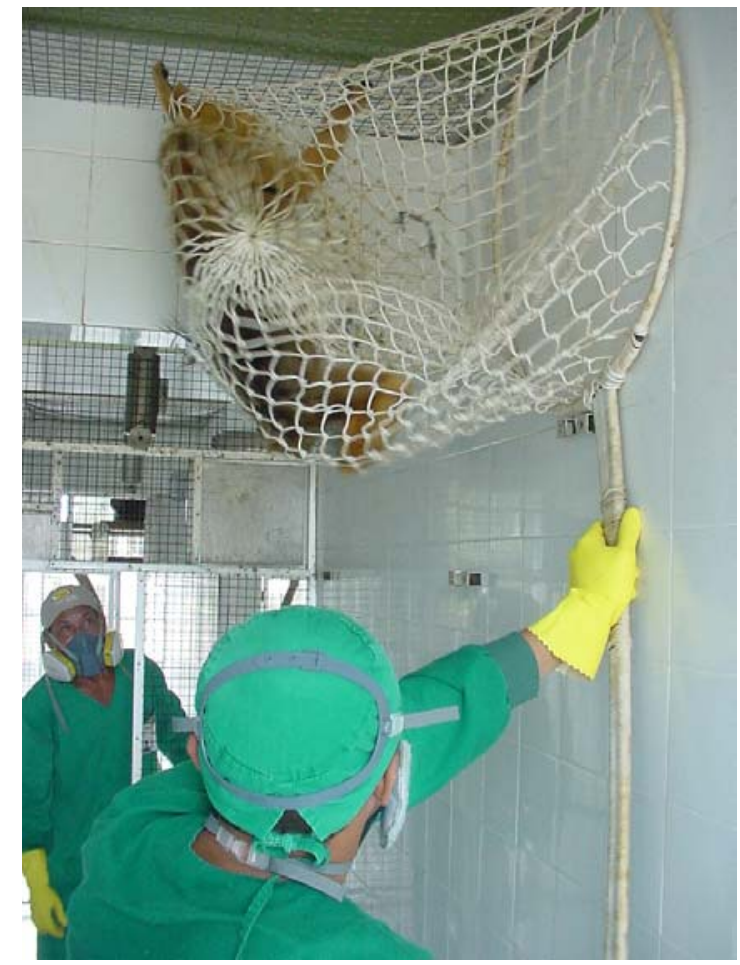

Figura 7 - Contenção de fêmea de bugio (Alouatta caraya) com o auxílio de puçá. CENP, Ananindeua PA

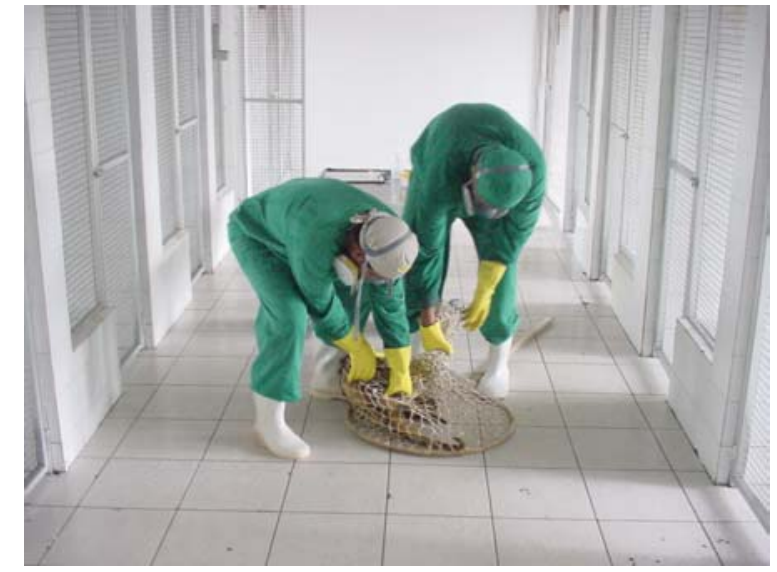

Figura 8 - Retirada de fêmea de bugio (Alouatta caraya) do puçá. CENP, Ananindeua - PA

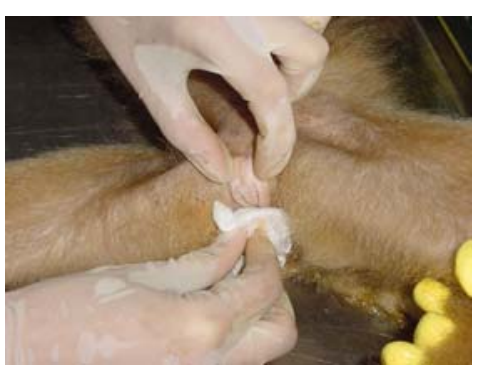

Figura 9 - Limpeza da vulva de fêmea de bugio (Alouatta caraya)

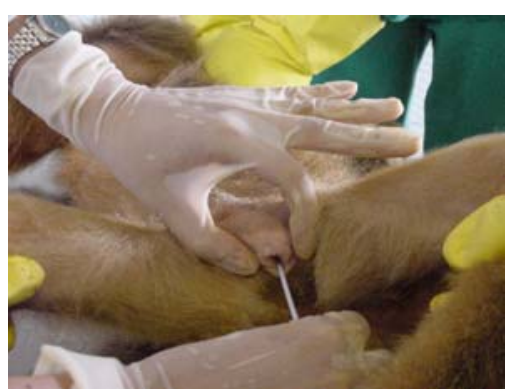

Figura 10 - Introdução de escova ginecológica na fêmea de bugio ( $A$. caraya)

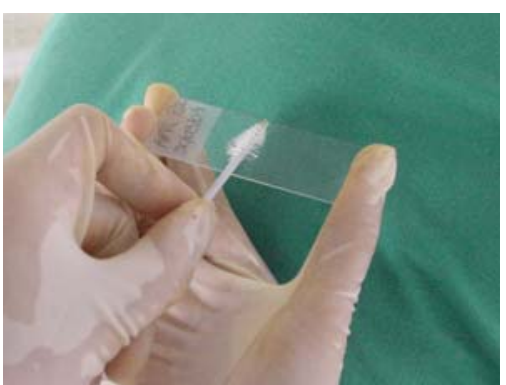

Figura 11 - Deslizamento da escova sobre a lâmina de vidro 


\subsection{PROCESSAMENTO DAS AMOSTRAS FECAIS PARA EXTRAÇÃO HORMONAL}

A metodologia empregada para extração dos hormônios foi adaptada da utilizada por Graham et al. (2001).

A uma alíquota de $0,5 \mathrm{~g}$ de fezes úmidas foram adicionados $5,0 \mathrm{ml}$ de solução de metanol a $70 \%$ (metanol:água destilada). A solução foi misturada em aparelho vortex ${ }^{2}$ durante 30 segundos ou até que as fezes estivessem totalmente partidas. Em seguida foram homogeneizadas em misturador mecânico ${ }^{3}$ por um período de 12 horas. A mistura foi então centrifugada a 2500 r.p.m. (rotações por minuto) durante 15 minutos. O sobrenadante foi transferido para microtubos de polipropileno e armazenado em freezer $\mathrm{a}-20^{\circ} \mathrm{C}$, até a realização das dosagens.

\subsection{DOSAGEM HORMONAL}

Os metabólitos fecais de estrógenos e progestinas foram dosados pela técnica de radioimunoensaio (RIE) em fase sólida, por meio de conjunto diagnóstico comercial $^{4}$, desenvolvido para dosagem de estradiol e progesterona no soro humano.

\footnotetext{
${ }^{2}$ Genie $2{ }^{\circledR}$-Scientific Industries, Inc., MOD G-560E

${ }^{3}$ Homogeneizador de sangue Phoenix ${ }^{\circledR}$, MOD AP22

4 Coat-A-Count ${ }^{\circledR}$, Diagnostic Products Corporation, Los Angeles, CA, USA. Importador: DPC MEDLAB PRODUTOS MÉDICO-HOSPITALARES LTDA, São Paulo, SP, Brasil
} 
Esta técnica baseia-se na competição do hormônio radioativo (neste caso marcado com ${ }^{125}$ I) com o hormônio presente na amostra que está sendo dosada. Os hormônios competem por um número limitado (saturado) de sítios de ligação de um agente ligante de alta afinidade e especificidade pelo hormônio em questão. As reações atingem o equilíbrio após um período de incubação (indicado pelo fabricante). A única concentração desconhecida é a do hormônio da amostra. O leitor de radioimunoensaio detecta a quantidade de hormônio marcado ligado e a partir daí calcula-se a quantidade de hormônio na amostra. Quanto maior a leitura menor a concentração de hormônio e vice e versa.

Para a dosagem, os extratos fecais foram previamente diluídos em uma solução tampão PBS + gelatina $0,1 \%(1,0 \mathrm{M}$, pH 7,0) e $100 \mu$ desta solução foi transferido para tubos contendo quantidades pré-determinadas de hormônio marcado com ${ }^{125} \mathrm{I}$. Posteriormente ao período de incubação de três horas, à temperatura ambiente, descartou-se a fase líquida e mediu-se a radioatividade remanescente em um contador gama computadorizado ${ }^{5}$, provido de software específico para cálculo automático dos resultados. Os resultados de estradiol foram apresentados em picogramas por mililitro $(\mathrm{pg} / \mathrm{ml})$ de líquido de extração e as progestinas em nanogramas por mililitro $(\mathrm{ng} / \mathrm{ml})$.

Em ambos os casos, os valores dos metabólitos hormonais foram corrigidos para peso e diluição e expressos em nanogramas por gramas de fezes úmidas (ng/g).

A porcentagem de reações cruzadas dos conjuntos diagnósticos utilizados neste estudo é apresentada no anexo B.

\footnotetext{
${ }^{5}$ Cobra, mod. Auto-Gamma ${ }^{\circledR}$
} 


\subsection{VALIDAÇÃO DO ENSAIO}

A validação dos conjuntos diagnósticos comerciais para o uso em extratos fecais de fêmeas de bugio ( $A$. caraya) foi realizada através da comparação entre a curva formada pelas concentrações obtidas a partir de diluições sucessivas da concentração inicial de hormônio marcado adicionado a um "pool" de amostras fecais e a curva padrão do conjunto diagnóstico.

Este método indica se os metabólitos hormonais da espécie estudada interagem com o anticorpo do conjunto diagnóstico de forma similar ao hormônio utilizado como padrão. Para tanto, foi utilizado um "pool" de amostras fecais com concentrações hormonais muito baixas, próximas de zero (matriz). A essa matriz adicionaram-se quantidades conhecidas do hormônio marcado em diluições tais que as concentrações finais deveriam se aproximar dos pontos da curva padrão do conjunto diagnóstico.

Os valores da curva assim obtida foram correlacionados com os valores da curva padrão do conjunto diagnóstico. A comparação foi realizada pelo coeficiente de regressão linear, expresso em qui-quadrado $\left(r=R^{2}\right)$ para expressão apenas de valores positivos e do coeficiente de correlação de Pearson. O ensaio foi validado quando os coeficientes de correlação foram próximos de 1 ou $100 \%$. 


\subsection{ANÁLISE ESTATÍSTICA}

O critério adotado para o cálculo dos valores de pico dos metabólitos fecais de estrógenos e progestinas baseou-se na observação dos perfis obtidos a partir das dosagens de ambos metabólitos para cada fêmea e correlação com eventos biológicos.

Para os estrógenos fecais, foram considerados valores de pico aqueles que excederam a média mais 1,5 desvios padrões (DP).

Para a determinação dos valores basais e elevação adotou-se um cálculo sucessivo descrito por Brown et al. (1996) no qual os valores que excediam a média acrescida de 1,5DP eram excluídos e uma nova média calculada com os valores restantes. Seguia-se novamente com a eliminação dos valores e cálculo das novas médias e desvios padrões de forma sucessiva até que nenhum valor excedesse a média acrescida de 1,5DP.

O limite entre basal e elevação foi determinado pela análise de variância nãoparamétrica utilizando-se o teste de Kruskall-Wallis e o pós-teste de Dunn (BERBARE, 2004). Por se tratar de um teste não-paramétrico, ele compara as medianas dos valores de cada coluna formada pela eliminação dos valores acima da média+1,5DP com as medianas dos valores das colunas seguintes. Quando foi verificada diferença estatística $(p<0,05)$ entre esses valores determinou-se o limite entre basal e elevação.

Desta maneira, os valores considerados basais foram todos aqueles presentes nas colunas abaixo do ponto onde se observou diferença estatística. Os valores elevados foram os compreendidos entre os valores da média acrescida de 1,5DP da coluna imediatamente anterior àquela onde foi observada diferença 
estatística e abaixo dos valores de pico. Os resultados que excederam a média mais quatro desvios padrões foram considerados "outliers" e portanto excluídos somente para realização dos cálculos, sendo mantidos na representação gráfica do perfil hormonal.

Os mesmos critérios acima descritos foram adotados para as progestinas fecais, no entanto utilizando-se a média+2DP. Cada fêmea foi analisada individualmente mas aplicou-se o mesmo critério de análise para todas.

Para o cálculo do intervalo de tempo em dias entre picos de estrógenos fecais foram considerados apenas aqueles acompanhados por valores elevados durante pelo menos três dias consecutivos. Quando ocorreu mais de um pico durante a mesma elevação foi considerado o mais alto. Para caracterizar uma ovulação, os valores de progestinas fecais deveriam permanecer elevados por no mínimo uma semana (ou sete dias) acompanhando um pico e elevação de metabólitos fecais de estrógenos.

O intervalo entre dois períodos consecutivos de sangramento foi calculado pelo número de dias decorridos a partir do primeiro dia de observação de eritrócitos no esfregaço vaginal e o dia imediatamente anterior ao novo aparecimento destas células.

Os resultados foram expressos em medianas, valores mínimos e máximos, médias e erros padrões das médias (EPM) para cada fêmea estudada.

Os dados foram analisados utilizando-se o programa estatístico BioEstat $3.0^{6}$, e os gráficos realizados no programa GraphPad Prism para Windows ${ }^{7}$ e Minitab 13.0 para Windows ${ }^{8}$.

\footnotetext{
${ }_{7}^{6}$ Manuel Ayres et al., 2003, Sociedade Civil Mamirauá/ MCT-CNPq/ Conservation International

${ }^{7}$ www.graphpad.com

${ }^{8}$ Minitab Inc., Stage College, PA-USA
} 


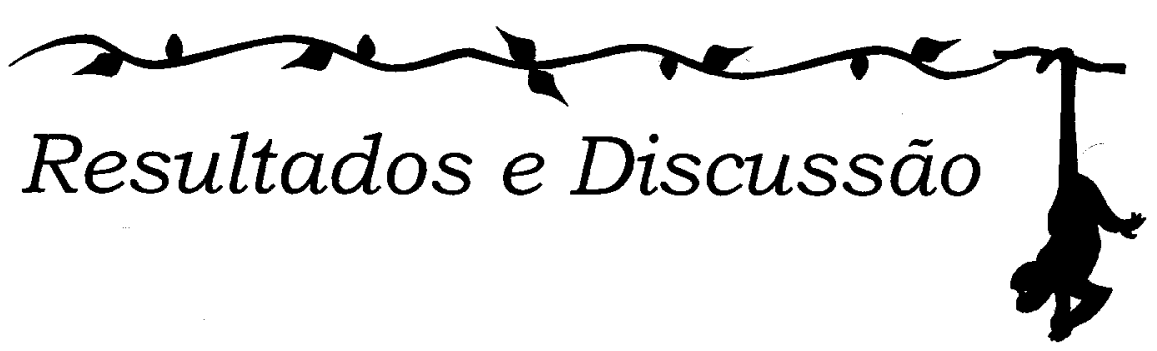




\section{RESULTADOS E DISCUSSÃO}

A seguir são descritos os resultados obtidos neste estudo e a discussão dos mesmos.

\subsection{CONTROLE DE QUALIDADE DOS ENSAIOS}

O controle de qualidade dos ensaios realizados para dosagem de metabólitos fecais de estrógenos e progestinas baseou-se na análise dos coeficientes de variação intra- e inter-ensaio.

Para os ensaios de metabólitos de estrógenos todos os coeficientes de variação intra-ensaio foram inferiores a $14 \%$ e o inter-ensaio inferior a $4 \%$. A concentração mínima detectada foi de 1,60pg/ml (Tabela 1).

Tabela 1 - Controle de qualidade dos ensaios de metabólitos de estrógenos em amostras fecais de fêmeas de bugio (Alouatta caraya). São Paulo, 2005

\begin{tabular}{ccccccc}
\hline \multirow{2}{*}{ Ensaio } & $\begin{array}{c}\text { CPM } \\
\text { total }\end{array}$ & $\begin{array}{c}\text { Cap. lig. } \\
\text { (B/B0) }\end{array}$ & $\begin{array}{c}\text { L.N.E. } \\
\mathbf{( \% )}\end{array}$ & $\begin{array}{c}\text { Sensibilidade } \\
\text { \% (dose) }\end{array}$ & $\begin{array}{c}\text { CV Intra } \\
\text { baixo }\end{array}$ & $\begin{array}{c}\text { CV intra } \\
\text { alto }\end{array}$ \\
\hline \hline 1 & 22318,5 & $56 \%$ & 0,50 & $92,7(2,55)$ & $2,72 \%$ & $13,37 \%$ \\
2 & 25690,0 & $52 \%$ & 0,40 & $94,3(1,61)$ & $10,31 \%$ & $1,99 \%$ \\
3 & 24369,5 & $52 \%$ & 0,38 & $89,9(1,60)$ & $2,78 \%$ & $12,37 \%$ \\
\cline { 3 - 7 } CV Inter-ensaio & & & & & & \\
\end{tabular}

Para as progestinas fecais os coeficientes intra-ensaios não excederam $15,18 \%$ e o inter-ensaio $7,30 \%$. A concentração mínima detectada foi de $0,004 \mathrm{ng} / \mathrm{ml}$ (Tabela 2). 
Tabela 2 - Controle de qualidade dos ensaios de metabólitos de estrógenos em amostras fecais de fêmeas de bugio (Alouatta caraya). São Paulo, 2005

\begin{tabular}{ccccccc}
\hline \multirow{2}{*}{ Ensaio } & $\begin{array}{c}\text { CPM } \\
\text { total }\end{array}$ & $\begin{array}{c}\text { Cap. lig. } \\
\text { (B/B0) }\end{array}$ & $\begin{array}{c}\text { L.N.E. } \\
\mathbf{( \% )}\end{array}$ & $\begin{array}{c}\text { Sensibilidade } \\
\text { \% (dose) }\end{array}$ & $\begin{array}{c}\text { CV Intra } \\
\text { baixo }\end{array}$ & $\begin{array}{c}\text { CV intra } \\
\text { alto }\end{array}$ \\
\hline \hline 1 & 35914,5 & $57 \%$ & 0,36 & $93,4(0,007)$ & $15,18 \%$ & $1,09 \%$ \\
2 & 28573,5 & $56 \%$ & 0,24 & $93,5(0,005)$ & $3,37 \%$ & $2,17 \%$ \\
3 & 29223,0 & $55 \%$ & 0,42 & $93,9(0,004)$ & $2,53 \%$ & $4,08 \%$ \\
\cline { 4 - 7 } CV Inter-ensaio & & & & & $\mathbf{7 , 3 0 \%}$ & $\mathbf{1 , 0 4 \%}$ \\
\cline { 2 - 7 } & & & & & & \\
\hline
\end{tabular}

Todos os coeficientes de variação ficaram dentro do padrão esperado de até 15\% (CHARD, 1995) e confirmaram a qualidade dos ensaios realizados.

\subsection{VALIDAÇÃO DO ENSAIO}

Os valores das curvas obtidas a partir das diluições do hormônio marcado em um "pool" de amostras fecais para os metabólitos de estrógenos e progestinas apresentaram alta e significativa correlação com as curvas padrões dos conjuntos diagnósticos (Figuras 12 e 13). Os valores de $r=R^{2}$ foram 0,98 para os metabólitos fecais de estrógenos e 0,99 para as progestinas fecais. Em ambos os casos $p<0,0005$. 


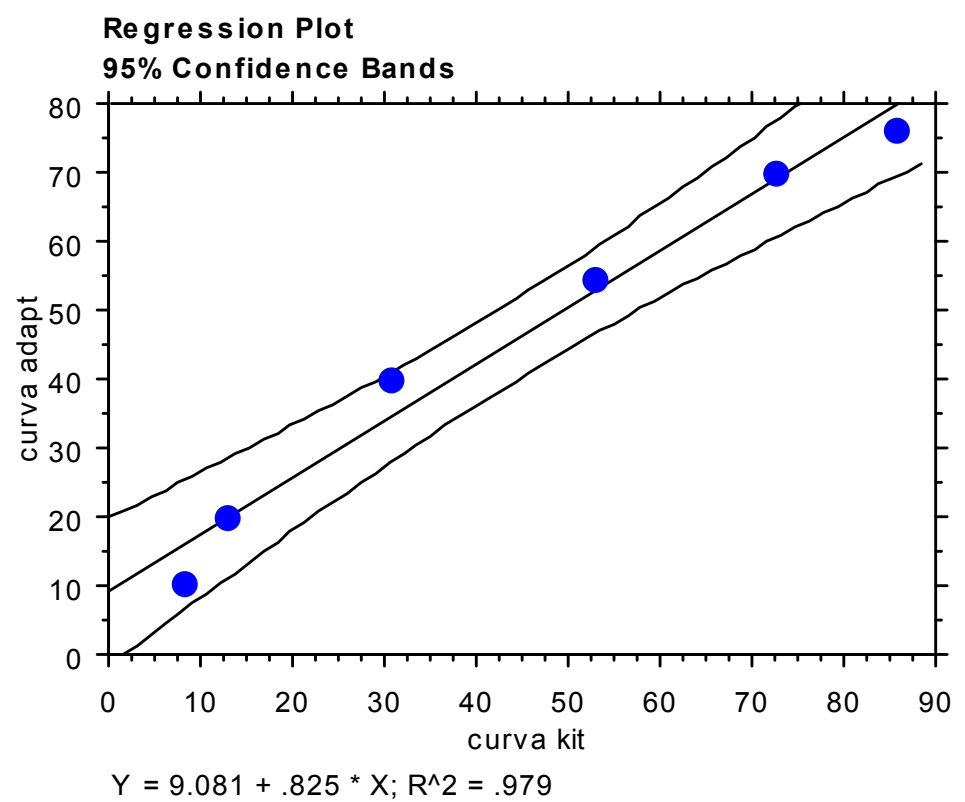

Figura 12 - Representação gráfica da curva de regressão linear entre a curva formada pelas concentrações de um "pool" de amostras fecais em diluições sucessivas e a curva padrão do conjunto diagnóstico da DPC ${ }^{\circledR}$ MedLab para dosagem de estradiol. São Paulo, 2005

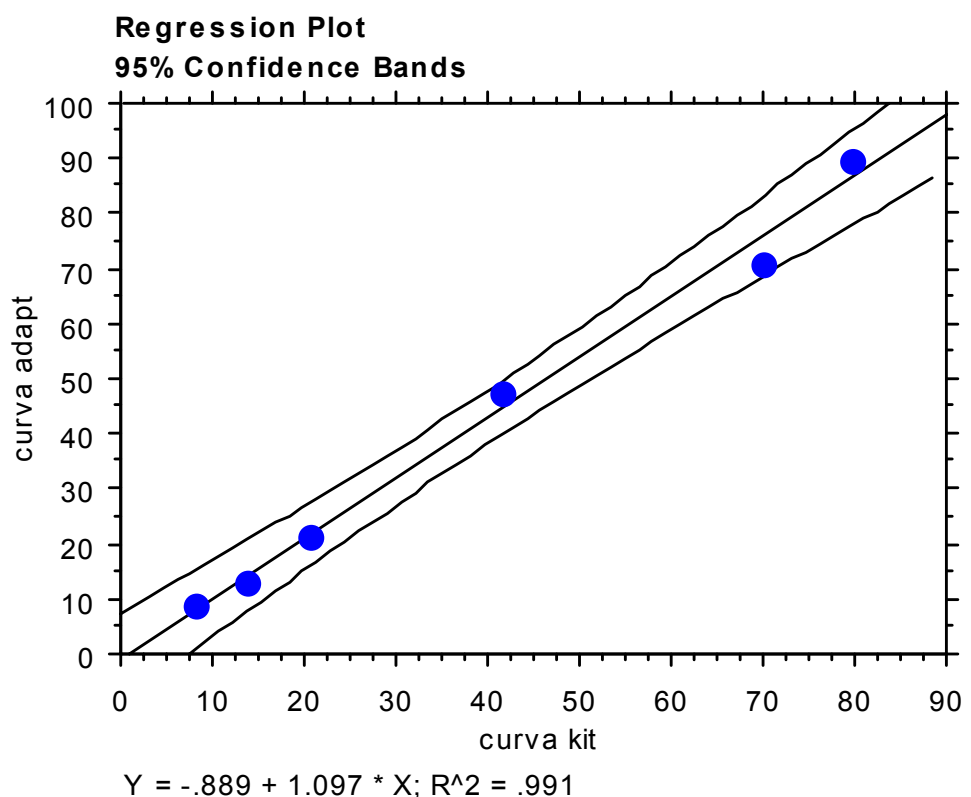

Figura 13 - Representação gráfica da curva de regressão linear entre a curva formada pelas concentrações de um "pool" de extratos fecais em diluições sucessivas e a curva padrão do conjunto diagnóstico da DPC ${ }^{\circledR}$ MedLab para dosagem de progesterona. São Paulo, 2005 
A alta correlação observada entre as curvas do "pool" de amostras e dos conjuntos diagnósticos para dosagem de estradiol e progesterona sugerem que a matriz (extrato fecal) não interferiu na ligação antígeno (hormônio) com o seu anticorpo. Desta maneira, a técnica para a dosagem de metabólitos fecais de estrógenos e progestinas com a utilização de conjuntos diagnósticos da DPC ${ }^{\circledR}$ MedLab e radioimunoensaio foi validada para aplicação em fêmeas de bugio ( $A$. caraya).

\subsection{PERFIS HORMONAIS DE METABÓLITOS DE ESTRÓGENOS E PROGESTINAS FECAIS}

No total foram extraídas e dosadas 395 amostras fecais. As médias, erros padrões, valores mínimos, máximos e medianas para as cinco fêmeas estão expressos na tabela 3 para os metabólitos fecais de estrógenos e na tabela 4 para as progestinas fecais. 
Tabela 3 - Médias, erros padrões, valores mínimos, máximos e medianas das concentrações de metabólitos fecais de estrógenos $(\mathrm{ng} / \mathrm{g})$ em fêmeas de bugio (Alouatta caraya). São Paulo, 2005

\begin{tabular}{cccccc}
\hline Animal & Média & Erro Padrão & Mínimo & Máximo & Mediana \\
\hline $\mathbf{1}$ & 284,01 & 25,26 & 2,00 & 1000,69 & 243,25 \\
$\mathbf{2}$ & 475,96 & 29,83 & 24,93 & 1346,45 & 385,34 \\
$\mathbf{3}$ & 95,75 & 7,32 & 2,00 & 465,68 & 86,55 \\
$\mathbf{4}$ & 16,86 & 4,08 & 1,68 & 216,70 & 3,70 \\
$\mathbf{5}$ & 4,05 & 0,48 & 1,27 & 22,63 & 2,00 \\
\hline
\end{tabular}

Tabela 4 - Médias, erros padrões, valores mínimos, máximos e medianas das concentrações de progestinas fecais $(\mathrm{ng} / \mathrm{g}$ ) em fêmeas de bugio (Alouatta caraya). São Paulo, 2005

\begin{tabular}{cccccc}
\hline Animal & Média & Erro Padrão & Mínimo & Máximo & Mediana \\
\hline $\mathbf{1}$ & 685,63 & 84,92 & 13,01 & 3158,17 & 382,69 \\
$\mathbf{2}$ & 525,63 & 73,61 & 4,37 & 4120,62 & 332,10 \\
$\mathbf{3}$ & 551,32 & 66,23 & 5,36 & 3033,10 & 272,24 \\
$\mathbf{4}$ & 67,50 & 11,37 & 5,50 & 468,37 & 29,70 \\
$\mathbf{5}$ & 43,24 & 8,33 & 1,78 & 476,76 & 23,03 \\
\hline
\end{tabular}

As fêmeas 4 e 5 mostraram valores de metabólitos de estrógenos e progestinas fecais muito baixos durante o período do estudo, diferindo significativamente do perfil apresentado pelas demais fêmeas. Assim, primeiramente serão apresentados e discutidos os resultados para estas duas fêmeas. O perfil da cada fêmea foi analisado individualmente. 


\subsubsection{Perfil hormonal das fêmeas 4 e 5 e a validação fisiológica}

\section{Fêmea 4}

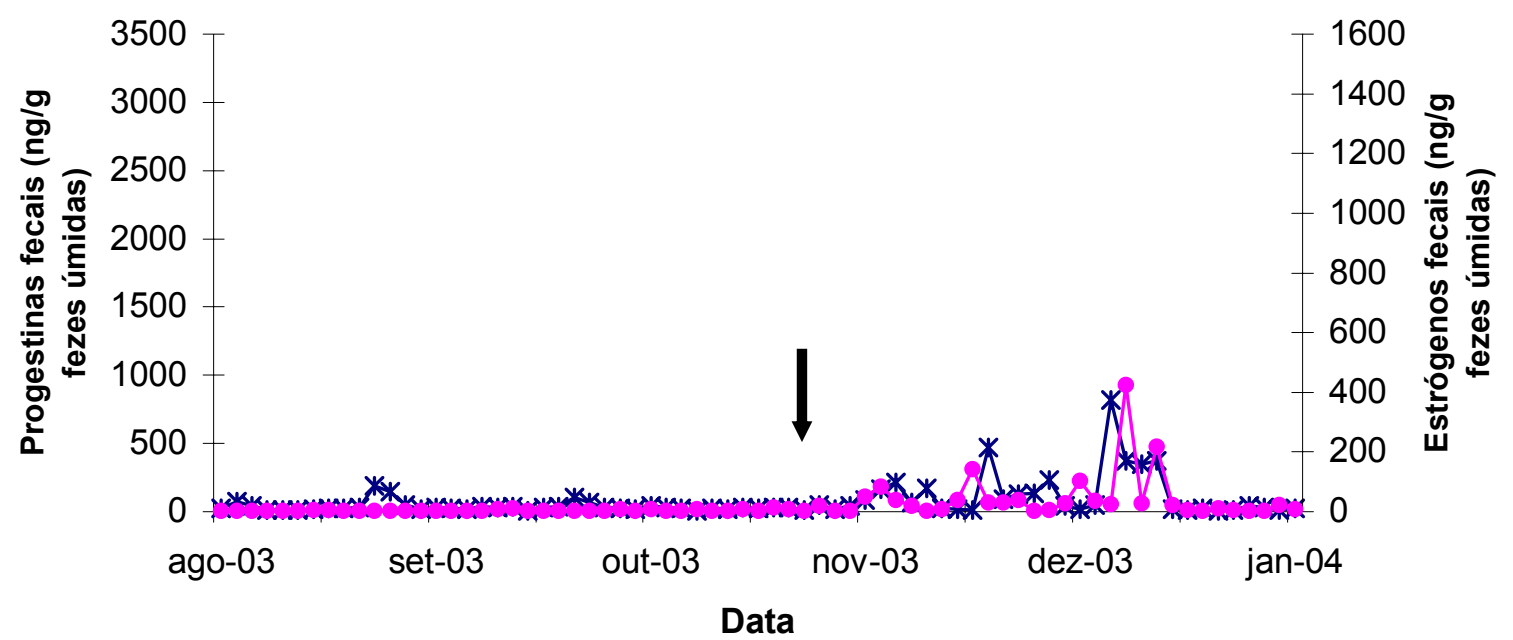

Figura 14 - Representação gráfica do perfil das concentrações de metabólitos fecais de progestinas e estrógenos da fêmea 4, durante quatro meses e meio de colheita. A seta indica o dia da mudança de galpão. São Paulo, 2005

O período de dosagem hormonal para a fêmea 4 iniciou-se em agosto 2003 e foi até 05 de janeiro de 2004, quando o animal veio a óbito. Desde o início de estudo esta fêmea apresentava-se caquética, com hiporexia e exames laboratoriais alterados (Apêndice A). No decorrer do estudo, ela passou a se alimentar bem, ganhou peso e tornou-se mais ativa.

A figura 14 evidencia total inatividade ovariana durante quase todo o período de estudo, condizente para um animal nas condições acima descritas. No período que sucede a transferência dos animais para outro galpão até meados de dezembro observou-se um aumento nas concentrações de metabólitos de estrógenos e progestinas fecais. 
A ausência de atividade ovariana na fêmea 4 poderia estar relacionada com a lactação. No entanto, o filhote já estava com oito meses de idade no início do estudo e outras duas fêmeas (1 e 3), também lactantes e com crias aproximadamente com a mesma idade, apresentaram atividade ovariana cíclica, como será visto adiante (Figuras 16 e 20).

A função reprodutiva é a primeira a sofrer frente a situações desfavoráveis (GRUNERT; GREGORY, 1989). A nutrição deficiente leva à redução da liberação de LH pela hipófise, provavelmente devido à diminuição da produção de $\mathrm{GnRH}$ pelo hipotálamo. Esta diminuição nos níveis de $\mathrm{GnRH}$ seria causada pela redução na quantidade de tecido adiposo, através de uma complexa cadeia de mecanismos endócrinos e neuronais (BREAZILE, 1987). A leptina está relacionada com a manutenção da função reprodutiva normal. Durante a restrição alimentar os níveis de leptina caem em conjunto com níveis diminuídos de LH e o comprometimento da fertilidade reprodutiva do animal (HILEMEN; PIERREZ; FLIER, 2000).

Assim, uma das hipóteses que poderia justificar $o$ aumento das concentrações de metabólitos hormonais seria a tentativa de reinício de atividade ovariana devido à melhora no estado clínico do animal e recuperação da condição corporal.

Outra hipótese passível de discussão seria o aumento das concentrações hormonais induzido pelo estresse da mudança de recinto. Chatdarong et al. (2004) observaram aumento nas concentrações de cortisol e progesterona após administração de ACTH em gatas pré-puberes e gatas ovariectomizadas. Para os autores estes resultados sugerem a produção de progesterona pela glândula adrenal. No estudo, o mesmo efeito foi observado quando os animais foram contidos para retirada de sangue. 
Efeitos estimuladores do eixo hipotálamo-hipofise-gonadal (HPG) pelo estresse foram relatados por Xiao et al. (1998) e Xiao, Xia-Zhang e Ferin (1999). Os autores especulam que o pequeno porém significante aumento de progesterona de origem adrenal que ocorre em reposta a estimulação do eixo hipotálamo-hipófiseadrenal (HPA) age em sinergia com o estradiol para aumentar a secreção de LH e conseqüentemente dos hormônios esteróides. Para os autores este estímulo só ocorreria na presença de concentrações elevadas de estradiol.

Ferin (1999) relata a dificuldade do estudo e entendimento da interação estresse e reprodução devido ao grande número de variáveis que podem modular a resposta de cada indivíduo. Além da variação individual o autor reforça que a resposta pode variar de acordo com o tipo de estímulo estressante.

Diante o exposto, acreditamos que para o animal em questão o fator nutricional seria o principal responsável pelo perfil hormonal apresentado. 


\section{Fêmea 5}

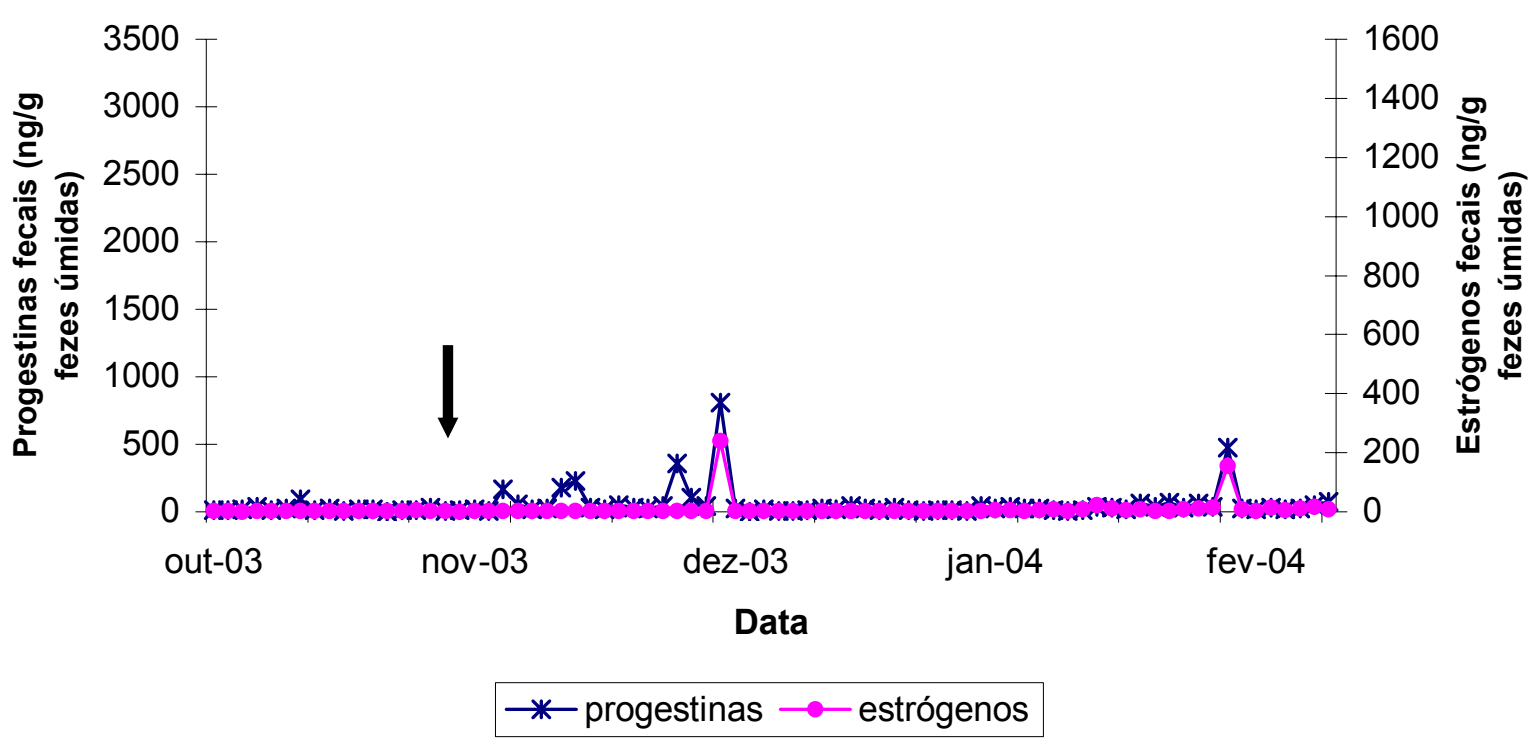

Figura 15 - Representação gráfica do perfil das concentrações de metabólitos fecais de progestinas e estrógenos da fêmea 5, durante cinco meses de colheita. A seta indica o dia da mudança de galpão. São Paulo, 2005

A fêmea 5, único animal subadulto no grupo estudado, também apresentou níveis basais de metabólitos fecais de estrógenos e progestinas durante quase todo o estudo. No período após a mudança de recinto observou-se um aumento nas concentrações de progestinas fecais e em dois momentos as concentrações de estrógenos fecais também se elevaram. Estas elevações porém, foram bem menores do que as concentrações elevadas apresentados pelas fêmeas adultas (Tabela 5).

A hipótese levantada para a fêmea 4 quanto à influência do estresse da mudança de galpão sobre a função reprodutiva resultando na elevação dos níveis hormonais também poderia ser levantada neste caso. No entanto, acreditamos que a melhor explicação seria o processo de puberdade, com a tentativa de início de atividade ovariana. 
Em fêmeas pré-puberes, ondas de hormônios esteróides iniciam-se gradativamente devido ao aumento, também gradativo, da atividade gonadotrófica. A puberdade é atingida quando o animal (macho ou fêmea) está apto a produzir gametas e manifestar comportamento sexual completo (HAFEZ; HAFEZ, 2000). Na mulher a ovulação só ocorre seis meses após a menarca e o aparecimento de ciclos ovulatórios menstruais regulares se estabelecem apenas alguns anos mais tarde (PLANT, 1994).

Em gorilas (Gorilla gorilla) Bellem et al. (1995) observaram concentrações basais de estrona conjugada $\left(E_{1} C\right)$ e pregnanediol-glucoronido $(P d G)$ na urina de uma fêmea pré-púbere, sem flutuações cíclicas até o início da puberdade (ao redor de 5,5 anos de idade). A partir desta idade as concentrações de $E_{1} C$ e PdG começaram a aumentar esporadicamente, porém em concentrações bem menores do que as observadas em fêmeas adultas. Aos seis anos de idade, um aumento significativo foi observado, comparável ao aumento pré-ovulatório de fêmeas adultas. Seguiu-se um período de aumentos irregulares e intermitentes de $E_{1} C$ sucedidos de pequenos e breves aumentos de PdG até ambos atingirem concentrações de um ciclo ovulatório. Nesta fêmea de gorila o processo de puberdade durou cerca de 1,75 anos.

Savage et al. (1994) também observou um breve período de atividade ovariana em uma fêmea de parauacu (Pithecia pithecia) pré-púbere com 12 meses de idade. Neste período as concentrações de $E_{1} C$ e $P d G$ fecais foram bem menores do que as observadas nas fêmeas adultas. Esta fêmea só apresentou atividade ovariana cíclica similar às outras fêmeas sexualmente maduras a partir de 32 meses de idade. 
Os perfis hormonais apresentados pelas fêmeas 4 e 5 confirmaram a validade fisiológica do ensaio realizado neste estudo. A permanência das concentrações de estrógenos e progestinas fecais em níveis basais durante quase todo o período correspondeu ao estado fisiológico de cada animal (uma fêmea caquética e outra pré-púbere).

Os ensaios realizados para as fêmeas 1, 2 e 3 por sua vez, mostraram uma variação nas concentrações dos metabólitos hormonais que refletiram a presença de atividade ovariana cíclica.

\subsubsection{Função ovariana das fêmeas 1, 2 e 3}

Os valores considerados basais, elevação e pico dos metabólitos fecais de estrógenos e progestinas para as fêmeas 1,2 e 3 estão expressos na tabela 5 . A representação gráfica do método adotado para a determinação destes valores e do limite entre basal e elevação encontra-se no apêndice C.

Tabela 5 - Valores basais, de elevação e pico para os metabólitos fecais de estrógenos e progestinas (ng/g) em fêmeas de bugio (Alouatta caraya). São Paulo, 2005

\begin{tabular}{cccc}
\hline \multicolumn{4}{c}{ Metabólitos de estrógenos (ng/g fezes úmidas) } \\
\hline Animal & Valores basais & Elevação & Pico \\
\hline 1 & $\leq 284,06$ & $294,06<x<622,38$ & $\geq 622,38$ \\
2 & $\leq 495,52$ & $495,52<x<890,41$ & $\geq 890,41$ \\
3 & $\leq 99,24$ & $99,24<x<179,43$ & $\geq 179,43$ \\
\hline & & Progestinas (ng/g fezes úmidas) & \\
\hline 1 & $\leq 622,82$ & $622,82<x<2204,16$ & $\geq 2204,16$ \\
2 & $\leq 516,89$ & $516,89<x<1607,47$ & $\geq 1821,34$ \\
3 & $\leq 535,54$ & $535,54<x<1821,34$ & \\
\hline
\end{tabular}


A tabela 6 contém os valores mínimos, máximos, medianas, médias e erros padrões das concentrações basais e de pico dos estrógenos e progestinas fecais para cada uma das três fêmeas.

Tabela 6 - Valores mínimos e máximos, medianas, médias e erros padrões (EP) das concentrações basais e de pico de metabólitos fecais de estrógenos e progestinas (ng/g) em fêmeas de bugio (Alouatta caraya). São Paulo, 2005

\begin{tabular}{|c|c|c|c|c|c|c|c|c|c|c|}
\hline \multicolumn{11}{|c|}{ Metabólitos de estrógenos (ng/g fezes úmidas) } \\
\hline \multirow[b]{2}{*}{ Animal } & \multicolumn{5}{|c|}{ Basal } & \multicolumn{5}{|c|}{ Pico } \\
\hline & mín. & máx. & mediana & média & EP & mín. & máx. & $\begin{array}{c}\text { median } \\
\mathbf{a}\end{array}$ & média & EP \\
\hline 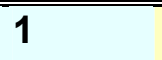 & 2,00 & 280,00 & 137,00 & 14143,29 & 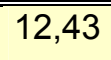 & 628,41 & 1000,69 & 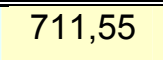 & 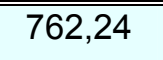 & $4 \quad 46,41$ \\
\hline 2 & 24,00 & 489,00 & 322,50 & 307,19 & 15,32 & 907,67 & 1346,45 & 1127,94 & 1115,16 & 70,13 \\
\hline 3 & 2,00 & 99,18 & 49,23 & 52,12 & 3,63 & 191,02 & 270,68 & 210,51 & 221,33 & 11,43 \\
\hline Geral & 2,00 & 489,46 & 130,51 & 169,71 & 10,83 & 191,02 & 1346,45 & 711,55 & 705,03 & 79,67 \\
\hline \multicolumn{11}{|c|}{ Progestinas (ng/g fezes úmidas) } \\
\hline 1 & 13,00 & 586,00 & 196,5 & 236,76 & 22,26 & 2247,00 & 3158,17 & 2702,37 & 2680,74 & 110,83 \\
\hline 2 & 4,00 & 472,00 & 80,50 & 136,25 & 19,74 & 1742,19 & 2284,24 & 2054,79 & 2173,25 & 251,90 \\
\hline 3 & 5,00 & 510,00 & 143,00 & 176,00 & 18,00 & 2128,24 & 3033,10 & 2632,15 & 2606,41 & 190,19 \\
\hline Geral & 4,37 & 586,62 & 149,88 & 188,36 & 12,10 & 1742,19 & 3158,17 & 2653,54 & 2525,59 & 106,96 \\
\hline
\end{tabular}

Os perfis hormonais das fêmeas 1, 2 e 3 estão representados nas próximas figuras. Para as três fêmeas as dosagens iniciaram-se no dia da mudança de recinto. 


\section{Fêmea 1}

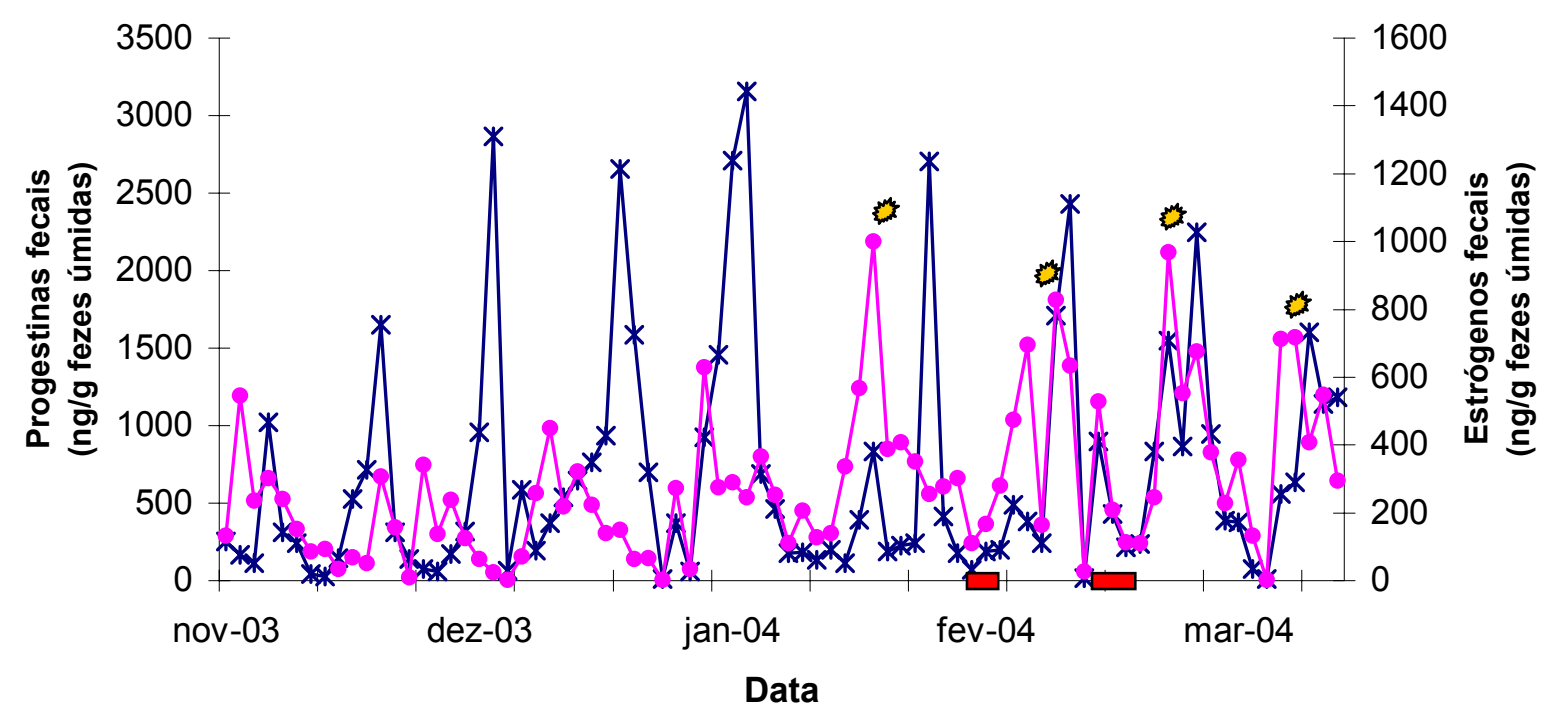

Figura 16 - Representação gráfica do perfil das concentrações de metabólitos fecais de estrógenos e progestinas da fêmea 1 durante cinco meses de colheita. As estrelas ressaltam os picos dos metabólitos de estrógenos acompanhados de valores elevados. As tarjas vermelhas indicam períodos de sangramento. São Paulo, 2005

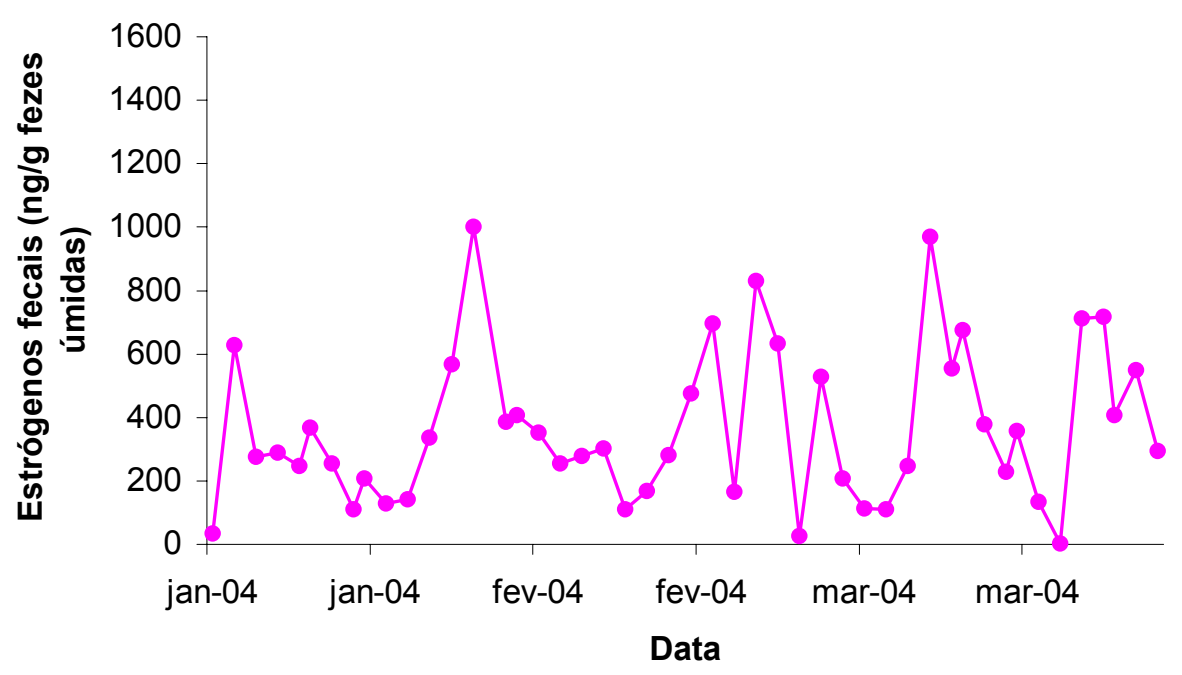

Figura 17 - Perfil dos metabólitos de estrógenos nas fezes da fêmea 1 no período de aparecimento dos picos. São Paulo, 2005 
A fêmea 1 estava lactante durante todo o período de estudo. Para esta fêmea foram identificados nove picos de estrógenos fecais e três intervalos entre picos com

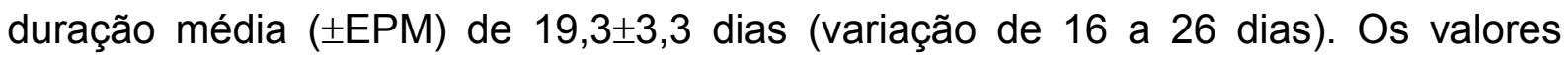
destes metabólitos permaneceram elevados durante $9,3 \pm 1,2$ dias. O primeiro pico foi observado apenas no início de janeiro, mas não foi considerado para os cálculos dos intervalos por não ter sido acompanhado de valores elevados de metabólitos fecais de estrógenos durante pelo menos três dias.

A concentração de progestinas fecais manteve-se elevada por pelo menos uma semana (neste caso oito dias) apenas no penúltimo pico e elevação das concentrações de estrógenos fecais. A elevação de progestinas fecais ocorreu entre 10/03 e 17/03 e os estrógenos fecais elevaram-se entre 12/03 e 17/03, com o pico ocorrendo no dia 12. Antes deste período as concentrações de progestinas fecais permaneceram basais durante sete dias.

Nos dias 15 e 16/12 a fêmea exibiu um comportamento que nos chamou a atenção. Nos dois dias permaneceu sentada no chão por longos períodos, próximo à porta da gaiola. Nesta posição o animal olhava constantemente para os dois machos com os quais possuía contato visual, mostrava a genitália, passava a mão na vulva e cheirava-a. Ao mesmo tempo fazia movimentos com a língua, colocando-a para fora e depois para dentro da boca repetidamente.

Movimentos rítmicos com a língua (“lingual display”) precedem a cópula em bugios (NEVILLE et al., 1988) e parecem comunicar receptividade, solicitar a cópula ou ser um componente de cortejo (JONES, 1983). Este comportamento foi observado em A. belzebul por Bonvicino (1989), A. palliata por Clarke et al. (1991), A. pigra por Horwich (1983) e Jones (1983) o descreveu em A. caraya. 
Os metabólitos de estrógenos fecais não atingiram valores de pico na elevação subseqüente a este comportamento. Contudo, este pode ter sido um importante sinalizador do início da atividade ovariana cíclica observada no restante do estudo.

O período de colheita de material colpocitológico para esta fêmea foi de 02/02/04 a 17/03/04 e o único intervalo entre sangramentos observado foi de 20 dias. O primeiro sangramento durou quatro dias e coincidiu com a queda nas concentrações tanto de estrógenos quanto de progestinas fecais. O segundo sangramento durou sete dias e no período houve uma elevação isolada nas concentrações de metabólitos fecais de estrógenos e progestinas. 


\section{Fêmea 2}

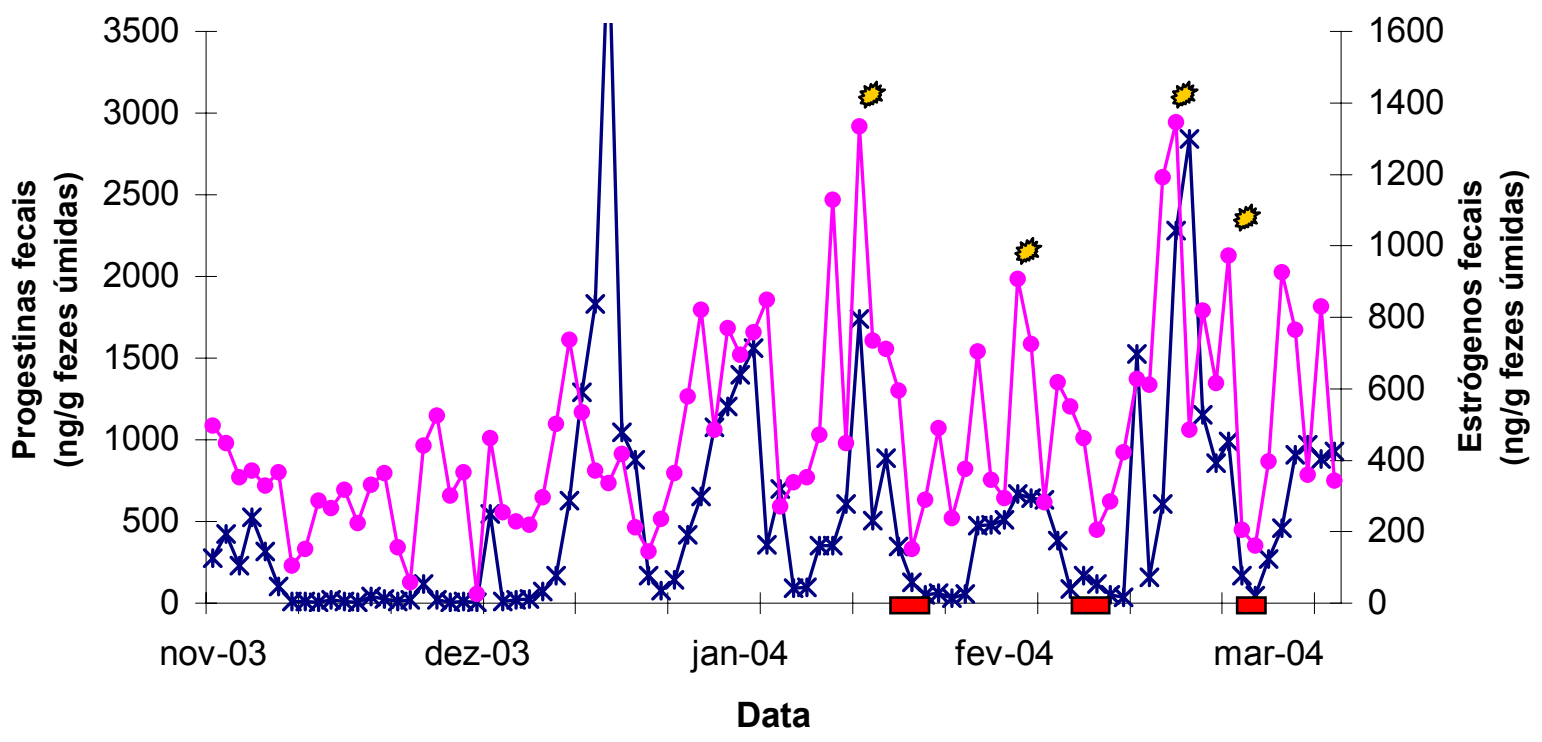

* - progestinas —- estrógenos

Figura 18 - Representação gráfica do perfil das concentrações de metabólitos fecais de estrógenos e progestinas da fêmea 2, durante cinco meses de colheita. As estrelas ressaltam os picos acompanhados de valores elevados dos metabólitos de estrógenos. As tarjas vermelhas indicam períodos de sangramento. São Paulo, 2005

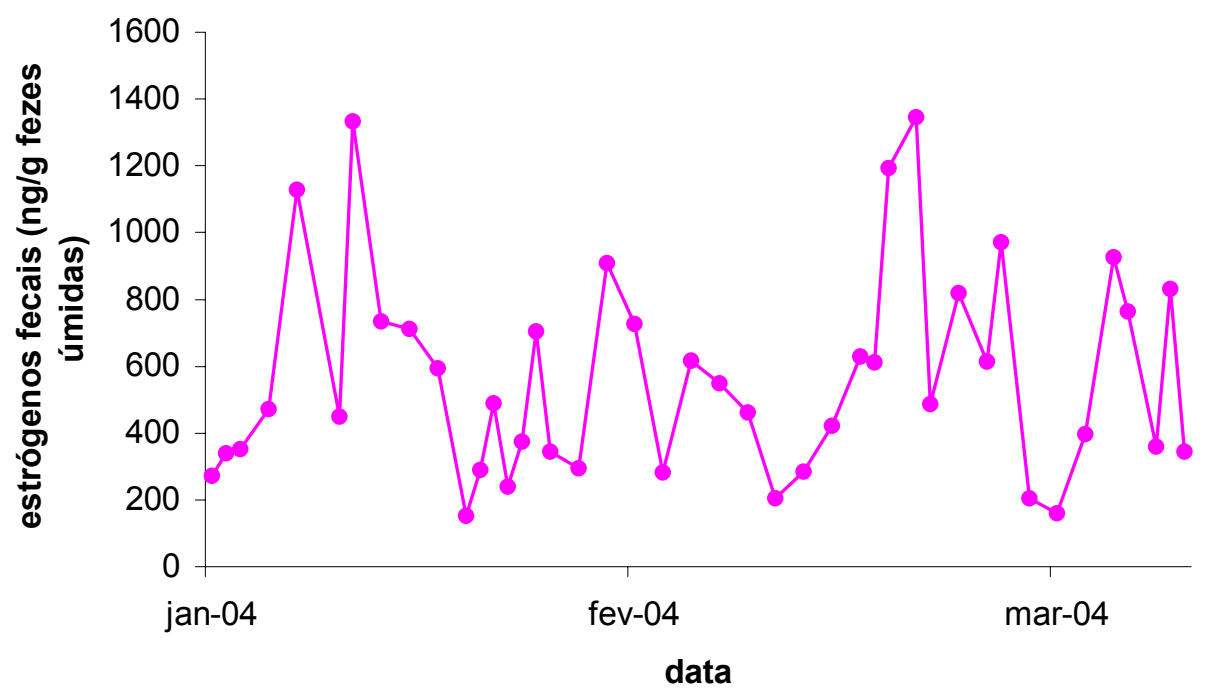

Figura 19 - Perfil dos metabólitos de estrógenos da fêmea 2 no período de aparecimento de picos. São Paulo, 2005 
A fêmea 2 apresentou sete picos de estrógenos fecais durante o período de dosagem. Foram considerados três intervalos com duração média de 18,0 $\pm 2,3$ dias

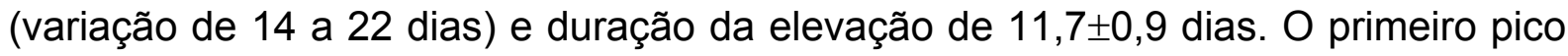
foi detectado apenas no final de janeiro.

Como na fêmea 1 , as concentrações de progestinas fecais se mantiveram elevadas por no mínimo uma semana (neste caso 9 dias) apenas no penúltimo pico e elevação de metabólitos de estrógenos fecais. A elevação de ambos metabólitos ocorreu entre 10/03 e 20/03 e foram observados dois picos de estrógenos fecais nos dias 12 e 14, sendo que o segundo foi mais elevado. Antes deste período de elevação as concentrações de progestinas fecais permaneceram basais durante aproximadamente 15 dias.

Em 20/12 um dos machos escapou de sua gaiola, se dirigiu para a gaiola da fêmea 2 e teve ereção. Episódio semelhante ocorreu em 13/02, porém com outro macho. Nos dois casos a fêmea se aproximou dos machos, cheirou-os e tentou passar a mão por entre as grades para tocá-los. Estes episódios podem indicar que a fêmea 2 apresentou atividade ovariana ovulatória durante o estudo. Os machos de bugio em vida livre dificilmente são atraídos por fêmeas fora da fase reprodutiva (JONES, 1983, 1985).

A citologia vaginal na fêmea 2 foi realizada de 15/01/04 a 31/03/04. O período inicial (15/01 a 02/02) foi utilizado apenas para o treinamento da metodologia de colheita e análise do material vaginal. Foram observados três períodos de sangramento com intervalos de 18 e 22 dias e a duração destes períodos variou entre de 1 a 6 dias. Todos os períodos coincidiram com a queda nas concentrações de estrógenos e progestinas fecais. 


\section{Fêmea 3}

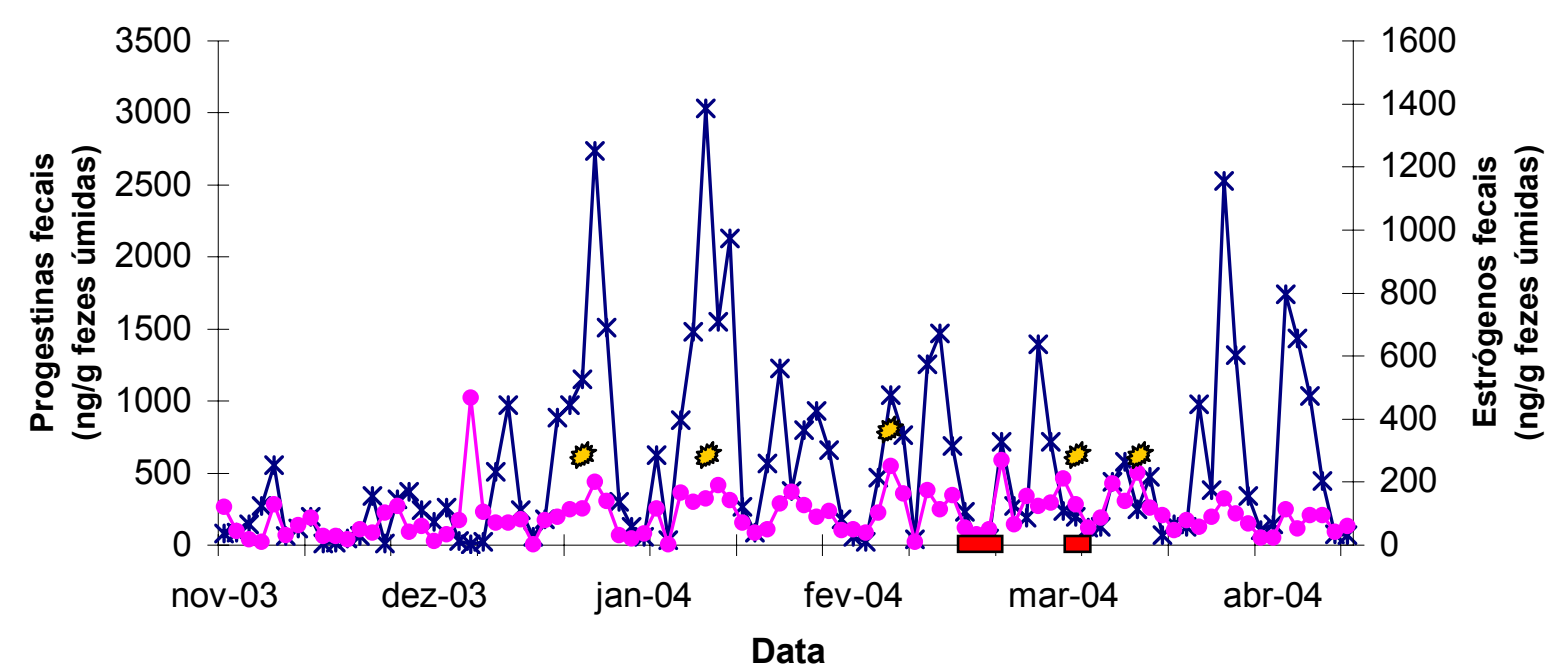

* - progestinas $\multimap-e s t r o ́ g e n o s$

Figura 20 - Representação gráfica do perfil das concentrações de metabólitos fecais de estrógenos e progestinas da fêmea 3 , durante seis meses de colheita. As estrelas ressaltam os picos acompanhados por valores elevados dos metabólitos de estrógenos. As tarjas vermelhas indicam períodos de sangramento. São Paulo, 2005

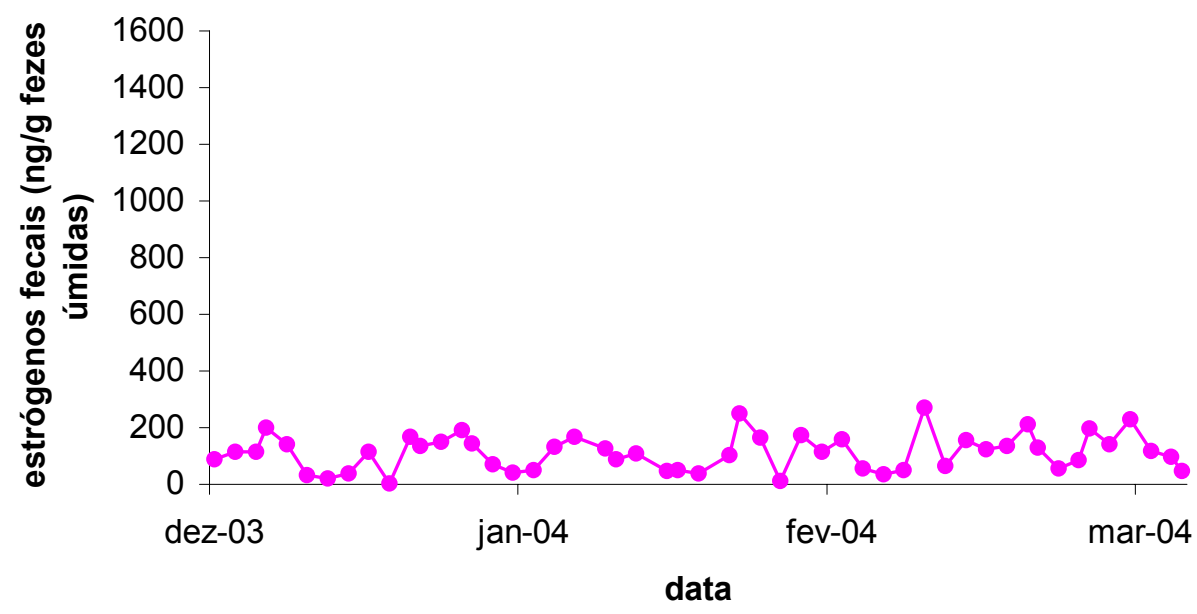

Figura 21 - Perfil dos metabólitos de estrógenos da fêmea 3 no período de aparecimento de picos. São Paulo, 2005

A fêmea 3 também estava em lactação durante o estudo. Como a sua cria veio a óbito em 01/03/04, optou-se por ampliar o período de colheita de amostras 
fecais por mais um mês para observação do perfil hormonal sem a interferência da amamentação. Assim, o período de dosagem para esta fêmea foi de novembro de 2003 a abril de 2004.

Neste período foram identificados sete picos de estrógenos fecais e quatro

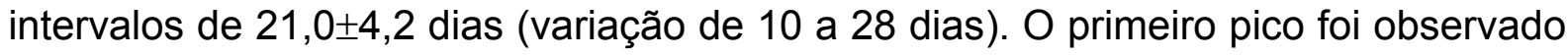
no final de dezembro de 2004 e as concentrações destes metabólitos permaneceram elevadas durante $7,00 \pm 1,1$ dias.

Para esta fêmea foram observados elevação nas concentrações de progestinas durante o período mínimo de uma semana nas duas primeiras elevações das concentrações de metabólitos de estrógenos. O primeiro período de elevação de progestinas fecais ocorreu entre 26/12/03 e 02/01/04 (duração de sete dias) e a elevação de estrógenos fecais ocorreu entre 28/12/04 e 02/02/04, com o pico em 31/12. O segundo período de elevação para ambos metabólitos ocorreu entre 10/01 e 20/01 e teve duração de nove dias, com o pico de estrógenos fecais em 19/01.

A citologia vaginal foi realizada de 25/02/04 a 01/04/04. Houve uma pausa entre 04/03 e 10/03, devido à perda do filhote. O único intervalo entre sangramentos observado foi de 19 dias. Os dois períodos de sangramento (um de sete dias e outro de um dia) coincidiram com a queda nas concentrações hormonais.

Recabarren et al. (2000) dividiu o período de lactação em duas fases. A primeira fase é caracterizada por total inatividade ovariana, denominada amenorréia ou aciclia lactacional e a segunda, onde já se observa atividade ovariana porém caracterizada por ciclos inférteis, é denominada infertilidade lactacional.

Os mesmos autores observaram que fêmeas de macaco-prego não apresentaram alterações na citologia vaginal nem menstruação durante os primeiros 
150 dias. Aliado ao perfil colpocitológico, as concentrações plasmáticas de estradiol e progesterona permaneceram em níveis basais ou muito baixos. Este período foi caracterizado como amenorréia lactacional. Em seguida os animais apresentaram um período de infertilidade residual com a presença de ciclos menstruais e cópula. $\mathrm{O}$ intervalo entre partos foi de 1,7 anos, sendo sete meses maior do que o intervalo observado para as fêmeas que pariram porém não amamentaram.

Estudos em macaco-rhesus mostraram que durante a maior parte da lactação não há desenvolvimento folicular e os níveis de estradiol e inibina se mantêm baixos. Nesta espécie observaram-se altos níveis de prolactina e a manutenção do corpo lúteo ativo com a produção de progesterona (Mc NEILLY, 1994).

No gênero Alouatta, Glander (1980) descreve a ocorrência de um período de aciclia lactacional para $A$. palliata em vida livre através de observações comportamentais. O período de aciclia durou de três a quatro meses, após o qual as fêmeas tornaram-se receptivas. Neste período elas copularam mas não conceberam até, provavelmente, os níveis hormonais atingirem valores ovulatórios. Neste estudo o intervalo entre partos (IEP) foi de 22,5 meses e a gestação de 180 a 194 dias.

Em A. guariba clamitans, DiBitetti e Janson (2000) e Strier, Mendes e Santos, (2001) observaram um intervalo de seis meses entre o desmame e a concepção e o IEP foi $21,2 \pm 2,5$ meses. Para $A$. caraya em cativeiro foram descritos IEP bem menores, de 12 a 15 meses (SHOEMAKER, 1982) a até 9 meses (CAMINATTI; STEZ, 2004). No último caso o desmame do filhote ocorreu com 16 semanas de idade

Savage et al. (1994) observou um aumento nas concentrações de estrona e pregnanos fecais em uma fêmea de parauacu logo em seguida a perda do filhote. 
Após a perda do filhote a fêmea 3 não apresentou alteração significativa no perfil hormonal.

As fêmeas 1 e 3 pariram no início de fevereiro de 2003. Assim no início do período de dosagem hormonal os filhotes estavam com nove meses de idade. Pelo histórico reprodutivo apresentado no quadro 1, a fêmea 1 pariu pelo menos uma cria antes desta e o IEP foi de 18 meses.

O perfil hormonal das duas fêmeas revelou atividade ovariana cíclica, mas os níveis dos metabólitos fecais de estrógenos da fêmea 3 foram bem mais baixos do que os da fêmea 1. Tal fato seria justificável devido a variações individuais.

Zucker, Clarke e Harrison (1995) também encontraram grande variação na concentração média dos estrógenos fecais, entre 20 e 1731ng/g de fezes para fêmeas ciclando de $A$. palliata.

Espinosa (2000) também observou grande variação individual nas concentrações hormonais em seu estudo com dosagem de estrona e pregnano urinários em fêmeas de $A$. palliata.

Diante do exposto torna-se aceitável a hipótese de que as fêmeas 1 e 3 já estivessem fora do período de aciclia lactacional.

A tabela 7 resume as medianas dos intervalos de tempo em dias entre os picos de estrógenos fecais para as fêmeas 1, 2 e 3, os valores mínimos e máximos destes intervalos e as medianas do número de dias que os valores de estrógenos fecais permaneceram elevados.

A tabela 8 resume as médias e erros padrões das médias (médiatEPM) dos intervalos entre picos de estrógenos fecais, do número de dias em que os valores destes metabólitos permaneceram elevados, dos períodos de concentrações basais 
e elevadas de progestinas fecais, dos intervalos entre períodos de sangramento e da duração destes períodos nas fêmeas 1,2 e 3 .

Tabela 7 - Medianas dos intervalos entre picos em dias, valores mínimos e máximos destes intervalos e número de dias que os valores de estrógenos fecais permaneceram elevados para fêmeas de bugio (Alouatta caraya). São Paulo, 2005

\begin{tabular}{cccc}
\hline & \multicolumn{3}{c}{ Estrógenos fecais (dias) } \\
\cline { 2 - 4 } Animal & Intervalo picos & Mín./ máx. picos & Duração elevação \\
\hline 1 & 16,0 & $16-26(n=3)$ & 10,0 \\
2 & 18,0 & $14-22(n=3)$ & 12,0 \\
3 & 23,0 & $10-28(n=4)$ & 6,5 \\
\hline Geral & $\mathbf{1 8 , 5}$ & $\mathbf{1 0 - 2 8 ( \mathbf { n = 1 0 } )}$ \\
\hline
\end{tabular}

Tabela 8 - Médias e erros padrões das médias (médiatEPM) dos intervalos entre picos de estrógenos fecais, do número de dias em que os valores destes metabólitos permaneceram elevados, dos períodos de concentrações basais e elevadas de progestinas fecais, intervalos entre períodos de sangramento e da duração destes períodos nas fêmeas de bugio (Alouatta caraya). São Paulo, 2005

\begin{tabular}{ccccccc}
\hline \multirow{2}{*}{ Animal } & \multicolumn{2}{c}{ Estrógenos fecais (dias) } & \multicolumn{2}{c}{ Progestinas fecais (dias) } & \multicolumn{2}{c}{ Sangramentos (dias) } \\
\cline { 2 - 7 } & $\begin{array}{c}\text { Intervalo } \\
\text { picos }\end{array}$ & $\begin{array}{c}\text { Duração } \\
\text { elevação }\end{array}$ & $\begin{array}{c}\text { Duração } \\
\text { Elevação }\end{array}$ & $\begin{array}{c}\text { Duração } \\
\text { basal }\end{array}$ & $\begin{array}{c}\text { Intervalo } \\
\text { sangramentos }\end{array}$ & $\begin{array}{c}\text { Duração } \\
\text { sangramentos }\end{array}$ \\
\hline 1 & $19,3 \pm 3,3$ & $9,3 \pm 1,2$ & 8,00 & 7,0 & 20,0 & 4 e 7 \\
2 & $18,0 \pm 2,3$ & $11,7 \pm 0,9$ & 11,00 & 15,0 & 18,0 e 22,0 & 7 e 1 \\
3 & $21,0 \pm 4,2$ & $7,0 \pm 1,1$ & 7,00 e 9,00 & 6,0 e 8,0 & 19,0 & 3,6 e 1 \\
\hline Média & $\mathbf{1 9 , 6 \pm 1 , 9}$ & $\mathbf{9 , 1} \pm \mathbf{0 , 9}$ & $\mathbf{8 , 3} \mathbf{0 , 0 , 5}$ & $\mathbf{9 , 0} \mathbf{0} \mathbf{4 , 1}$ & $\mathbf{1 9 , 8 \pm 0 , 9}$ & $\mathbf{4 , 1} \pm \mathbf{1 , 0}$ \\
\hline
\end{tabular}

As médias dos intervalos entre picos de estrógenos fecais e sangramentos foram muito próximas entre si. Estes intervalos foram também próximos da duração do ciclo ovariano de 19,7 $\pm 1,0$ dias (variação de 17 a 24 dias) encontrado por Colillas e Coppo (1978) através de citologia vaginal em $A$. caraya. 
Para A. palliata, Espinosa (2000) encontrou ciclos com durações entre seis e 33 dias através da dosagem de estrona e pregnano urinários. O autor levanta a hipótese do estudo ter sido conduzido com animais recém-capturados na natureza para explicar esta maior variação na duração dos ciclos.

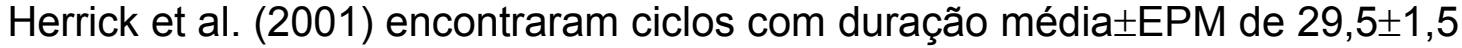
dias para $A$. seniculus em vida livre através da dosagem de progesterona urinária. Além de ser uma duração bem maior da encontrada para outras espécies do gênero, difere também do intervalo entre estros observado por Crocket e Sekulic (1982) para a mesma espécie. Neste caso um dos fatores que pode ter contribuído para estes resultados foi o fato do estudo ter sido conduzido a partir da colheita de material urinário em animais de vida livre o que dificulta a colheita deste tipo de material e pode induzir a maiores índices de erro.

Os intervalos entre picos de metabólitos de estrógenos e sangramentos em nosso estudo foram também próximos da duração do ciclo descrito para outras espécies de primatas neotropicais como Ateles geoffroy (GOODMAN; WISLOCKY, 1935; HERNÁNDEZ-LÓPEZ et al., 1998), B. hypoxantus (STRIER; ZIEGLER, 1997). Callicebus moloch (VALEGGIA et al., 1999), Cebus apella (GUIMARÃES, 1999; NAGLE; DENARI, 1983) e Pithecia pithecia (SAVAGE et al., 1995).

A duração de alguns períodos de sangramento observados em nosso estudo pode ser 1 ou 2 dias maior, pois na maioria dos casos a colheita de material vaginal foi realizada em dias alternados para evitar estresse excessivo dos animais. A duração dos períodos de sangramentos encontrada neste estudo foi similar à descrita para macaco-prego (HAMLET, 1939) e macaco-aranha (HERNÁNDEZLÓPEZ et al., 1998). 
Todos os sangramentos foram discretos. Não houve sinal macroscópico de corrimento sangüíneo pela vagina, nem alterações na estrutura da genitália externa (como coloração e intumescência vulvares),o que corrobora com o observado por Colillas e Coppo (1978) e Crockett e Eisenberg (1987) para a espécie.

As melhores colorações para as lâminas citológicas foram o Panótico rápido e o Papanicolaou. O Panótico rápido é uma técnica mais simples, rápida e barata. A técnica de Papanicolaou por sua vez, facilitou a identificação dos tipos celulares presentes nos esfregaços vaginais pela diferenciação na coloração das células. As colorações segundo Shorr e Leishman não permitiram a diferenciação dos tipos celulares.

Quanto ao perfil colpocitológico nenhuma das fêmeas apresentou um padrão de alteração celular que pudesse ser correlacionado com o perfil hormonal. A fêmea 2 mostrou certa variação cíclica no perfil celular no entanto em momento algum se observou pico de células superficiais anucleadas ou cornificadas. Pelo Papanicolaou foi possível observar apenas a eosinifilazação (coloração alaranjada) de células maduras (Apêndice D).

As fêmeas 1 e 3 apresentaram padrões citológicos muito semelhantes ao longo do período de estudo. Os esfregaços mostraram grande quantidade de células parabasais e intermediárias pequenas, leucócitos e muco. Devido à freqüente presença de leucócitos colheu-se material vaginal para cultura bacteriana. Observou-se crescimento de Proteus mirabilis e Escheria coli, ambas pertencentes à flora bacteriana normal da vagina em mulheres (GOMPEL; KOSS, 1997) e na própria espécie A. caraya (CLAVER; COLILLAS; TRAVI, 1984).

Veras (2004), em seu estudo do aparelho reprodutor de fêmeas de bugio, encontrou diferenças em relação à compactação das células do estrato 
intermediário, no número de camadas que compõem o epitélio vaginal e no número de pregas. Contudo, não foram observados uma camada superficial de células queratinizadas, nem alterações cíclicas no epitélio vaginal pela análise histológica.

Claver, Colillas e Travi (1984) descrevem as mesmas características histológicas da vagina de $A$. caraya. Os autores sugerem uma diferença na capacidade de reação do epitélio vaginal destes animais ao estímulo hormonal.

Dempsey (1939, apud LANG, $1967^{1}$ ) foi incapaz de encontrar um padrão de variação cíclica nas células do epitélio vaginal de $A$. palliata, ao contrário do observado para macaco-prego (NAGLE; DENARI, 1983) e macaco-aranha (HERNÁNDEZ-LÓPEZ et al., 1998). Colillas e Coppo observaram um aparecimento cíclico de células eosinofílicas no esfregaço vaginal, porém a maioria com núcleo picnótico.

Os achados descritos pelos autores acima mencionados corroboram com os deste estudo e por isso consideramos o aparecimento de eritrócitos como o resultado mais consistente que pudemos observar a partir da análise colpocitológica.

De maneira geral, o perfil de progestinas fecais mostrou-se inconsistente durante a maior parte do estudo. A elevação sustentada destes metabólitos foi observada acompanhando apenas quatro picos de metabólitos de estrógenos fecais nas três fêmeas.

Os mesmos conjuntos comerciais da $\mathrm{DPC}^{\circledR}$ foram utilizados para estudo da fisiologia reprodutiva de A. palliata em vida livre por Clarke et al. (1991), Zucker et al. (1994) e Zucker, Clarke e Harrison (1995). Os autores encontraram uma correlação significativa porém fraca entre as concentrações de metabólitos fecais de estrógenos e de estradiol sérico $(r(42)=0,36, p=0,016)$ e entre as progestinas fecais e a

\footnotetext{
${ }^{1}$ DEMPSEY, E. W. The reproductive cycle of New World monkeys. American Journal of Anatomy, v. 64, p. 381-405, 1939.
} 
progesterona sérica $(r(42)=0,52, p=0,0003)$. As concentrações de estrógenos e progestinas fecais permitiram diferenciar fêmeas cíclicas, lactantes e prenhes, porém não permitiram diferenciar fêmeas nas fases folicular e lútea. Apesar da fraca correlação com as concentrações séricas, todas as cópulas observadas no estudo foram associadas ao aumento dos níveis de metabólitos fecais de estrógenos.

Shideler et al. (1993) realizaram HPLC (high-pressure liquid chromatography) na tentativa de identificar os metabólitos de progesterona nas fezes de Macaca fascicularis. Os autores não conseguiram identificar os metabólitos devido sua natureza complexa, mas acreditam que existam pelo menos de oito a dez metabólitos diferentes para o hormônio nas fezes desta espécie e que muitos deles exerçam importante influência no perfil imunorreativo da progesterona. Os autores concluíram que, para espécies do gênero Macaca, o melhor seria utilizar um anticorpo para pregnanos em geral.

Heisterman et al. (2001) encontraram grande quantidade de $5 \alpha$-pregnane-3 $\alpha$ ol-20-one nas fezes de $M$. silenus através da técnica de HPLC. Trabalhos com primatas do novo mundo também utilizaram a dosagem de pregnanos fecais ou urinários para o estudo do ciclo ovariano (CAMPBELL et al., 2001; ESPINOSA, 2000; PRYCE et al., 1994; SAVAGE et al., 1995; SHIDELER et al., 1994; ZIEGLER et al., 1997).

O porcentual de reações cruzadas do conjunto diagnóstico para dosagem de progesterona utilizado neste estudo é de apenas 9,0\% para 5 $\alpha$-Pregnan-3,20-dione e menos de $4 \%$ para outros pregnanos (Tabela 2). Os anticorpos para dosagem de pregnanos por radioimunoensaio não são disponíveis comercialmente.

O estresse também pode ter interferido no perfil dos metabólitos fecais de progestinas e estrógenos em dois momentos do estudo. O primeiro, logo após a 
mudança de galpão e o segundo durante a realização da colheita de material para citologia vaginal.

Veras (2004) em seu estudo da morfologia do aparelho reprodutor de fêmeas de $A$. guariba clamitans e $A$. caraya encontraram muitos folículos em estágios iniciais de desenvolvimento, muitos folículos atrésicos em estágio mais avançado de desenvolvimento e nenhum corpo lúteo verdadeiro. O que a autora observou foi grande quantidade de tecido intersticial formado por células glandulares secretoras de aparência luteinizada que pareciam ser de origem tecal.

A autora sugere que a grande quantidade de folículos atrésicos poderia ser explicada pela presença de ciclos anovulatórios causados por baixos níveis de $\mathrm{FSH}$. Como para a realização do estudo foram utilizados animais que vieram a óbito em centros de triagem ou reabilitação a autora sugere que os níveis altos de estresse ambiental poderiam inibir a secreção de $\mathrm{FSH}$ e conseqüentemente o desenvolvimento final do folículo e o processo de ovulação.

Em primatas o desenvolvimento folicular até o estágio pré-ovulatório é relativamente independente de gonadotropinas. Apenas no final do desenvolvimento ocorre aumento do número de receptores para LH e FSH (ZELEZNICK, 1993).

Claver e Von Lawzewitisch (1984) também observaram as características descritas por Veras (2004) no estudo histológico dos ovários de $A$. caraya na Argentina. Claver, Collilas e Travi (1984) sugerem que as condições de cativeiro poderiam resultar em função ovariana insuficiente. Os autores ressaltaram que as espécies do gênero Alouatta estão entre os primatas neotropicais mais difíceis de se manter e reproduzir em cativeiro.

Em nosso estudo não foi observado pico de metabólitos fecais de estrógenos antes de aproximadamente dois meses após a mudança de galpão. Durante a 
colheita de material colpocitológico observamos picos de metabólitos de estrógenos com um padrão cíclico e aparentemente a maior alteração neste período foi a redução nas concentrações de progestinas fecais.

Chatterton (1990) e Dettmer et al. (1996) sugerem que o estresse gerado pela contenção para múltiplas colheitas de sangue pode alterar os parâmetros reprodutivos estudados devido à ação dos níveis aumentados de glucorticóides sobre o eixo hipotálamo-hipófise-gônadas. No estudo com macaco-prego Dettmer et al. (1996) observaram a diminuição dos níveis de cortisol após cinco semanas de colheita de sangue.

Foley, Papageorge e Wasser (2001) relataram diminuição das concentrações de progestinas fecais enquanto as concentrações de metabólitos de cortisol elevaram-se em elefantes africanos durante condições adversas, como acesso limitado a recursos alimentares e água. Os mesmos autores sugerem que os níveis de progestinas em fêmeas estão altamente relacionados a condições ambientais.

Xiao et al. (1998) concluíram que a diminuição na secreção de progesterona na fase lútea representa o primeiro estágio que um episódio estressante pode provocar sobre o ciclo ovariano normal. Os autores também demonstraram que em primatas o estímulo estressante durante a fase folicular pode prolongar a foliculogênese, levando ao aumento da duração da fase e conseqüentemente do ciclo menstrual.

O período de elevação das concentrações de metabólitos fecais de estrógenos foi, em média, um dia maior do que o período de elevação das progestinas fecais. O pico de estrógenos fecais ocorreu no meio da elevação das concentrações de metabólitos fecais de progestinas, entre dois e nove dias após o início da elevação. Em Callimico goeldi as concentrações de estrona fecal atingiram 
valores de pico apenas três a cinco dias após o suposto momento da ovulação (PRYCE et al., 1994).

Este parece ser o padrão para as espécies de primatas neotropicais onde não há um pico pré-ovulatório de metabólitos fecais de estrógenos. Ao contrário, os dois metabólitos elevam-se durante o que se presume ser a fase lútea (ZIEGLER et al., 1996).

Ziegler et al. (1996) encontraram maiores níveis de estradiol do que estrona nas fezes de calitriquídeos (Saguinus oedipus e Callithrix jacchus). Nestas espécies altos níveis de estrona circulante são encontrados durante a fase lútea enquanto o estradiol encontra-se elevado e atinge concentrações de pico durante a fase folicular. Os autores sugerem que a interconversão de estradiol e estrona como conseqüência do metabolismo periférico e ação bacteriana intestinal pode explicar as altas concentrações de estrógenos fecais e urinários durante a fase lútea. Adicionalmente os autores observaram que a maioria do estradiol fecal é encontrada na forma de di- ou tri-conjugados derivados da estrona.

Entre as espécies de primatas neotropicais estudadas por meio de dosagem não-invasiva de hormônios esteróides sexuais onde este padrão foi descrito encontram-se o macaco-aranha (Ateles geoffroyi), (CAMPBELL et al., 2001); o muriqui (Brachyteles arachnoides); (ZIEGLER et al; 1997); o parauacu (Pithecia pithecia), (SHIDELER et al; 1994); o mico-de-Goeldi ou mico-preto (Callimico goeldi), (PRYCE; SCHWARZENBERGER; DÖBELI, 1994); e calitriquídeos (Callithrix jacchus, Saguinus fuscicolis e S. oedipus oedipus), (ZIEGLER et al., 1989, 1996; HEISTERMAN; TARI; HODGES, 1993).

A figura 22 ilustra o perfil da média das concentrações dos metabólitos fecais de estrógenos e progestinas em um intervalo entre sangramentos nas fêmeas 1 e 2 . 


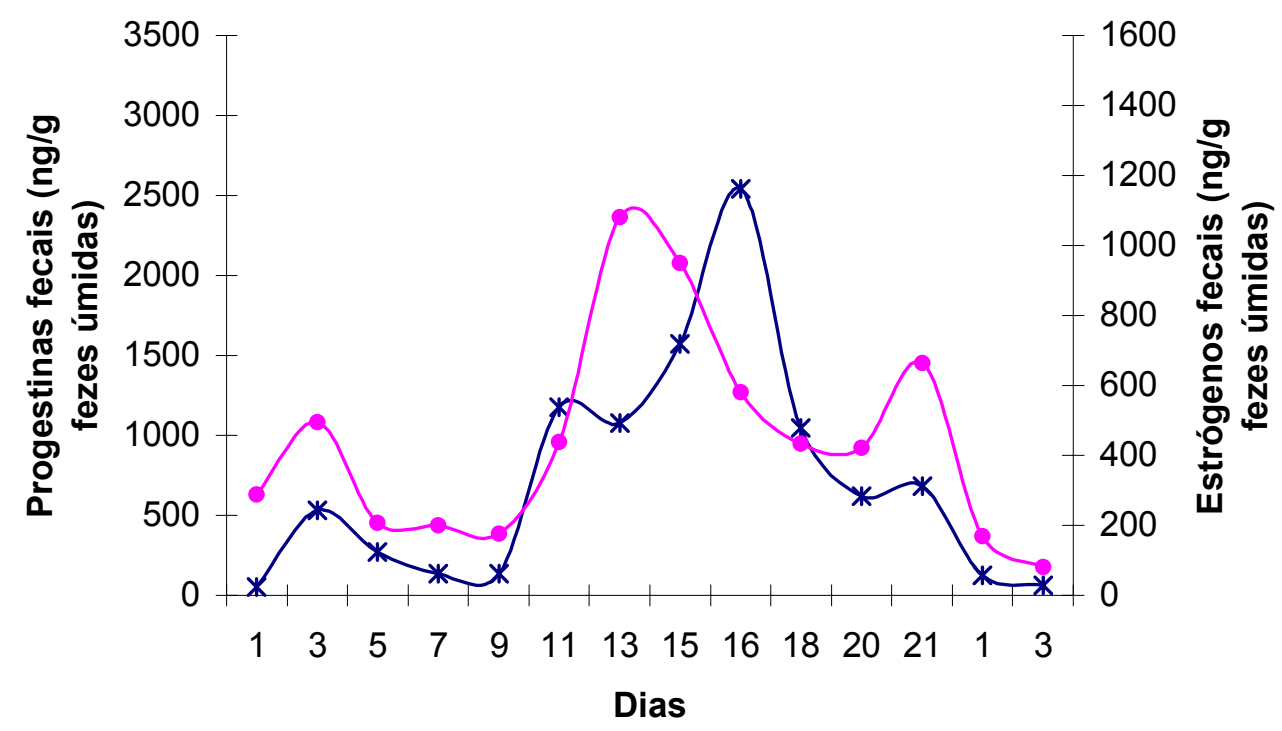

*-progestinas —-estrógenos

Figura 22 - Representação gráfica (curva suavizada) da variação das concentrações de metabólitos fecais de estrógenos e progestinas durante um intervalo entre sangramentos obtido a partir dos dados de duas fêmeas (1 e 2) de bugio (Alouatta caraya). O dia 1 corresponde ao primeiro dia de observação de sangramento. São Paulo, 2005

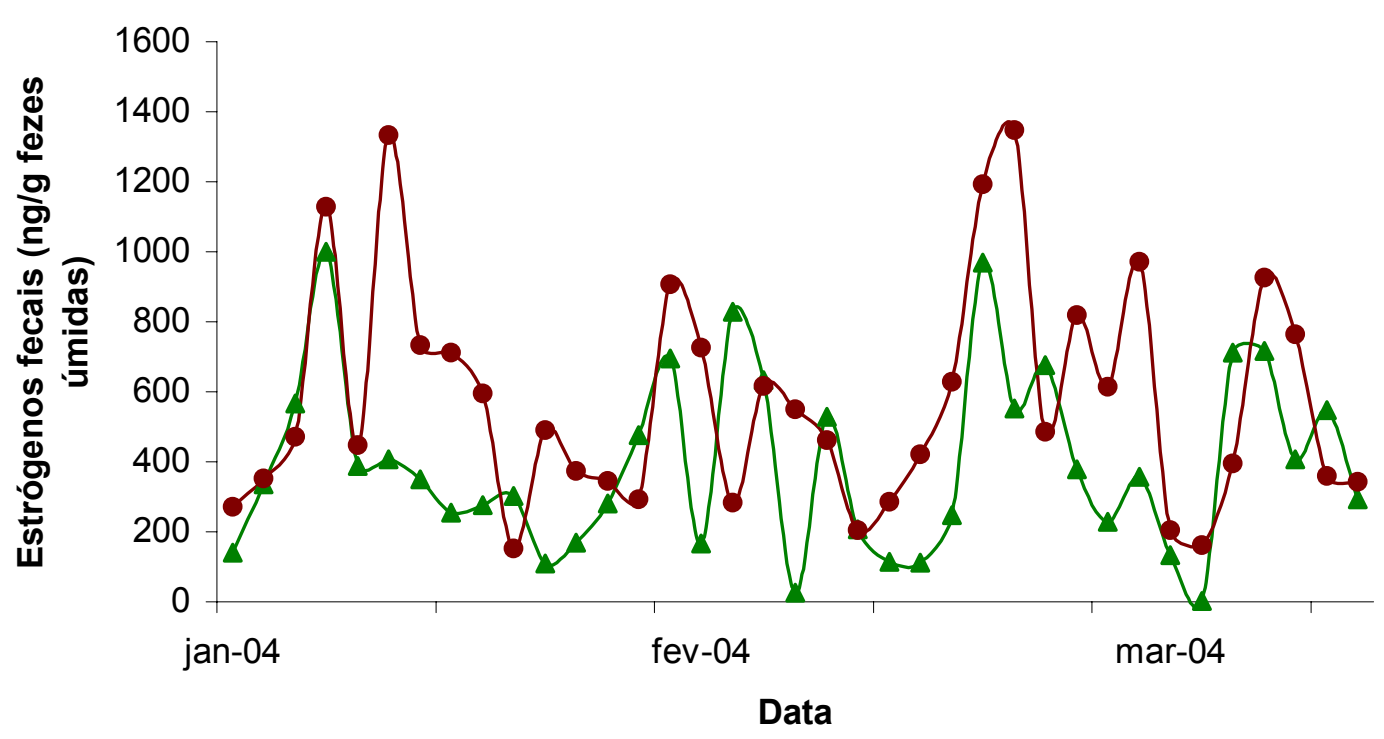

- fêmea $1 \multimap$ fêmea 2

Figura 23 - Representação gráfica (curva suavizada) do perfil de metabólitos fecais de estrógenos das fêmeas 1 e 2 mostrando o fenômeno da sincronização dos períodos de elevação destes metabólitos. As estrelas representam os valores de pico. São Paulo, 2005 
Embora no presente estudo não se possa afirmar o momento exato da ovulação, ela parece ter ocorrido antes do aumento de metabólitos de estrógenos e progestinas fecais. Pelo critério adotado para a detecção de ovulação, ou seja, concentrações de pico de estrógenos fecais acompanhados de elevação sustentada de progestinas fecais, as fêmeas 1 e 3 possivelmente tiveram pelo menos uma ovulação e a fêmea 3 pelo menos duas.

Entre as fêmeas 1 e 2 observou-se sincronização dos períodos de elevação e picos de estrógenos fecais (Figura 23). Este fenômeno só foi observado com a fêmea 3 nos dois últimos períodos de elevação destes metabólitos.

As fêmeas 1 e 2 estavam alojadas em recintos próximos e possuíam contato visual, olfativo e auditivo enquanto a fêmea 3 não possuía contato visual com as outras duas e o olfativo poderia estar reduzido pela maior distância. Entre a fêmea 3 e as outras duas encontravam-se, além dos machos, as fêmeas 4 e 5 que não estavam ciclando.

Os bugios possuem glândulas produtoras de odores e a olfação desempenha importante papel na identificação do status reprodutivo dos indivíduos (KINZEY, 1997). Glander (1980) conseguiu distinguir fêmeas receptivas de não-receptivas pelo odor pungente da urina das fêmeas no estro.

Espinosa (2000) observou a sincronização dos picos de estrona em A. palliata em cativeiro. Segundo o mesmo autor os bugios são um dos primatas do novo mundo a possuir o órgão vomeronasal mais desenvolvido. Tal característica possibilita maior capacidade para estabelecer comunicação química e sincronizar seus estros.

A sincronização de estros foi observada em A. palliata (JONES, 1985) em dois habitats diferentes, um com um padrão sazonal evidente e outro onde os 
recursos alimentares eram igualmente disponíveis ao longo do ano. A duração do ciclo estral foi praticamente igual em ambos habitats mas houve maior variação na duração das fases no habitat sazonal, onde a sincronização era mais marcante.

Glander (1980) relata que em $A$. palliata o nascimento dos filhotes da fêmea alfa (aquela que ocupa o posto mais alto na hierarquia social) ocorre primeiro.

Espinosa (2005) sugere que a sincronização dos estros garante o sucesso reprodutivo de todas as fêmeas do grupo com mínimo gasto energético, importante para animais com dieta energeticamente pobre como os bugios. Quando todas as fêmeas se encontram em fase de estro a fêmea alfa concebe primeiro, então as fêmeas posicionadas logo abaixo já podem reproduzir-se. Com todas as fêmeas dominantes prenhes as subordinadas conseguem acesso aos machos e também garantem sua reprodução (informação verbal) ${ }^{2}$.

Paul (1997) relata que do ponto de vista da fêmea a sincronia reprodutiva é uma tática efetiva para confundir a paternidade, de forma a diminuir as chances de suas crias serem vítimas de infanticídio.

O fenômeno da sincronização dos estros ainda carece de explicações mais profundas constituindo-se em importante área para investigações futuras que envolvam o comportamento sexual de bugios, a contextualização do papel dos ferormônios e a fisiologia reprodutiva de machos e de fêmeas.

\footnotetext{
${ }^{2}$ Informação fornecida por Espinosa em Porto Alegre, RS, 2005.
} 


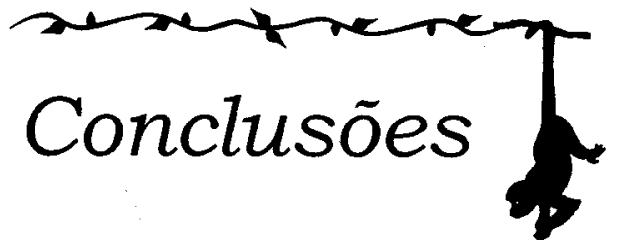




\section{Conclusões}

A técnica de extração e dosagem de metabólitos fecais de estrógenos e progestinas foi validada para a espécie Alouatta caraya.

$\checkmark$ Foi possível estimar as faixas de variação de estrógenos e progestinas fecais nas cinco fêmeas de bugio.

A técnica empregada para mensuração destes metabólitos permite diferenciar significativamente concentrações basais, elevadas e de pico.

$\checkmark$ A média \pm o erro padrão da média dos intervalos entre picos de metabólitos de estrógenos fecais de $A$. caraya, nas condições em que

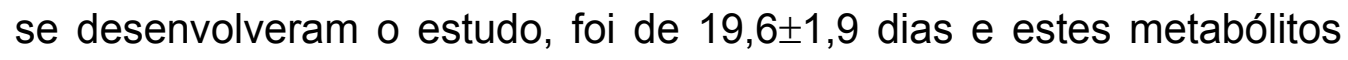
permaneceram elevados durante $9,1 \pm 0,9$ dias.

$\checkmark$ A estimativa da ocorrência de ovulação foi possível em apenas quatro momentos durante todo o estudo precedente ao início da elevação de metabólitos fecais de estrógenos e progestinas.

$\checkmark$ A ocorrência de sangramentos discretos coincidiu com o momento de queda nas concentrações de ambos metabólitos. 
$\checkmark$ A mensuração de metabólitos de estrógenos e progestinas fecais permitiu diferenciar fêmeas com ausência de atividade ovariana de fêmeas cíclicas. 


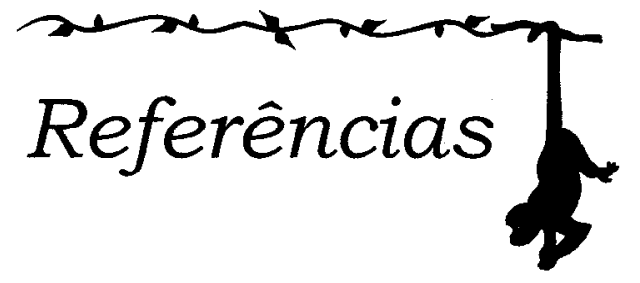




\section{REFERÊNCIAS}

AGORAMOORTHY, G.; HSU, M. J. Extragroup copulation among wild red howler monkeys in Venezuela. Folia Primatologica, v. 71, p. 147-151, 2000.

ALMEIDA, M. F.; MASSAD, E.; AGUIAR, E. A. C.; MARTORELLI, L. F. A.; JOPPERT, A. M. S. Neutralizing antirabies antibodies in urban terrestrian wildlife in Brazil. Journal of Wildlife Diseases, v. 37, n. 2, p. 394-398, 2001.

ARRUDA, M.; NARDIN, E. H.; NUSSENZWEIG, R. S.; COCHRANE, A. H. Seroepidemiological studies of malaria in Indian tribes and monkeys of the Amazon Basin of Brazil. American Journal of Tropical Medicine and Hygiene, v. 41, n. 4, p. 379385, 1989.

AURICCHIO, P. Primatas do Brasil. São Paulo: Terra Brasilis, 1995. 168 p.

BAMBERG, E.; MÖSTL, D.; PATZL, M.; KING, G. J. Pregnancy diagnosis by enzyme immunoassay of estrogens in feces from nondomestic species. Journal of Zoo and Wildlife Medicine, v. 22, n. 1, p. 73-77, 1991.

BELLEM, A. C.; MONFORT, S. L.; GOODROWE, K. L. Monitoring reproductive development, menstrual cyclicity and pregnancy in the lowland gorilla (Gorilla gorilla) by enzime imunnoassay. Journal of Zoo and Wildlife Medicine, v. 26, p. 24-31, 1995.

BERBARE, P. E. B. Avaliação longitudinal das concentrações de esteróides fecais em fêmeas de gato-mourisco (Herpailurus yagouaroundi, Lacépède, 1809). 2004. 111 f. Dissertação (Mestrado em Reprodução Animal) - Faculdade de Medicina Veterinária e Zootecnia, Universidade de São Paulo, São Paulo, 2004.

BICCA-MARQUES, J. C.; CALEGARO-MARQUES, C. Behavioral thermoregulation in a sexually and developmentally dichromatic Neotropical Primate, the black-andgold howling monkey (Alouatta caraya). American Journal of Physical Anthropology, v. 106, p. 533-546, 1998.

BITTETI, M. S.; JANSON, C. H. When will the stork arrive? Patterns of birth seasonality in neotropical primates. American Jorunal of Primatology, v. 50, p. 109-130, 2000. 
BOINSKY, S.; SWING, S. P.; TIMOTHY, G. S.; DAVIS, J. K. Environmental enrichment of brown capuchins (Cebus apella): Behavioral and plasma and fecal cortisol measures of effectiveness. American Journal of Primatology, v. 48, p. 4968, 1999.

BONVICINO, C. R. Ecologia e Comportamento de Alouatta belzebul na Mata Atlântica. Revista Nordestina de biologia, v. 6, n. 2, p. 149-179, 1989.

BRACK, M. Yellow Fever. In: man. Berlin: Springer-Verlag, 1987, p. 29-33.

BRANDON-JONES, D.; RYLANDS, A. B. The scientific names of the howling monkeys, Alouatta, from the Guianas and the Atlantic Forest. Neotropical Primates, v. 7, n. 2, p. 57-58, 1999.

BRAVO, S. P.; ZUNINO, G. E. Germination of Seeds from Three Species Dispersed by Black Howler Monkeys (Alouatta caraya). Folia Primatologia, v. 71, n. 5, p. 342345, 2000.

BRAZA, F.; ALVAREZ, F.; AZCÁRATE, T. Datos sobre la reproducción de Alouatta seniculus en los Llanos de Venezuela. Doñana, Acta Vertebrata, v. 8, p. 321-323, 1981.

BREAZILE, J. E. Physiologic basis and consequences of distress in animals. Journal of the American Medical Association, v. 191, n. 10, p. 1212-1215, 1987.

BROWN, J. L.; WILDT, D. E.; WIELEBNOWSKI, N.; GOODROWE, K. L.; GRAHAM, L. H.; WELLS, S.; HOWARD, J. G. Reproductive activity in captive female cheetahs (Acinonyx jubatus) assessed by faecal steroids. Journal of Reproduction and Fertility, v. 106, p. 337-346, 1996.

CALEGARO-MARQUES, C.; BICCA-MARQUES, J. Emigration in a black howling monkey group. International Journal of Primatology, v. 17, n. 2, p. 229-237, 1996.

CAPEZZUTO, A. Excreção fecal de progesterona e 17 $\beta$-estradiol: estudo endocrinológico longitudinal durante e gestação em cabras (Capra hircus LINNAEUS, 1758). 2005. 116 f. Dissertação (Mestrado em Reprodução Animal) Faculdade de Medicina Veterinária e Zootecnia, Universidade de São Paulo, São Paulo, 2005. 
CARLISLE, M. S.; PROCIV, P.; GRENNAN, J.; PASS, M. A.; CAMPEBELL, G. L.; MUDIE, A. Cerebrospinal angiostrongyliasis in five captive tamarins (Sanguinus spp). Australian Veterinary Journal, v. 76, n. 3, p. 167-170, 1998.

CAMPBELL, C. J.; SHIDELER, S. E.; TODD, H. E.; LASLEY, B. L. Fecal analysis of ovarian cycles in female black-handed spider monkeys (Ateles geoffroyi). American Journal of Primatology, v. 54, p. 79-89, 2001.

CARMINATTI, M. O. F.; SETZ, E. Z. F. Cuidado parental em Alouatta caraya em cativeiro. In: CONGRESSO BRASILEIRO DE ZOOLOGIA, 25., 2004, Brasília.

Anais... Brasília : Sociedade Brasileira de Zoologia, 2004. p. 249.

CAROSI, M.; HEISTERMANN, M.; VISALBERGHI, E. Display of proceptive behaviors in relation to urinary and fecal progestin levels over the ovarian cycle in female tufted capuchin monkeys. Hormones and Behavior, v. 36, p. 252-265, 1999.

CHAOUI, N. J.; HASLER-GALLUSSER, S. Incomplete sexual supression in Leontopithecus chrysomelas: A behavioral and hormonal study in a semi-natural environment. Folia Primatologica, v. 70, p. 47-54, 1999.

CHARD, T. An introduction to radioimunnoassay techniques. 5. ed. Amsterdam: Elsevier, 1995. $316 \mathrm{p}$.

CHATDARONG, K.; PONGLOWHAPAN, S.; KARLSSON, A.; LINDE-FORSBERG, C. Exogenous ACTH induced progesterone levels in female domestic cats. In: INTERNATIONAL SYMPOSIUM ON CANINE AND FELINE REPRODUCTION, 5., 2004, São Paulo. Anais... Embu das Artes, 2004. p. 182-185.

CHATTERTON, R. T. The Role of Stress in Female Reproduction: Animal and Human Considerations. International Journal of Fertility, v. 35, n. 1, p. 8-13, 1990.

CHELINI, M. O. M.; OLIVEIRA, C. A.; SOUZA, N. L.; ROCHA, A. M. da. Dosagem de metabólitos de estradiol e progesterona em fezes de hamsters sírius (Mesocricetus auratus). Revista de Patologia Tropical, v. 31, p. 26, 2002.

CLARKE, M. R.; CROCKETT, C. M.; ZUCKER, E. L.; ZALDIVAR, M. Mantled howler population of Hacienda La Pacifica, Costa Rica, between 1991 and 1998: effects of deforestation. American Journal of Primatology, v. 56, p. 115-163, 2002. 
CLARKE, M. R.; HARRISON, R. M.; O'NEIL, J. A. S.; ZUCKER, E. L. Reproductive hormones and migration patterns in free-ranging juvenile howling monkeys (Alouatta palliata) in Costa Rica. In: ANNUAL MEETING OF THE AMERICAN SOCIETY OF PRIMATOLOGISTS, 20., 1997. San Diego. American Journal of Primatology, v. 42, n. 2, p. 100-101, 1997.

CLARKE, M. R.; TEAFORD, M. F. Preliminary study on hormone measurement in dried feces of free-ranging howling monkeys (Alouatta palliata) in Costa Rica. In: ANNUAL MEETING OF THE AMERICAN SOCIETY OF PRIMATOLOGISTS, 25. 2002. American Journal of Primatology, v. 57, p. 67. supplement 1.

CLARKE, M. R.; ZUCKER, E. L.; HARRISON, R. M. Fecal estradiol, sexual swelling, and sociosexual behavior of free-ranging female howling monkeys in Costa Rica. In: ANNUAL MEETING OF THE AMERICAN SOCIETY OF PRIMATOLOGISTS, 14. 1991, Veracruz. American Journal of Primatology, v. 24, p. 93, 1991.

CLAVER, J. A.; COLILLAS, O. J.; TRAVI, B. L. Histological and microbiological aspects of the vagina in captive howler monkeys (Alouatta caraya). Primates, v. 25, n. 1, p. 110-116, 1984.

CLAVER, J. A.; VON LAWZEWITSCH, I. Microscopic anatomy of the ovary of Alouatta caraya. Primates, v. 25, n. 3, p. 362-371, 1984.

COLILLAS, O.; COPPO, J. Breeding Alouatta caraya in Centro Argentino de Primates. In: CHIVERS, D. J.; LANE-PETTER, W. Recent Advances in Primatology: Conservation. London: Academic Press, 1978. v. 2, p. 201-214.

CORTÉS-ORTIZ, L.; BERMINGHAM, E.; RICO, C.; RODRÍGUEZ-LUNA, E.; SAMPAIO, I.; RUIZ GARCIA, M. Molecular systemics and biogeography of the Neotropical monkey genus, Alouatta. Molecular Phylogenetics and Evolution, v. 26, p. 64-81, 2003.

CROCKETT, C. M.; EISENBERG, J. F. Howlers: Variation in group size and demography. In: SMUTS, B. B.; CHENEY, D. L.; SEYFARTH, R. M.; WRANGHAM, R. W.; SRUHSAKER, T. T. Primate Societies. Chicago: University of Chicago Press, 1987. p. 54-68.

CROCKETT, C. M.; SEKULIC, R. Gestation length in red howler monkeys. American Jounal of Primatology, v. 3, p. 291-294, 1982. 
CROGSWELL, F. B. Malaria and piroplasms of non-human primates. Companion and Exotic Animal Parasitology. 2003. Disponível em: <http://www.ivis.org>. Acesso em: 30 set. 2003.

CUNNINGHAN, J. G. Ciclos Reprodutivos. In: Tratado de Fisiologia

Veterinária. Rio de Janeiro: Guanabara Koogan, 1993, p. 312-318.

CURTIS, J. D.; ZARAMODY, D. I.; PICKARD, A. R. Non-invasive monitoring of reproductive status in wild mongoose lemurs (Eulemur mongoz). Reproduction, Fertility and Development, v. 12, p. 21-29, 2000.

DEANE, L. M.; NETO, J. A. F. Malária de macacos no Estado de Goiás, Brasil. Encontro de guaribas, Alouatta caraya, infectados com Plasmodium brasilianum. Revista do Instituto de Medicina Tropical de São Paulo, v. 15, n. 3, p. 107-111, 1973.

DEREURE, J.; BARNABÉ, C.; VIÉ, J. C.; MADÉLENAT, F.; RACCURT, G.

Trypanosomatidae from wild mammals in the neotropical rainforest of French Guiana. Annals of Tropical Medicine \& Parasitology, v. 95, n. 2, p. 157-166, 2001.

DETTMER, E. L.; PHILLIPS, K. A.; RAGER, D. R.; BERNSTEIN, I. S.; FRAGASZY, D. M. Behavioral and cortisol responses to repeated capture and venipuncture in Cebus apella. American Journal of Primatology, v. 38, p. 357-362, 1996.

DIAS, E. A. Determinação do sexo de psitacídeos por radioimunoensaio (RIE) de esteróides sexuais e por reação em cadeia pela polimerase (PCR) a partir de excretas cloacais. 2003, 109 f. Dissertação (Mestrado em Reprodução Animal) Faculdade de Medicina Veterinária e Zootecnia, Universidade de São Paulo, São Paulo, 2003.

DOMINGUES, S. F. S.; FERREIRA, H. S.; MUNIZ, J. A. P. C.; LIMA, A. K. F.; OHASHI, O. M.; FIGUEIREDO, J. R.; SILVA, L. D. M. Mechanical isolation of capuchin monkey (Cebus apella) preantral ovarian follicles. Arquivo Brasileiro de Medicina Veterinária e Zootecnia, v. 55, n. 3, 2003. Disponível em: <http://www.scielo.org>. Acesso em: 28 fev. 2005.

ESPINOSA, D. C. Evaluación de la función ovárica en hembras adultas de $\mathbf{A}$. Palliata (mono aullador) en cativerio. 2000. 70 f. Dissertação (Mestrado em Neuroetologia) - Instituto de Neuroetologia, Universidade Veracruzana, Veracruz, 2000. 
ESTRADA, A.; COATES-ESTRADA, R. Frugivory by howling monkeys (Alouatta palliata) at Los Tuxtlas, Mexico: Dispersal and fate of seeds. In: ESTRADA, A.; FLEMING, T. H. Frugivores and Seed Dispersal. Dordrecht: Dr. W. Junk, 1986. p. 93-104.

ESTRADA, A. Primates in agroecosystems: conservation value of some agricultural practices in neotropical landscapes. In: CONGRESSO BRASILEIRO DE PRIMATOLOGIA, 11., 2005, Porto Alegre. Anais..., 2005, p. 34.

FERIN, M. Stress and the reproductive cycle. Journal of Clinical Endocrinology and Metabolism, v. 84, n. 6, p. 1768-1774, 1999.

FERREIRA, S. F. Algumas características hormonais e da citologia vaginal da espécie Aotus infulatus (macaco-da-noite) [Cebidae-Primates], em cativeiro. 1998. 82 f. Dissertação (Mestrado em Ciências Biológicas) - Centro de Ciências Biológicas, Universidade Federal do Pará, Museu Paraense Emílio Goeldi e Empresa Brasileira de Pesquisa Agropecuária, Belém-PA, 1998.

FLESHER, K. Primates of the Chapada das Mangabeiras, Piauí, Brasil: a northern extension to the range of Alouatta caraya. Neotropical Primates, v. 9, n. 1, p. 19-22, 2001.

FOLEY, C. A. H.; PAPAGEORGE, S.; WASSER, S. K. Noninvasive stress and reproductive measures of social and ecological pressures in free-ranging African elephants. Conservation Biology, v. 15, n. 4, p. 1134-1142, 2000.

FORD S. M.; DAVIS, L. C. Systematics and body size: Implications for feeding adaptations in New World monkeys. American Journal of Physical Anthropology, v. 88, n. 4, p. 415-468, 1992.

FUJITA, S.; MITSUNAGA, F.; SUGIURA, H.; SHIMIZU, K. Measurement of urinary and fecal steroid metabolites during the ovarian cycle in captive and wild japanese macaques, Macaca fuscata. American Journal of Primatology, v. 53, p. 167-176, 2001.

FUJITA, S.; SUGIURA, H.; MITSUNAGA, F.; SHIMIZU, K. Hormone profiles and reproductive characteristics in wild female japaneses macaques (Macaca fuscata). American Journal of Primatology, v. 64, p. 367-375, 2004. 
(Humboldt, 1812) pelo T. cruzi. Revista do Instituto de Medicina Tropical de São Paulo, v. 12, n. 4, p. 257-265, 1970.

FURTADO, P. V. Estudo da função ovariana em fêmeas de onça-pintada (Panthera onca LINNAEUS, 1758) mantidas em cativeiro, por meio da extração e quantificação de esteróides fecais. 2003. 83 f. Dissertação (Mestrado em Reprodução Animal) - Faculdade de Medicina Veterinária e Zootecnia, Universidade de São Paulo, São Paulo, 2003.

GARDINER, C. H.; WELLS, S.; GUTTER, A. E.; FTZGERALD, L.; ANDERSON, D. C.; HARRIS, R. K.; NICHOLS, D. K. Eosinophilic meningoencephalitis due to Angiostrongylus cantonensis as the cause of death in captive non-human primates. American Journal of Tropical Medicine and Hygiene, v. 42, n. 1, p. 70-74, 1990.

GERBER, P.; MOISSON, P.; HEISTERMANN, M. Urinary progestogen and estrogen excretion during pregnancy in Eulemur macaco flavifrons, E. rubriventer, and Hapalemur griseus occidentalis. International journal of Primatology, v. 25, n. 2, p. 449-463, 2004.

GLANDER, K. E. Reproduction and population growth in free-ranging mantled howling monkeys. American Journal of Physical Anthropology, v. 53, p. 25-36, 1980.

GOMPEL, C.; KOSS, L. G. Citologia ginecológica e suas bases anatomoclínicas, 1. ed. São Paulo: Manole, 1997. 200 p.

GOODMAN, L.; WISLOCKI, G. B. Cyclical uterine bleeding in a new world monkey (Ateles geoffroy). The Anatomical Record, v. 61, n. 4, p. 379-387, 1935.

GRAHAM, L. H.; BROWN, J. L. Cortisol metabolism in the domestic cat and implications for non-invasive monitoring of adrenocortical function in endangered felids. Zoo Biology, v. 15, p. 71-82, 1996.

GRAHAM, L.; SCHWARZENBERGER, F.; MÖSTL, E.; GALAMA, W.; SAVAGE, A. A Versatile Enzyme Immunoassay for the Determination of Progestogens in Feces and Serum. Zoo Biology, v. 20, p. 227-236, 2001.

GRUNERT, E.; GREGORY, R. M. Causas alimentares de infertilidade. In: Diagnóstico e terapêutica da infertilidade na vaca. 2. ed. Porto Alegre:

Sulina, 1989, 137-143. 
GUEDES, P. G.; BORGES-NOJOSA, D. M.; SILVA, J. A. G.; SALLES, L. O. Novos registros de Alouatta no Estado do Ceará (Primates, Atelidae). Neotropical

Primates, v. 8, n. 1, p. 29-30, 2000.

GUIMARÃES, M. A. B. V. A aplicação de técnicas de reprodução assistida em animais silvestres mantidos em cativeiro. Revista Brasileira de Reprodução Animal, v. 25, n. 2, p. 116-117, 2001a.

GUIMARÃES, M. A. B. V. Ciclo ovariano do macaco-prego (Cebus apella, LINNAEUS, 1758): técnicas de extração e dosagem de progestinas fecais e hormônio luteinizante urinário. 1999. 63 f. Tese (Doutorado em Reprodução Animal) - Faculdade de Medicina Veterinária e Zootecnia, Universidade de São Paulo, São Paulo, 1999.

GUIMARÃES, M. A. B. V. Reproduction. In: FOWLER, M. E.; CUBAS, Z. S. Biology, Medicine and Surgery of South American wild Animals. Iwoa: Iwoa State University Press, 2001b. p. 274-278.

HAFEZ, E. S. E.; HAFEZ, B. Reproductive cycles. In: Reproduction in Farm Animals. 7. ed. Philadelphia: Lippincutt Williams \& Wilkins, 2000. p. 55-67.

HAMLETT, G. W. D. Reproduction in American Monkeys. The Anatomical Record, v. 73, p. 171-187, 1939.

HEARN, J. P. Physiological aids in the conservation of primates. In: ELSE, J. G.; LEE, P. C. (Eds) Primate Ecology and Conservation. Cambridge: Cambridge University Press, 1986, v. 2, p. 383-387.

HEISTERMANN, M.; MÖHLE, U.; VERVÄCKE, H.; VAN ELSACKER, L.; HODGES, J. K. Application of urinary and fecal steroid measurements for monitoring ovarian function and pregnancy in bonobo (Pan paniscus) and evaluation of perineal swelling patterns in relation to endocrine events. Biology of Reproduction, v. 55, p. 844-853, 1996.

HEISTERMANN, S.; TARI, S.; HODGES, J. K. Measurement of faecal steroids for monitoring ovarian function in New World primates, Callitrichidae. Journal of Reproduction and Fertility, v. 99, p. 243-251, 1993.

HEISTERMANN, M.; UHRIGSHARDT, J.; HUSUNG, A.; KAUMANNS, W.; HODGES, J. K. Measurement of faecal steroid metabolites in the lion-tailed macaque (Macaca 
silenus): a non-invasive tool for assessing female ovarian function. Primate Report, v. 59 , p. $27-42,2001$.

HERNÁNDEZ-LÓPEZ, L.; MAYAGOITIA, L.; ESQUIVEL-LACROIX, C.; ROJASMAYA, S.; MONDRAGÓN-CEBALLOS, R. The menstrual cycle of the spider monkey (Ateles geoffroy). American Journal of Primatology, v. 44, p. 183-195, 1998.

HERRICK, J. R.; AGORAMOORTHY, R. R. G.; HARDER, J. D. Urinary progesterone in free-ranging red howler monkeys (Alouatta seniculus). Preliminary observations of the estrous cycle and gestation. American Journal of Primatology, v. 51, n. 4, p. 257-263, 2000.

HERVÉ, J.; DÉGALLIER, N.; ROSA, A. P. A. T.; SÁ FILHO, G. C. A febre amarela silvestre no Brasil e os riscos de propagação urbana. Hiléia Médica, v. 7, n. 1, p. 31- 40, 1985.

HILEMAN, S. M.; PIERROZ, D. M.; FLIER, J. S. Leptin, Nutrition, and Reproduction: Timing is Everything. The Journal of Clinical Endocrinology \& Metabolism, v. 85, n. 2 , p. $804-807,2000$.

HILTON-TAYLOR, C.; RYLANDS, A. B. The 2002 IUCN Red List of threatened species. Neotropical Primates, v. 10, n. 3, p. 149-153, 2002.

HODGES, J. K. The ovarian cycle and control of ovulation. Journal of Zoology, v. 213, p. 383-393, 1987.

HORWICK, R. H. Breeding Behavior in the Black Howler Monkey (Alouatta pigra) of Belize. Primates, v. 24, n. 2, p. 222-230, 1983.

IBAMA [Instituto Nacional do Meio Ambiente e dos Recursos Naturais não Renováveis]. Lista oficial da fauna silvestre brasileira ameaçada de extinção, 2003. Disponível em: <http://www.mma.gov.br/port/sbf/fauna/index.cfm>. Acesso em: 17 set. 2003.

IUCN [International Union for Conservation of Nature]. The red list of threatened species, 2001. Disponível em: <http://www.iucn.org>. Acesso em: 01 mar. 2005.

JONES, C. B. Social organization of captive black howler monkeys (Alouatta caraya): "Social competition" and the use of non-damaging behavior. Primates, v. 24, n. 1, p. 25-39, 1983. 
JONES, C. B. Reproductive patterns in mantled howler monkeys: estrus, mate choice and copulation. Primates, v. 26, n. 2, p. 130-142, 1985.

JONES, C. B. The function of status in the mantled howler monkey, Alouatta palliata, Gray: intraespecific competition for group membership in a folivorous Neotropical Primate. Primates, v. 21, p. 389-405, 1980.

KOWALEWSKY, M. M.; PEKER, S. M.; ZUNINO, G. E. Promiscuous howlers: Extragroup copulation in female Alouatta caraya in northern Argentina. In: CONGRESSO BRASILEIRO DE PRIMATOLOGIA, 11., 2005, Porto Alegre. Anais... 2005. p. 116.

KOWALEWSKY, M. M.; ZUNINO, G. E. Birth seasonality in Alouatta caraya in northern Argentina. International Journal of Primatology, v. 25, p. 383-400, 2004.

KOWALEWSKY, M. M.; ZUNINO, G. E. Impact of Deforestation on a Population of Alouatta caraya in Northern Argentina. Folia Primatologica, v. 70, p. 163-166, 1999.

KYNZEY, W. G. Alouatta. In: New World Primates: Ecology, Evolution and Behavior. New York: Aldine de Gruyter, 1997. p. 174-185.

LABRUNA, M. B.; De PAULA, C. D.; LIMA, T. F.; SANA, D. A. Ticks (Acari: ixodidae) on wild animals from the Porto-Primavera Hydroelectric Power Station Area, Brazil. Memórias do Instituto Oswaldo Cruz, v. 97, n. 8, p. 1133-1136, 2002.

LANG, C. M. The estrous cycle of non-human primates: a review of the literature. Laboratory Animal Care, v. 17, n. 2, p. 172-179, 1967.

LIVRO Vermelho da Fauna Ameaçada de Extinção no Estado do Paraná. 2004. Disponível em: <http://www.gb2.com.br/livro/index.asp>. Acesso em: 13 jun. 2004.

LÖTTKER, P.; HUCK, M.; HEYMANN, E. W.; HEISTERMANN, M. Endocrine correlates of reproductive status in breeding and non-breeding wild female moustached tamarins. International Journal of Primatology, v. 25, n. 4, p. 919937, 2004.

LUIZ, T. G.; OLIVEIRA, C. A. Concentrações de esteróides fecais de fêmeas de cutia (Dasyprocta aguti) durante o ciclo reprodutivo. In: SIMPÓSIO INTERNACIONAL DE INICIAÇÃO CIENTÍFICA DA USP, 11., 2003, Piracicaba. Anais... São Paulo: USP, 2003. v.1,2. 
LYNCH, J. W.; KHAN, J. A.; ALTMANN, J.; NJAHIRA, M. N.; RUBENSTEIN, N. Concentrations of four fecal steroids in wild baboons: short-term storage conditions and consequences for data interpretation. General and Comparative

Endocrinology, v. 132, p. 264-271, 2003.

LYNCH, J. W.; ZIEGLER, T. E.; STRIER, K. B. Individual and seasonal variation in fecal testosterone and cortisol levels of wild male tufted capuchin monkeys, Cebus apella nigritus. Hormones and Behavior, v. 41, p. 275-287, 2002.

MÁRQUEZ-MONTER, H.; FUENTES-OROZCO, R.; CORREA-LEMUS, I.; BECKER, I. Invasive amebiasis in a spider monkey (Ateles geoffroyi). Case report and a short review of the literature of amebiasis in non-human primates. Archivo de Investigación Médica (México), v. 22, n. 1, p. 75-78, 1991.

MARSHALL, A. J.; HOHMANN, G. Urinary testosterone levels of wild male bonobos (Pan paniscus) in the Lomako Forest, Democratic Republic of Congo. American Journal of Primatology, v. 65, p. 87-92, 2005.

MATSUMURO, M.; SANKAI, T.; CHO, F.; YOSHIKAWA, Y.; YOSHIDA, T. A two-step extraction method to measure fecal steriod hormones in female cynomolgus monkeys (Macaca fascicularis). American Journal of Primatology, v. 48, p. 291298, 1999.

MEIRELES, C. M.; CZELUSNIAK, J.; FERRARI, S. F.; SCHNEIDER, M. P. C.; GOODMAN, M. Phylogenetic relationships among Brazilian howler monkeys, genus Alouatta (Platyrrhini, Atelidae), based on $\gamma^{1}$-globin pseudogene sequences. Genetics and Molecular Biology, v. 22, n. 3, 1999. Disponível em: <http://www.scielo.br>. Acesso em: 12 out. 2003.

McNEILY, A. S. Suckling and the control of gonadotropin secretion. In: KNOBILL, E.; NEILL, J. D. The Physiology of Reproduction. 2. ed. New York: Raven Press, 1994. v. 2, p. 1179-1212.

MILTON, K. Diet and primate evolution. Scientific American, v. 269, n. 2, p. 70-77, 1993.

MILTON, K. Foraging behaviour and the evolution of primate intelligence. In: BYRNE, R. W; WHITEN, A. Machiavellian Intelligence. Oxford: Clarendon Press, 1988. p. 285-305. 
MILTON, K. The foraging strategy of Howler Monkeys. New York: Columbia University Press, 1980. 165 p.

MITTERMEIER, R. A. A global overview of primate conservation. In: ELSE, J. G.; LEE, P. C. Primate Ecology and Conservation. Cambridge: Cambridge University Press, 1986. v. 2, p. 325-340.

MITTERMEIER, R. A. Introduction. In: ROWE, N. The Pictorial Guide to the Living Primates. New York: Pogonias Press, 1996. p 1.

MONTEIRO, F. O. B. Avaliação uterina e diagnóstico de gestação em macacoda-noite (Aotus azarae infulatus) por ultra-som em modo B. 2004. $70 \mathrm{f}$.

Dissertação (Mestrado em Medicina Veterinária), Faculdade de Ciências Agrárias e Veterinárias, Universidade Estadual Paulista, 2004.

MOORMAN, E. A.; MENDONZA, S. P.; SHIDELER, S. E.; LASLEY, B. L. Excretion and Measurement of Estradiol and Progesterone Metabolites in the Feces and Urine of Female Squirrel Monkeys (Saimiri sciureus). American Journal of Primatology, v. 57, p. 79-90, 2002.

MORATO, R. G. Reprodução assistida como ferramenta auxiliar no manejo e conservação da onça-pintada (Panthera onca, LINNAEUS, 1758). São Paulo, 2001. $127 \mathrm{f}$. Tese (Doutorado em Medicina Veterinária), Faculdade de Medicina Veterinária e Zootecnia da Universidade de São Paulo, São Paulo, 2001.

MORELAND, R. B.; RICHARDSON, M. E.; LAMBERSKI, N.; LONG, J. A. Characterizing the reproductive physiology of the male southern black howler monkey, Alouatta caraya. Journal of Andrology, v. 22, n. 3, p. 395-403, 2001.

MYIAMOTO, S.; CHEN, Y.; KUROTORI, H.; YOSHIDA, T. SANKAI, T.; MACHIDA, T. Monitoring the reproductive status of female gorillas (Gorilla gorilla gorilla) by measuring the steroid hormones in fecal samples. Primates, v. 42, n. 4, p. 291-299, 2001.

NADLER, R. D. Primate menstrual cycle. Atlanta: Yerkes Regional Primate Center, Emory University, 2000. Disponível em:

<http://www.primate.wisc.edu/pin/menstrual.html>. Acesso em: 28 jan. 2003.

NAGLE, C. A.; DENARI, J. H. The Cebus Monkey (Cebus apella). In: HEARN, J. Reproduction in new world monkeys: new models in medical sciences. Lancaster: MTP Press Limited, 1983. p. 39-67. 
NASCIMENTO, C. C. Avaliação da função reprodutiva de fêmeas de peixe-boi da Amazônia (Trichechus inunguis, NATTERER, 1883), mantidas em cativeiro, por meio de extração e dosagem de esteróides fecais. 2004. 113 f. Dissertação (Mestrado em Reprodução Animal) - Faculdade de Medicina Veterinária e Zootecnia, Universidade de São Paulo, São Paulo, 2004.

NEVILLE, M. K.; GLANDER, K. E.; BRAZA, F.; RYLANDS, A. B. The howling monkeys, Genus Alouatta. In: MITTERMEIER, R. A.; RYLANDS, A. B.; COIMBRAFILHO, A.; FONSECA, G. A. B. Ecology and Behavior of Neotropical primates. Washington, D.C.: World Wildlife Fund, 1988. v. 2, 609 p.

OLIVEIRA, D. A. G. Vocalizações de longo alcance do bugio (Alouatta fusca clamitans) na área do Parque Estadual da Cantareira (São Paulo, SP). 1997. 94 f. Dissertação (Mestrado em Psicologia) - Instituto de Psicologia, Universidade de São Paulo, São Paulo, 1997.

OLIVEIRA, D. A. G. Vocalizações de longo alcance de Alouatta fusca clamitans e Alouatta belzebul belzebul: Estrutura e Contextos. 2002. 155 f. Tese (Doutorado em Psicologia) - Instituto de Psicologia, Universidade de São Paulo, São Paulo, 2002.

OSTNER, J.; HEISTERMANN, M. endocrine characterization of female reproductive status in wild redfronted lemurs (Eulemur fulvus rufus). General and Comparative Endocrinology, v. 131, p. 274-283, 2003.

PATTON, M. L.; SWAISGOOD, R. R.; CZEKALA, N. M.; WHITE, A. M.; FETTER, G. A.; MONTAGNE, J. P.; RIECHES, R. G.; LANCE, V. A. Reproductive cycle length and pregnancy in the southern white rhinoceros (Ceratotherium simum simum) as determined by fecal pregnane analysis and observations of mating behavior. Zoo Biology, v. 18, p. 111-127, 1999.

PAUL, A. Breeding seasonality affects the association between dominance and reproductive success in non-human male primates. Folia Primatologica, v. 68, p. 344-349, 1997.

PLANT, T. M. Puberty in Primates. In: KNOBILL, E.; NEILL, J. D. The Physiology of Reproduction. 2. ed. New York: Raven Press, Ltda, 1994. v. 2, p. 453-485.

PRYCE, C. R.; SCHWARZENBERGER, F.; DÖBELI, M. Monitoring fecal samples for estrogen excretion across the ovarian cycle in Goeldi's monkey (Callimico goeldi).

Zoo Biology, v. 13, p. 219-230, 1994. 
PRYCE, C. R.; SCHWARZENBERGER, F.; DÖBELI, M.; ETTER, K. Comparative study of oestrogen excretion in female New World monkeys: an overview of noninvasive ovarian monitoring and a new application in evolutionary biology. Folia Primatologica, v. 64, p. 107-123, 1995.

PUSEY, A. E. E.; PACKER, C. Dispersal and philopatry. In: SMUTS, B. B.; CHENEY, D. L.; SEYFARTH, R. M.; WRANGHAM, R. W.; STRUHSAKER, T. T Primate Societes. Chicago: University of Chicago Press, 1987. p. 250-266.

QUEIROZ, H. L. Preguiças e guaribas: os mamíferos folívoros arborícolas do Mamirauá. Brasília: CNPq. 1995. 176 p.

RAMINELLI, J. L. F.; SOUSA, M. B. C. de; CUNHA, M. S.; BARBOSA, F. V. Morning and afternoon patterns of fecal cortisol excretion among reproductive and nonreproductive male and female common marmosets, Callithrix jacchus. Biological Rhythm Research, v. 32, n. 2, p. 159-167, 2001.

RECABARREN, M. P.; VERGARA, M.; MARTÍNEZ, M. C.; GORDON, K.; SERÓNFERRÉ, M. Impact of lactation upon fertility in the New World primate capuchin monkey (Cebus apella). Journal of Medical Primatology, v. 29, p. 350-360, 2000.

RIBEIRO, E. A. A. Uma análise da relação entre o comportamento reprodutivo e os níveis de progestinas fecais em um grupo silvestre do mico-leão-dourado, Leotopithecus rosalia. 1994. 175 f. Tese (Doutorado em Ciências Biológicas) Instituto de Biociências, Universidade de São Paulo, São Paulo, 1994.

ROBINSON, J. A.; GOY, R. W. Steroid hormones and the ovarian cycle.. In: Comparative Primate Biology: Reproduction and Development. [S.I.]: Alan R. Liss, Inc, 1986. v. 3, p. 63-91.

RODHAIN, F. The role of monkeys in the biology of dengue and yellow fever. Comparative Immunology and Microbiology in infectious Diseases, v. 14, n. 1 , p. 9-19, 1991.

RODRIGUES, F. H. G.; MARINHO-FILHO, J. Feeding on a marsh-living herbaceous plant by black howler monkeys (Alouatta caraya) in Central Brazil. Folia Primatologica, v. 65. v. 2, p. 115-117, 1996.

ROWE, N. The Pictorial Guide to the Living Primates. New York: Pogonias Press, 1996. 263 p. 
RYLANDS, A. B. Two taxonomies of the new world primates - A comparison of Rylands et al. (2000) and Groves (2001). Neotropical Primates, v. 3, n. 4, p. 173174, 2001.

RYLANDS, A. B.; SCHENEIDER, H.; LANGGUTH, A.; MITTERMEIER, R. A.; GROVES, C. P.; RODRIGUEZ-LUNA, E. An assessment of the diversity of New World primates. Neotropical Primates, v. 8, n. 2, p. 61-93, 2000.

SANTINI, M. E. L. Padrões de atividade diária de Alouatta caraya (Primates, Cebidae), reintroduzido no Parque Nacional de Brasília. In: A PRIMATOLOGIA NO BRASIL-2; CONGRESSO DA SOCIEDADE BRASILEIRA DE PRIMATOLOGIA, 2., 1985, Campinas. Anais... Brasília : Sociedade Brasileira de Primatologia, 1986 p. 293-304.

SAVAGE, A.; LASLEY, B. L.; VECCHIO, A. J.; MILLER, A. E.; SHIDELER, S. E. Selected aspects of female white-faced saki (Pithecia pithecia) reproductive biology in captivity. Zoo Biology, v. 14, p. 441-452, 1995.

SCHNEIDER, $\mathrm{H}$. The current status of the New World monkey phylogeny. Anais da Academia Brasileira de Ciências, v. 72, n. 2, 2000. Disponível em <http://www.scielo.br>. Acesso em: 12 out. 2003.

SCHOU, S.; HOLMSTRUP, P.; KORNMAN, K. S. Non-human primates used in studies of periodontal disease pathogenesis: a review of the literature. Journal of Periodontology, v. 64, n. 6, p. 497-508, 1993.

SEYMOUR, C.; PERALTA, P. H.; MONTGOMERY, G. G. Serologic evidence of natural togavirus infections in Panamanian sloths and other vertebrates. American Journal of Tropical Medicine and Hygiene, v. 32, n. 4, p. 854-861, 1983.

SHIDELER, S. E.; ORTUÑN, A. M.; MORÁN, F. M.; MOORMAN, E. A.; LASLEY, B. $\mathrm{L}$. Simple extraction and enzyme immunoassays for estrogen and progesterone metabolites in the feces of Macaca fascicularis during non-conceptive and conceptive ovarian cycles. Biology of Reproduction, v. 48, p. 1290-1298, 1993.

SHIDELER, S. E.; SAVAGE, A.; ORTUÑO, A. M.; MOORMAN, E. A.; LASLEY, B. L. Monitoring female reproductive function by measurement of fecal estrogen and progesterone metabolites in the white-faced saki (Pithecia pithecia). American Journal of Primatology, v. 32, p. 95-108, 1994. 
SHOEMAKER, A. H. F. Fecundity in the captive howler monkey (Alouatta caraya). Zoo Biology, v. 1, n. 2, p. 149-156, 1982.

SMITH, T. E.; McGREER-WHITWORTH, B.; FRENCH, J. A. Close proximity of the heterosexual partner reduces the physiological and behavioral consequences of novel-cage housing in black tufted-ear marmosets (Callithrix kuhli). Hormones and Behavior, v. 34, p. 211-222, 1998.

SOUSA, M. R. C.; ZIEGLER, T. E. Diurnal variation on the excretion patterns of fecal steroids in common marmoset (Callithrix jacchus) females. American Journal of Primatology, v. 46, p. 105-117, 1998.

STEELE, J. Hominid evolution and primate social cognition. Journal of Human Evolution, v. 18, p. 421-432,1989.

STRIER, K. B.; MENDES, S. L.; SANTOS, R. R. Timing of births in sympatric brown howler monkeys (Alouatta fusca clamitans) and northern muriquis (Brachyteles arachnoides hypoxanthus). American Journal of Primatology, v. 55, p. 87-100, 2001.

STRIER, K. B; ZIEGLER, T. E. Behavioral and endocrine characteristics of the reproductive cycle in wild muriqui monkeys, Brachyteles arachnoides. American Journal of Primatology, v. 42, n. 4, p. 299-310, 1997.

STRIER, K. B.; ZIEGLER, T. E. Insights into ovarian function in wild muriqui monkeys (Brachyteles arachnoides). American Journal of Primatology, v. 32, p. 31-40, 1994.

STRIER, K. B.; ZIEGLER, T. E.; WITTWER, D. J. Seasonal and social correlates of fecal testosterone and cortisol levels in wild male muriquis (Brachyteles arachnoides). Hormones and Behavior, v. 35, p. 125-134. 1999.

TALARMIN, A.; CHANDLER, L. J.; KAZANJI, M.; THOISY, B.; DEBON, P.; LELARGE, J.; LABEAU, B.; BOURREAU, E.; VIÉ, J. C.; SHOPE, R. E.; SARTHOU, $\mathrm{J}$. Mayaro virus fever in French Guiana: isolation, identification, and seroprevalence. American Journal of Tropical Medicine and Hygiene, v. 59, n. 3, p. 452-456, 1998.

TERBORGH, J. Conserving New World primates: present problems and future solutions. In: ELSE, J. G.; LEE, P. C. Primate Ecology and Conservation. Cambridge: Cambridge University Press, 1986. v. 2, p. 355-365. 
THORINGTON JR., R. W.; RUIZ, J. C.; EISENBERG, J. F. A study of a black howling monkey (Alouatta caraya) population in northern Argentina. American Journal of Primatology, v. 6, p. 357-366, 1984.

TOMORI, O. Impact of yellow fever on the developing world. Advances in Virus Research, v. 53, p. 5-33, 1999.

TORRES, M. A. N. Febre amarela silvestre reemergiu no Rio Grande do Sul. A Hora Veterinária, v. 22, n. 127, p. 56-57, 2002.

TREVES, A. Reproductive consequences of variation in the composition of howler monkey (Alouatta spp.) groups. Behavioral Ecology and Sociobiology, v. 50, p. 61-71, 2001.

VALEGGIA, C. R.; MENDONZA, S. P.; FERNANDEZ-DUQUE, E.; MASON, W. A.; LASLEY, B. Reproductive biology of female titi monkeys (Callicebus moloch) in captivity. American Journal of Primatology, v. 47, p. 183-195, 1999.

VALLE, R. R. Características físicas e morfológicas do sêmen de Alouatta caraya (HUMBOLDT, 1812) mantidos em cativeiro. 2002. 66 f. Dissertação (Mestrado em Reprodução Animal) - Faculdade de medicina Veterinária e Zootecnia, Universidade de São Paulo, São Paulo, 2002.

VALSECCHI, R. M.; DEGROSSI, O. J.; ALTSCHULER. Thyroid studies in the New World Primate Alouatta caraya. International Journal of Nuclear Medicine and Biology, v. 7, p. 43-45, 1980.

VASCONCELOS, P. F. C. Febre Amarela. Revista da Sociedade Brasileira de Medicina Tropical, v. 36, n. 2, p. 1-29, 2003.

VERAS, M. M. Aspectos morfológicos do aparelho reprodutor em bugios (Alouatta guariba clamitans e Alouatta caraya): o modelo feminino. 2004. $113 \mathrm{f}$. Dissertação (Mestrado em Anatomia dos Animais Domésticos e Silvestres) Faculdade de Medicina Veterinária e Zootecnia, Universidade de São Paulo, São Paulo, 2004.

VIEIRA, P. F. Apresentação. In: LEFF, H. Epistemologia Ambiental. São Paulo: Cortez, 2002. p. 9-15. 
VON HOHENDORFF, R. Aplicação e avaliação de enriquecimento ambiental na manutenção de bugio (Alouatta spp, LACÉPEDE, 1799) no Parque Zoológico de Sapucaia do Sul - RS. 2003. 118 f. Dissertação (Mestrado em Ciências Veterinárias) - Faculdade de Medicina Veterinária, Universidade Federal do Rio Grande do Sul, Porto Alegre, 2003.

WASSER, S. K.; MONFORT, S. L.; SOUTHERS, J.; WILDT, D. E. Excretion rates and metabolites of estradiol and progesterone in baboons (Papio cynocephalus cynocephalus) faeces. Journal of Reproduction and Fertility, v. 101, p. 213-220, 1994.

WASSER, S. K.; MONFORT, S. L.; WILDT, D. E. Rapid extraction steroids for measuring reproductive cyclicity and early pregnancy in free-ranging yellow baboons (Papio cynocephalus cynocephalus). Journal of Reproduction and Fertility, v. 92, p. 415-423, 1991.

WHITTEN, P. L.; STAVISKY, R.; AURELI, F.; RUSSELL, E. Response of fecal cortisol to stress in captive chimpanzees (Pan troglodytes). American Journal of Primatology, v. 44, p. 57-69, 1998.

WIRTHLIN, M. R. Natural and experimental periodontal diseases in non-human primates. Periodontal Abstracts, v. 39, n. 4, p. 89-107, 1991.

XIAO, E.; XIA-ZHANG, L.; BARTH, A.; ZHU, J.; FERIN, M. Stress and the menstrual cycle: relevance of cycle quality in the short- and long-term response to a 5-day endotoxin challenge during the follicular phase in the rhesus monkey. Journal of Clinical Endocrinology and Metabolism, v. 83, n. 7, p. 2454-2460, 1998.

XIAO, E.; XIA-ZHANG, L.; FERIN, M. Stress and the menstrual cycle: short- and long-term response to a five-day endotoxin challenge during the luteal phase in the rhesus monkey. Journal of Clinical Endocrinology and Metabolism, v. 84, n. 2, p. 623-626, 1999.

ZELESNIK, A. J. Dynamics of primate follicular growth - A physiologic perspective. In: ADASHI, E. Y.; LEUNG, P. C. K. The Ovary. New York: Raven Press, 1993. p. 41-55.

ZICCARDI, M.; OLIVEIRA, R. L.; LAINSON, R.; BRÍGIDO, M. C. O.; MUNIZ, J. A. P. C. Trypanosomes of non-human primates from the National Center of Primates, Ananindeua, state of Pará, Brazil. Memórias do Instituto Oswaldo Cruz, v. 95, n. 2, p. 157-159, 2000. 
ZIEGLER, T. E.; HODGES, K.; WINKLER, P.; HEISTERMANN, M. Hormonal correlates of reproductive seasonality in wild female hanuman langurs (Presbytis entellus). American Journal of Primatology, v. 51, p. 119-134, 2000.

ZIEGLER, T. E.; SANTOS, C. V.; PISSINATTI, A.; STRIER, K. B. Steroid extraction during the ovarian cycle in captive and wild muriquis, Brachyteles arachnoids. American Journal of Primatology, v. 42, p. 311-321, 1997.

ZIEGLER, T. E.; SCHEFFER, G.; WITTWER, D. J.; SCHULTZ-DARKEN, N.; SNOWDON, C. T.; ABBOTT, D. H. Metabolism of reproductive steroids during the ovarian cycle in two species of Callithrichids, Saguinus oedipus and Callithrix jacchus, and estimation of the ovulatory period from fecal steroids. Biology of Reproduction, v. 54, p. 91-99, 1996.

ZIEGLER, T. E.; SHOLL, S. A.; SCHEFFLER, G.; HAGGERTY, M. A.; LASLEY, B. L. Excretion of estrone, estradiol, and progesterone in the urine and feces of the female cotton-top tamarin (Saguinus oedipus oedipus). American Journal of Primatology, v. 17, p. 185-195, 1989.

ZUCKER, E. L.; CLARKE, M. R.; HARISSON, R. M. Fecal estradiol values for groupliving cycling, pregnant, and lactating female howling monkeys (Alouatta palliata) in Costa Rica. In: ANNUAL MEETING OF THE AMERICAN SOCIETY OF PRIMATOLOGISTS, 18., 1995, Scottsdale. American journal of Primatology, v. 36, n. 2, p. 167, 1995.

ZUCKER, E. L.; CLARKE, M. R.; O’NEIL, J. A. S.; HARISSON, R. M. Fecal testosterone values for free-ranging male mantled howling monkeys (Alouatta palliata) in Costa Rica. In: ISPIASP JOINT CONGRESS, 1996, Madison. Anais... 1996. p. 12.

ZUCKER, E. L.; CLARKE, M. R.; PUTNAN, P. M.; HARISSON, R. M. Validity of measures assessing reproductive status of female howling monkeys (Alouatta palliata) in Costa Rica. In: ANNUAL MEETING OF THE AMERICAN SOCIETY OF PRIMATOLOGISTS, 17., 1994, Seattle. American Journal of Primatology, v. 33, n. 3, p. 225, 1994. 
ar 2

Anexos e Apêndices 
ANEXO A - Mapa de distribuição das espécies do gênero Alouatta.

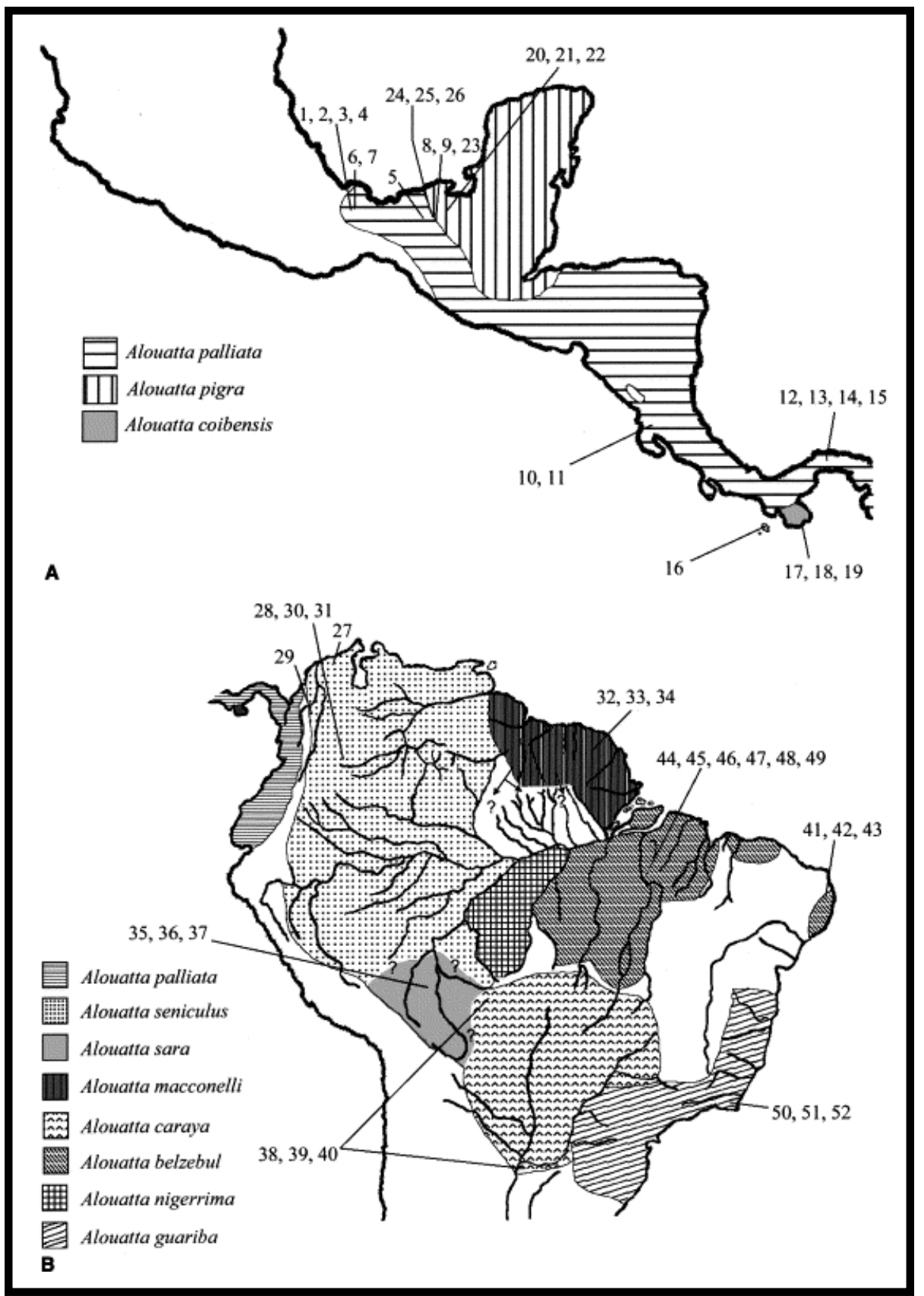

Figura 24 - Espécies do gênero Alouatta mesoamericanas (A) e sulamericanas (B), de acordo com Groves (2001). Fonte: Cortés-Ortiz et al. (2003) 
ANEXO B - Percentual de reações cruzadas dos conjuntos diagnósticos da DPC ${ }^{\circledR}$ MedLab para a dosagem de estradiol e progesterona.

Tabela 9 - Percentual de reações cruzadas dos conjuntos diagnósticos comerciais da DPC ${ }^{\circledR}$ MedLab para dosagem de estradiol por radioimunoensaio, em fase sólida. Fornecido pelo fabricante

\section{Composto}

$\alpha$-Equilenina

Equilina

$17 \alpha$-Estradiol

$17 \beta$-Estradiol-3-monosulfato

$\beta$-Estradiol 17-proprionato

Estriol

Estriol-3-Glucoronido

Estriol-3-sulfato

Estriol-16 $\alpha$-glucoronido

Estrona

Estrona- $\beta$-D-glucoronido

Estrona-3-sulfato

DHEA

Ethinyl Estradiol

11-Ketotestosterona

$5 \alpha$-Dihydrotestosterona

Testosterona

19-Hydroxyandrostenediona

Outros
Reações cruzadas

$4,4 \%$

$0,80 \%$

$0,017 \%$

$0,29 \%$

$0,70 \%$

$0,32 \%$

$0,012 \%$

$0,002 \%$

$0,001 \%$

$10,0 \%$

$1,8 \%$

$0,58 \%$

$0,001 \%$

$1,8 \%$

$0,006 \%$

$0,004 \%$

0,001\%

$0,006 \%$

$1,08 \%$ 
Tabela 10 - Percentual de reações cruzadas dos conjuntos diagnósticos comerciais da DPC ${ }^{\circledR}$ MedLab para dosagem de progesterona por radioimunoensaio, em fase sólida. Fornecido pelo fabricante

\section{Composto}

Progesterona

Corticosterona

Cortisol

Danazol

11-Deoxycorticosterona

11-Deoxycortisol

DHEA-SO 4

$20 \alpha$-Dihydroprogesterona

$17 \alpha$-Hydroxyporgesterona

Medroxyprogesterona

$5 \beta$-Pregnan-3 $\alpha$-ol-20-one

$5 \alpha$-Pregnan-3,20-dione

$5 \beta$-Pregnan-3,20-dione

Pregnenolona

5Pregnen-3 $\beta$-ol-20-one-sulfato

Testosterona

\section{Reações cruzadas}

$100 \%$

$0,9 \%$

$0,03 \%$

$0,006 \%$

$2,2 \%$

$0,01 \%$

$0,002 \%$

$0,2 \%$

$3,4 \%$

$0,3 \%$

$0,05 \%$

$9,0 \%$

$3,2 \%$

$0,1 \%$

$0,05 \%$

$0,1 \%$ 
APÊNDICE A - Resultados da avaliação clínica e reprodutiva dos animais participantes do estudo e medicação administrada.

Para a realização dos exames os animais foram sedados com uma associação de levomepromazina (Neozine ${ }^{\circledR} 25 \mathrm{mg}$ em $\left.5 \mathrm{ml}\right): 0,2$ a 0,4mg/kg $(0,04$ a $0,08 \mathrm{ml} / \mathrm{kg}$ ); midazolan (Dormium ${ }^{\circledR} 15 \mathrm{mg}$ em 3ml) - 0,2 a $0,4 \mathrm{mg} / \mathrm{kg} \quad(0,04$ a $0,08 \mathrm{ml} / \mathrm{kg}$ ); cetamina (Vetanarcol $\left.{ }^{\circledR} 50 \mathrm{mg} / \mathrm{ml}\right): 10$ a $15 \mathrm{mg} / \mathrm{kg}(0,2$ a $0,3 \mathrm{ml} / \mathrm{kg})$, tudo na mesma seringa, administrados via intramuscular.

Os principais resultados dos exames laboratoriais são apresentados no quadro 2.

\begin{tabular}{|c|c|c|c|c|c|}
\hline Animal & $\begin{array}{l}\text { Peso } \\
(\mathrm{Kg})\end{array}$ & $\begin{array}{l}\text { Hemo- } \\
\text { grama }\end{array}$ & $\begin{array}{l}\text { Leuco- } \\
\text { grama }\end{array}$ & $\begin{array}{l}\text { Bioquímica } \\
\text { sérica }\end{array}$ & Coproparasitológico \\
\hline $\begin{array}{l}\text { BF-ABH } \\
\text { (fêmea 1) }\end{array}$ & 4,70 & & $\begin{array}{l}\text { eosinofilia e } \\
\text { monocitose }\end{array}$ & $\begin{array}{l}\text { ALT e creatinina } \\
\text { diminuídos }\end{array}$ & proglotes de cestódeo \\
\hline $\begin{array}{l}\text { BF-ACJ } \\
\text { (fêmea 2) }\end{array}$ & 6,00 & $\begin{array}{l}\text { discreta } \\
\text { anemia }\end{array}$ & $\begin{array}{l}\text { eosinofilia e } \\
\text { monocitose }\end{array}$ & $\begin{array}{l}\text { AST e creatinina } \\
\text { diminuídas }\end{array}$ & Giardia sp (+) \\
\hline $\begin{array}{l}\text { BF-AFR } \\
\text { (fêmea 3) }\end{array}$ & 5,20 & & $\begin{array}{l}\text { eosinofilia e } \\
\text { monocitose }\end{array}$ & AST diminuída & $\begin{array}{l}\text { Entamoeba sp, Shilomastix } \\
\text { sp e cogumelos. }\end{array}$ \\
\hline $\begin{array}{l}\text { BF-AFX } \\
\text { (fêmea 4) }\end{array}$ & 3,00 & anemia & $\begin{array}{l}\text { eosinofilia e } \\
\text { monocitose }\end{array}$ & $\begin{array}{l}\text { creatinina } \\
\text { dimunída }\end{array}$ & $\begin{array}{l}\text { Giardia sp e cogumelos em } \\
\text { brotamento }\end{array}$ \\
\hline $\begin{array}{l}\text { BF-AGH } \\
\text { (fêmea 5) }\end{array}$ & 4,60 & anemia & & $\begin{array}{l}\text { AST e creatinina } \\
\text { diminuídas }\end{array}$ & $\begin{array}{l}\text { Bertiella studeri e cogumelos } \\
\text { em brotamento }\end{array}$ \\
\hline
\end{tabular}

Quadro 2 - Peso corporal e resultados dos exames hemograma, leucograma, bioquímica sérica e coproparasitológico realizados nas fêmeas de bugio (Alouatta caraya). São Paulo, 2005

Baseado nos exames coproparasitológicos os animais receberam, em setembro de 2003, albendazol (Albendazol $4 \%{ }^{\circledR}$ ), VO, nas doses de $7 \mathrm{~mL}$ para os machos, $5 \mathrm{~mL}$ para as fêmeas e $3 \mathrm{~mL}$ para as crias. Em outubro repetiu-se o 
tratamento com albendazol, nas mesmas doses. No mesmo mês os animais receberam secnidazol (Secni-plus ${ }^{\circledR}$ suspensão, $30 \mathrm{mg} / \mathrm{ml}$ ), VO, nas doses de $10 \mathrm{~mL}$ para os machos, $5 \mathrm{~mL}$ para as fêmeas e $3 \mathrm{~mL}$ para as crias, indicado para giardíase. Em março de 2004 realizou-se nova desverminação com uma associação de pamoato de pirantel, pamoato de oxantel e praziquantel (Basken ${ }^{\circledR}$ plus 20, comprimidos), VO, na dose de 2 comprimidos para os machos e 1 comprimido para as fêmeas e crias.

Os resultados dos exames ultra-sonográficos e colpocitológicos estão resumidos no quadro 3 .

\begin{tabular}{|c|c|c|c|}
\hline \multirow[t]{2}{*}{ Tatuagem } & \multicolumn{2}{|c|}{ Ultra-som } & \multirow[t]{2}{*}{ Colpocitologia } \\
\hline & $\begin{array}{l}\text { Volume } \\
\text { uterino }\end{array}$ & Aspecto do útero & \\
\hline BF-ABH & $2.46 \mathrm{~cm}^{3}$ & Normal, não prenhe & $\begin{array}{l}\text { Leucócitos, muco e debris } \\
\text { celulares }(+++)\end{array}$ \\
\hline BF-ACJ & $4.13 \mathrm{~cm}^{3}$ & Normal, não prenhe & $\begin{array}{l}\text { Leucócitos e eritrócitos }(+++), \\
\text { muco }(++) \text {, células intermediárias }\end{array}$ \\
\hline BF-AFR & $2.30 \mathrm{~cm}^{3}$ & Normal, não prenhe & $\begin{array}{l}\text { Leucócitos e muco }(+++), \\
\text { predomínio células intermediárias }\end{array}$ \\
\hline BF-AFX & $1.56 \mathrm{~cm}^{3}$ & Difícil visualização & $\begin{array}{l}\text { Leucócitos e debris celulares } \\
(+++) \text {, presença de eosinófilos }(+)\end{array}$ \\
\hline BF-AGH & $0.81 \mathrm{~cm}^{3}$ & Normal & $\begin{array}{l}\text { Muco }(+++) \text {, difícil identificar } \\
\text { células }\end{array}$ \\
\hline
\end{tabular}

Quadro 3 - Resultados dos exames ultra-sonográficos e colpocitológicos realizados nas fêmeas de bugio (Alouatta caraya). São Paulo, 2005 
APÊNDICE B - Descrição das técnicas de coloração de lâminas citológicas pelos métodos de Panótico rápido, Papanicolaou, Shorr e Leishman.

\section{PANÓTICO RÁPIDO}

Para a realização desta coloração utilizou-se o conjunto de corantes para coloração diferencial rápida Instant Prov da Newprov ${ }^{\circledR}$ Produtos para Laboratório Ltda, Pinhais, PR.

A técnica de coloração adotada neste estudo consistiu em mergulhar a lâmina fixada em etanol absoluto no corante I por 10 segundos. Em seguida, mergulhar no corante II por 20 segundos e finalmente no III por 30 segundos. A cuba contendo o corante foi suavemente agitada durante a coloração. O tempo total de coloração foi de 1 minuto.

\section{PAPANICOLAOU}

Os corantes utilizados para a realização desta técnica foram comprados separadamente ou preparados por técnico capacitado no Centro Nacional de Primatas (CENP/SVS/MS), Ananindeua, PA.

As lâminas foram fixadas em etanol absoluto durante 30 minutos a 24 horas. O tempo total de coloração excetuando-se a fixação foi de 30 minutos. As etapas da técnica de coloração encontram-se no quadro 4. 


\begin{tabular}{|l|l|}
\hline Reagente & Tempo \\
\hline 1. Álcool a $80 \%$ & 10 passagens \\
2. Álcool a $70 \%$ & 10 passagens \\
3. Álcool a $50 \%$ & 10 passagens \\
4. Água destilada & 1 minuto \\
5. Hematoxilina de Harris & 6 minutos \\
6. Água destilada & 7 passagens \\
7. Água (200ml) - Ácido clorídrico (2 gotas) & 3 passagens \\
8. Água corrente & 1 minuto \\
9. Álcool a $50 \%$ & 10 passagens \\
10. Álcool a $70 \%$ & 10 passagens \\
11. Álcool a $80 \%$ & 10 passagens \\
12. Álcool a $95 \%$ & 10 passagens \\
13. Alaranjado 6 & 3 minutos \\
14. Álcool a 95\% & 10 passagens \\
15. Eosina 36 & 2 minutos \\
16. Álcool a $95 \%$ & 10 passagens \\
17. Álcool a $95 \%$ & 10 passagens \\
18. Álcool a $100 \%$ & 10 passagens \\
19. Álcool a $100 \%$ & 10 passagens \\
20. Xilol & 10 passagens \\
\hline
\end{tabular}

Quadro 4 - Etapas da técnica de Papanicolaou para a coloração de lâminas citológicas

\section{SHORR}

O corante de Shorr foi preparado no laboratório de histopatologia do CENP. As lâminas foram fixadas em etanol absoluto, depois mergulhadas no corante de Shorr 
durante quatro a seis minutos. Em seguida foram mergulhadas aproximadamente 10 vezes, com agitação, em uma cuba contendo álcool a 95\%, duas cubas com álcool absoluto e por último uma cuba com xilol.

\section{LEISHMAN}

O corante de Leishman também foi preparado no laboratório de histopatologia do CENP.

Os esfregaços foram secos ao ar e mergulhados no corante de Leishman durante 10 minutos. Em seguida foram mergulhados em água destilada durante mais 10 minutos e por último lavados com água corrente. 
APÊNDICE C - Representações gráficas dos cálculos utilizados para determinação dos limites entre os valores basais e elevados das concentrações de estrógenos e progestinas fecais.

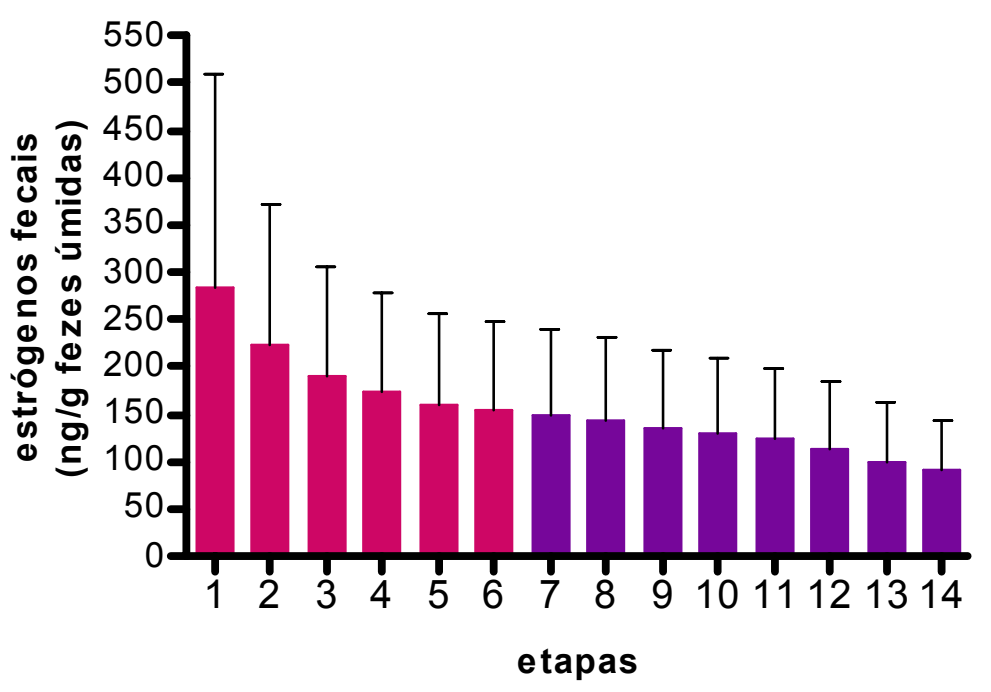

Figura 25 - Representação gráfica do método adotado para determinação dos valores elevados (rosa) e basais (roxo) de estrógenos fecais (ng/g fezes úmidas), utilizando a média+1,5DP e $p<0,05$ (Animal 1). São Paulo, 2005

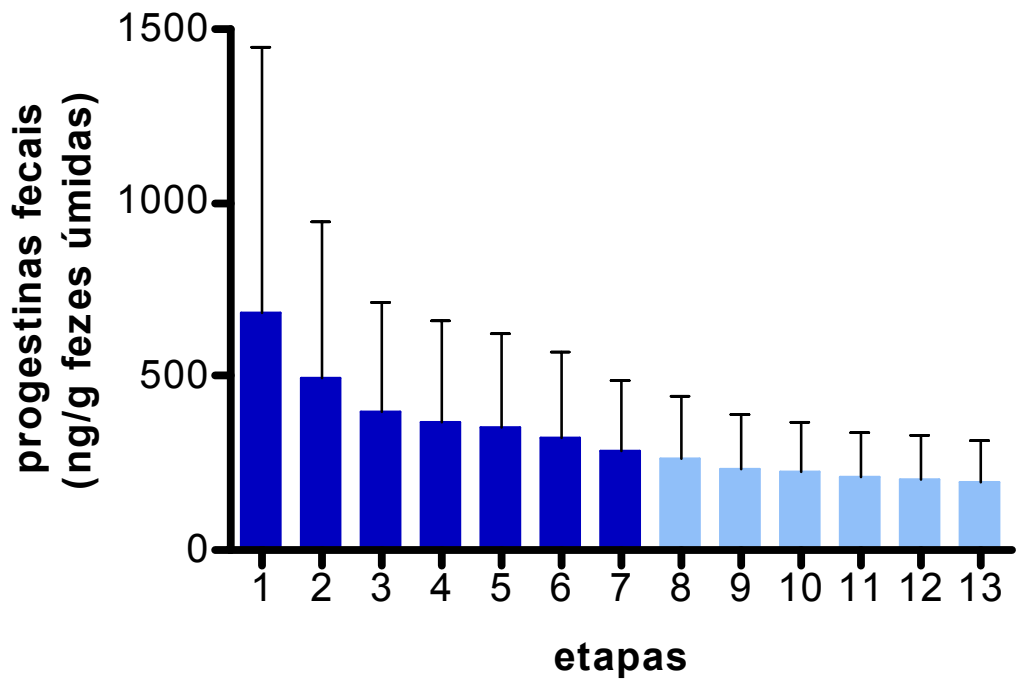

Figura 26 - Representação gráfica do método adotado para determinação dos valores elevados (azul escuro) e basais (azul claro) de progestinas fecais (ng/g fezes úmidas), utilizando a média+2DP e $p<0,05$ (Animal 1). São Paulo, 2005 


\section{APÊNDICE D - llustrações das lâminas de citologia vaginal coradas por diferentes}

\section{técnicas de coloração}

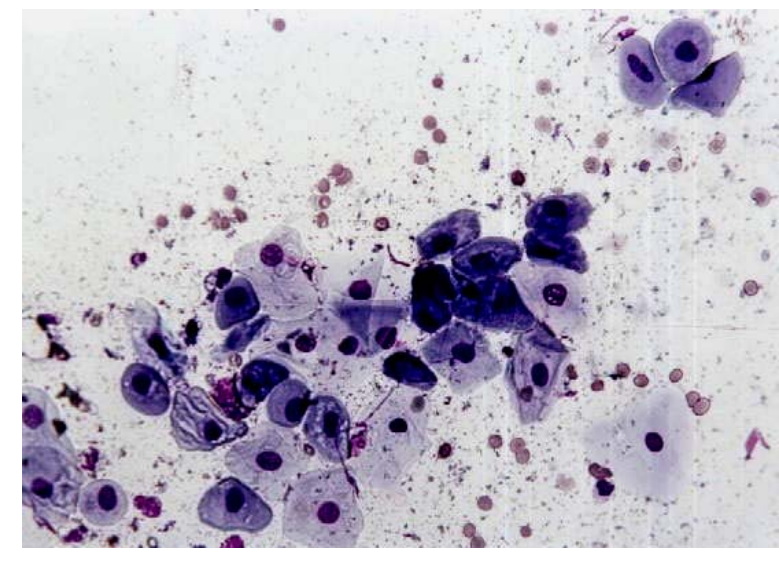

Figura 27 - Aspecto da lâmina colpocitológica no momento do aparecimento de células sangüíneas (fêmea 2). Coloração Panótico, aumento 200x. São Paulo, 2005

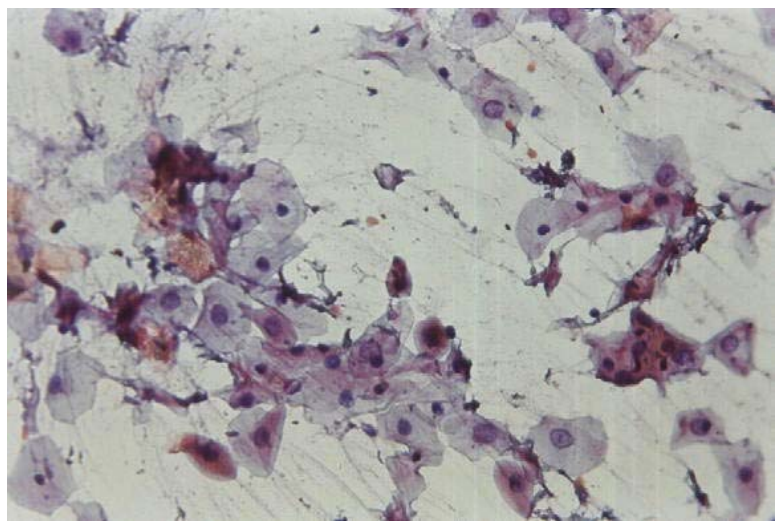

Figura 28 - Aspecto da lâmina colpocitológica no momento do aparecimento de células sangüíneas (fêmea 2). Coloração Papanicolaou, aumento 200x. São Paulo, 2005

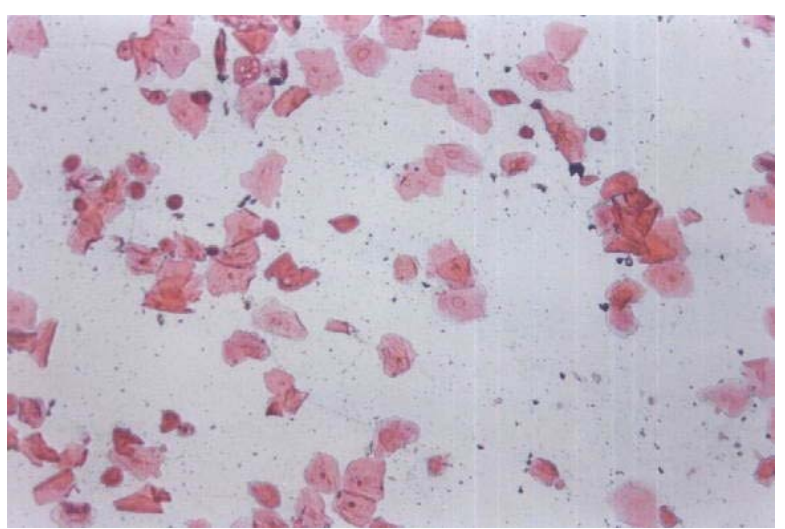

Figura 29 - Aspecto da lâmina colpocitológica corada pelo corante de Shorr (fêmea 2), aumento 100x. São Paulo, 2005

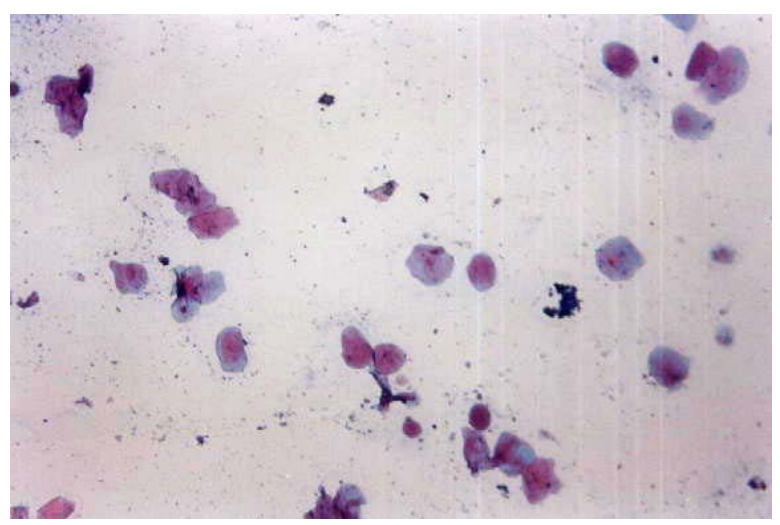

Figura 30 - Aspecto da lâmina colpocitológica corada pelo corante de Leishman (fêmea 2), aumento 100x. São Paulo, 2005 